\title{
A QUALIDADE DA INFORMAÇÃO DE MORTALIDADE EM ALGUNS MUNICÍPIOS DA REGIONAL DE MARÍLIA-SP: CORREÇÃO DE DISTORÇÕES POR MEIO DE TÉCNICAS SIMPLES
}

\author{
MARIA CRISTINA ROLIM BAGGIO
}

Tese apresentada ao Departamento de Epidemiologia da Faculdade de Saúde Pública da Universidade de São Paulo para obtenção do título de Doutor em Saúde Pública.

Área de concentração: Epidemiologia

ORIENTADORA: PROF ${ }^{a}$. DRA. SABINA LEA DAVIDSON GOTLIEB

São Paulo 2002

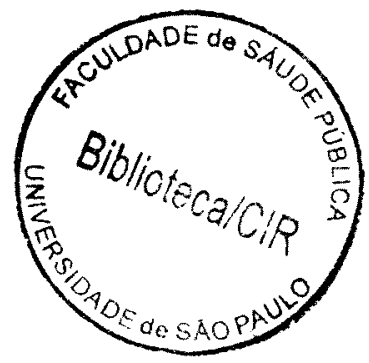


Autorizo, exclusivamente para fins acadêmicos e cientificos, a reprodução total ou parcial desta tese, por processos fotocopiadores.

Assinatura:

Data:

$$
4275112002 \text { doc }
$$


Aos meus grandes amores: Theodoro, Liza, Danilo, Bruno

e Beatriz 


\section{AGRADECIMENTOS}

Entre as várias pessoas e instituições que colaboraram para a concretização deste trabalho, agradeço especialmente:

À professora Sabina Léa Davidson Gotlieb pela orientação, dedicação, amizade e, sobretudo, compreensão das dificuldades impostas pela distância.

À amiga, professora Maria Elizabeth da Silva Hernandes Corrêa, pelo auxílio e vivência conjunta do trabalho de campo.

Aos professores Maria Helena Prado de Mello Jorge e Ruy Laurenti pela participação e apoio nas etapas deste estudo.

À professora Maria Cecília Cordeiro Dellatorre pela ajuda na obtenção de referências bibliográficas.

À professora Marisa Pastori pelo carinho e incentivo constantes, durante todos os anos de realização deste trabalho.

A FAPESP pelo apoio financeiro.

Às Secretarias Municipais de Saúde de Echaporã, Garça, Marília, Osvaldo Cruz e Tupã, pela colaboração e apoio para a obtenção dos dados.

Á Regional de Saúde de Marília pela compreensão em relação aos meus dias de afastamento.

A Paula pelo auxílio recebido na etapa de coleta dos dados. 
Ao Theodoro pelo incentivo e leitura prévia e criteriosa, nas várias etapas deste trabalho.

À Liza pelo apoio na versão do resumo para o inglês.

À minha familia, por estar ao meu lado. 


\section{RESUMO}

Baggio MCR. A qualidade da informação de mortalidade em alguns municípios da Regional de Saúde de Marilia - SP: correção de distorções por meio de técnicas simples. São Paulo; 2002. [Tese de Doutorado - Faculdade de Saúde Pública da USP].

As informações de mortalidade, indispensáveis para a elaboração de diversos indicadores de saúde, permitem o conhecimento dos agravos que afetam uma população, orientando a implantação de modelos de atenção, promoção da saúde e das ações de prevenção e controle. No Brasil, o Sistema de Informações de Mortalidade do Ministério da Saúde (SIM/MS) foi implantado, em nivel nacional, em 1975. No entanto, a qualidade e a confiabilidade das declarações de óbito (DO) vem sendo analisada e questionada em todo o mundo. $O$ aspecto mais relevante na análise qualitativa é o que mede a fidedignidade das informações relativas à mortalidade por causa. Objetivos. Avaliar o SIM do ponto de vista qualitativo e testar metodologias simples e uniformes capazes de minimizar suas distorções. Método. Foram coletadas as DO das mortes ocorridas em cinco municípios da Regional de Saúde de Marilia/SP, em um periodo de quatro meses. Destas, foram investigadas as que não apresentavam a causa de morte bem definida, as codificadas como causas externas e presumiveis de AIDS, e as mortes de mulheres em idade fértil (10 a 49 anos). Para o esclarecimento da causa de morte e elaboração de uma DO-nova, foram coletadas informações adicionais em prontuários ambulatoriais e hospitalares, entrevistas no domicilio, laudos do Instituto Médico Legal e boletins das Delegacias de Polícia. Ao final, a causa básica de óbito da DO original foi comparada com a refeita pelo estudo. Resultados. Do total de óbitos ocorridos nos municipios selecionados, $16,5 \%$ foram por causas mal definidas, $6,7 \%$ tinham como causa diagnósticos incompletos e $8,6 \%$ causas externas. Das 302 mortes investigadas, foi possivel tornar bem definidas $68,2 \%$ das causas mal definidas, $74,5 \%$ das com 
diagnósticos incompletos, $70 \%$ das externas mal definidas e $77,3 \%$ das externas incompletas. Foram encontrados três casos de AIDS e um de morte materna, não declarados na DO original. As fontes consultadas, tanto os prontuários e laudos, como as entrevistas no domicílio, mostraram-se suficientes para o esclarecimento da causas de morte. Conclusões. A proporção de mortes por causas mal definidas em relação ao total de óbitos, no conjunto dos municípios estudados, foi maior do que a observada no estado, tendo sido possivel obter um ganho apreciável na qualidade da informação por meio do uso de técnicas simples e acessiveis. 


\section{SUMMARY}

Baggio MCR. The quality of mortality information in some cities of the Regional of Health of Marilia - SP: correcting the distortions by using simple techniques.

The statistics of mortality, essential to development of various health indicators, allow the acquaintance of the diseases that affect the population, guiding the adoption of attention pattern, health promotion and actions of prevention e control. In Brazil, the Information System of Mortality which belongs to the Health Ministry (SIM/MS) was implanted, in national level, in 1975. However, the quality of the death certificates is being analyzed and questioned all over the world. The most relevant aspect in the qualitative analyses is the one that measure the accuracy of the mortality cause. Objectives. The purpose of this study is to evaluate SIM under qualitative aspects and to test simple and uniform methodology capable to decrease the distortions of SIM. Method. Death certificates were collected from five cities of the Regional Health of Marilia, from deaths that occurred within a period of four months. From these deaths, were investigated the ones that were not coded as "well defined" cause, the one coded as external causes and probable of AIDS and the deaths of woman with age between 10 to 49 years old. Aiming to clarify the death cause and to elaborate a new death certificate, additional information were collected from hospitals records, interviews at home, autopsy reports from the Legal Medicine Institute and police reports. At the end, the basic cause of the death from original death certificate was compared with the one that was remade by this study. Results. From the total number of deaths that occurred in the selects cities, $16,5 \%$ were coded as ill-defined, $6,7 \%$ as incomplete diagnostic and $8,6 \%$ as external causes. From the 302 deaths were investigated, it was possible to turn into "well defined": $68,2 \%$ of the ill-defined causes, $74,5 \%$ of the ones with incomplete diagnostics, $70 \%$ of the events of undetermined intent. Three cases of AIDS and one of maternal death, that were not declared in the 
original death certificate, were founded. The sources that were consulted, medical records, autopsy reports and interviews at home as well, were considered as being enough to clarify the death causes. Conclusion. The proportion of deaths by illdefined causes, from the cities that were studied, was bigger than the one observed in the state, being possible to gain in the quality of information about mortality, through the adoption of simple and accessible techniques. 


\section{LISTA DE FIGURAS E TABELAS}

Figura 1: Localização dos municipios da Regional de Saúde de Marilia, Estado de São Paulo, 1999

Figura 2: Municípios da Regional de Saúde de Marília - DIR-14 - 1999.

Quadro 1: Informações relativas aos municipios selecionados segundo área, DIRMarilia, 2000.

Tabela $1: N^{\circ}$ total de óbitos e por causas mal definidas ( $n^{\circ} \mathrm{e} \%$ ), na Dir-Marília, Estado de Sāo Paulo, 1993-2000.

Figura 3 : Proporção (\%) de óbitos por causas mal definidas, em relação ao total de óbitos, nos Municipios de Echaporã, Garça, Marília, Osvaldo Cruz e Tupã, no período de 1993/2000.

Tabela 2: Número de óbitos por local de ocorrência e número e percentual de óbitos investigados, nos municipios selecionados da DIR-Marilia, agosto/ dezembro, 1999.

Tabela 3: Número de óbitos analisados segundo municipio de ocorrência e motivo de inclusão, DIR-Marilia, agosto/dezembro, 1999.

Tabela 4: Número e porcentagem de óbitos segundo faixa etária e sexo, nos municípios selecionados da DIR-Marilia, agosto/dezembro, 1999.

Figura 4: Número de óbitos investigados segundo faixa etária e motivo de inclusão, nos municipios selecionados da DIR-Marília, agosto/dezembro, 1999.

Tabela 5: Número e porcentagem de óbitos segundo município de residência, DIRMarilia, agosto/dezembro, 1999. 
Tabela 6: Número e porcentagem de óbitos segundo local de ocorrência, nos municípios selecionados da DIR-Marília, agosto/dezembro, 1999.

Tabela 7: Número e porcentagem de declarações de óbito segundo médico que assina, nos municípios selecionados da DIR-Marilia, agosto/dezembro, 1999.

Tabela 8: Número de óbitos ocorridos e número e porcentagem de óbitos por causas mal definidas segundo municipio da DIR-Marilia, agosto/dezembro, 1999.

Tabela 9: Distribuição dos óbitos por causas mal definidas, segundo faixa etária e sexo, nos municipios selecionados da DIR-Marilia, agosto/dezembro, 1999.

Tabela 10: Número e porcentagem de óbitos por causas mal definidas segundo o tipo de médico que assinou a DO, nos municípios selecionados da DIR-Marilia, agosto/dezembro, 1999.

Tabela 11: Distribuição dos óbitos por causas mal definidas, segundo categorias e subcategorias da CID-10, nos municipios selecionados da DIR-Marilia, agosto/dezembro, 1999.

Tabela 12: Número e porcentagem de óbitos por causas mal definidas redistribuidos, após investigação, segundo causas*, nos municipios selecionados da DIR-Marilia, agosto/dezembro, 1999.

Tabela 13: Porcentagem e ordenação das causas de morte, segundo situação pré e pós-investigação e a que propõe a OPS, nos municipios selecionados da DIR-Marilia, agosto/dezembro, 1999.

Tabela 14: Número e porcentagem de óbitos com diagnóstico incompleto, segundo faixa etária e sexo, nos municipios selecionados da DIR-Marília, agosto/dezembro, 1999.

Tabela 15: Número de diagnósticos incompletos, segundo a DO original e a situação após a investigação, nos municípios selecionados da DIR-Marilia, agosto/dezembro, 1999. 
Tabela 16: Número de óbitos com diagnóstico incompleto, segundo causas (capitulos da CID-10), nas DO original e nova, nos municípios selecionados da DIR-Marilia, agosto/dezembro, 1999.

Tabela 17: Número de óbitos por causas externas, segundo tipo e motivo de análise, nos municipios selecionados da DIR-Marília, agosto/dezembro, 1999.

Tabela 18: Número e porcentagem dos óbitos por causas externas, segundo faixa etária e sexo, nos municipios selecionados da DIR-Marilia, agosto/dezembro, 1999.

Tabela 19: Número de acidentes de transporte, segundo código da CID nas DO original e nova, nos municípios selecionados da DIR-Marilia, agosto/dezembro, 1999.

Quadro 2: No de óbitos por causas externas bem definidas que apresentaram mudança na causa básica de óbito após a investigaçāo, nos municípios selecionados da DIRMarilia, agosto/dezembro, 1999.

Tabela 20: Número e porcentagem de óbitos em mulheres em idade fértil, segundo a situação após a investigação, nos municipios selecionados da DIR-Marilia, agosto/dezembro, 1999.

Tabela 21: Número e porcentagem de óbitos com causas presumiveis, segundo a causa básica da DO-nova, nos municípios selecionados da DIR-Marilia, agosto/dezembro, 1999.

Tabela 22: Número e porcentagem de óbitos mal definidos, segundo ganho de informação nas causas de morte, nos municípios selecionados da DIR-Marília, agosto/dezembro, 1999.

Tabela 23: Número e porcentagem de óbitos com diagnósticos incompletos, segundo ganho de informação nas causas de morte, nos municipios selecionados da DIRMarilia, agosto/dezembro, 1999.

Tabela 24: Número e porcentagem de óbitos, segundo ganho de informação nas causas de morte, nos municípios selecionados da DIR-Marilia, agosto/dezembro, 1999. 
Figura 5: Situação dos óbitos, pré e pós-investigação, no conjunto dos municípios da DIR-Marilia, agosto/dezembro, 1999.

Figura 6: Situação dos óbitos, pré e pós-investigação, no municipio de Marilia, DIRMarilia, agosto/dezembro, 1999.

Figura 7: Situação dos óbitos, pré e pós-investigação, no municipio de Tupã, DIRMarilia, agosto/ dezembro, 1999.

Figura 8: Situação dos óbitos, pré e pós-investigação, no municipio de Garça, DIRMarilia, agosto/dezembro, 1999.

Figura 9: Situação dos óbitos, pré e pós-investigação, no município de Osvaldo Cruz, DIR-Marilia, agosto/dezembro, 1999.

Figura 10: Situação dos óbitos, pré e pós-investigação, no municipio de Echaporã, DIRMarilia, agosto/dezembro, 1999.

Tabela 25: Número e porcentagem de óbitos investigados por meio de prontuários e visitas domiciliares, segundo capítulo da CID-10 e fonte utilizada, nos municípios selecionados da DIR-Marilia, agosto/dezembro, 1999.

Tabela 26: Valor preditivo (VP), sensibilidade (S) e especificidade (E) das informações da visita domiciliária (VD) para alguns dos capitulos da CID-10, nos municípios selecionados da DIR-Marilia, agosto/dezembro, 1999.

Tabela 27: Valor preditivo (VP), sensibilidade (S) e especificidade (E) das informações da visita domiciliária (VD) e coeficiente de Kappa para algumas das categorias da CID10, nos municipios selecionados da DIR-Marilia, agosto/dezembro, 1999.

Tabela 28: $\mathrm{N}^{\circ}$ e porcentagem de óbitos hospitalares, segundo tipo de hospital e de causa, nos municipios selecionados da DIR-Marilia, agosto/dezembro, 1999.

Tabela 29: $N^{\circ}$ e porcentagem de óbitos hospitalares, segundo tipo de hospital e tipo de causa, , nos municípios selecionados da DIR-Marília, agosto/dezembro, 1999. 


\section{ÍNDICE}

1-INTRODUÇÃO

1.1 As estatisticas de mortalidade ........................................................ 2

1.2 Usos e limitações das informações de mortalidade ............................... 6

1.3 A qualidade das informações de mortalidade - O Sistema de Informaçōes sobre Mortalidade (SIM) ................................................ 10

. Óbitos por causas mal definidas e sem assistência médica ............. 13

. Óbitos com diagnósticos incompletos ............................................ 14

. Óbitos por causas externas ........................................................ 14

. Óbitos de mulheres em idade fértil ............................................... 17

. Óbitos presumiveis de AIDS ...................................................... 18

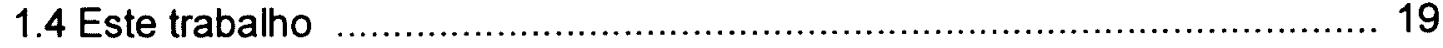

2 - OBJETIVOS

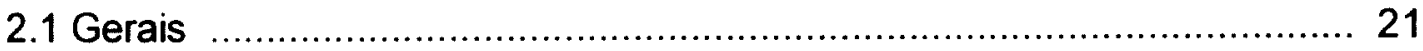

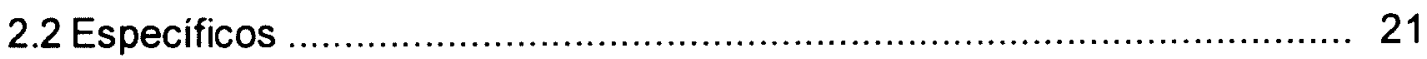

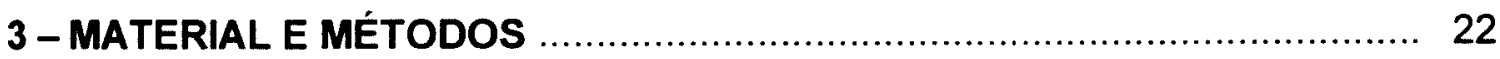

3.1 População de estudo ……............................................................. 23

3.2 Variáveis de estudo .................................................................... 27

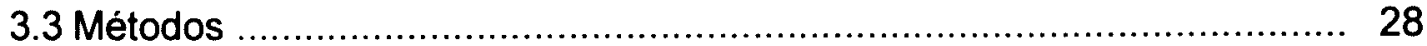

3.4 Análise de ganhos ..................................................................... 31

3.5 Medidas e técnicas utilizadas ...................................................... 32

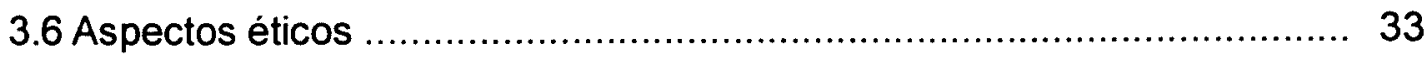




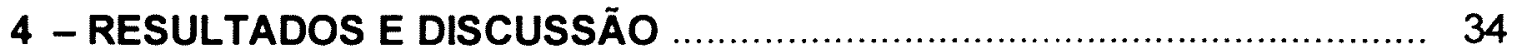

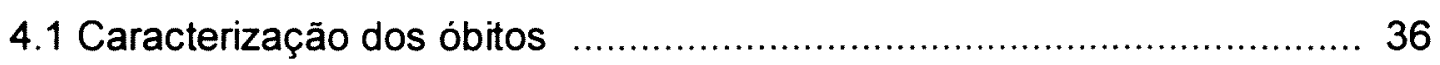

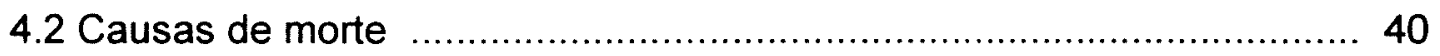

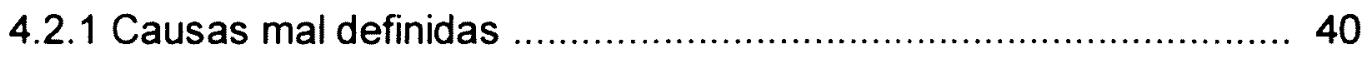

4.2.2 Causas com diagnósticos incompletos ................................... 48

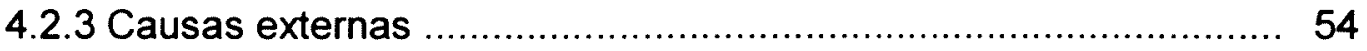

Causas externas mal definidas .......................................... 56

Causas externas com diagnósticos incompletos .................... 57

Causas externas bem definidas ............................................ 59

4.2.4 Óbitos de mulheres em idade fértil ............................................. 63

4.2.5 Óbitos por causas presumiveis de AIDS …................................ 66

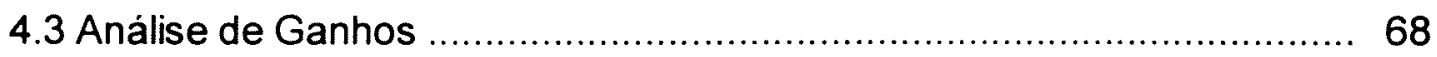

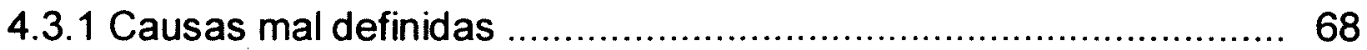

4.3.2 Causas com diagnósticos incompletos ..................................... 71

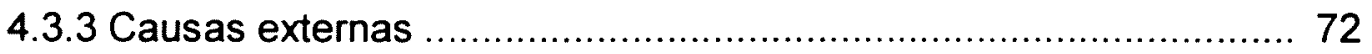

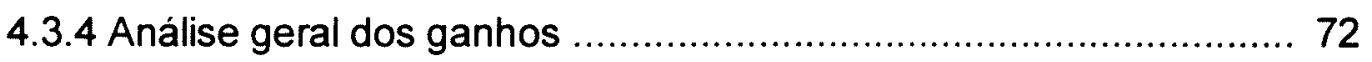

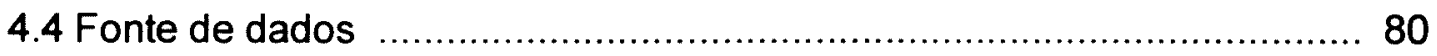

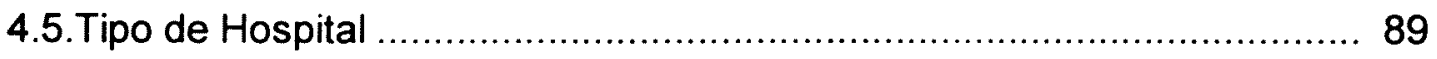

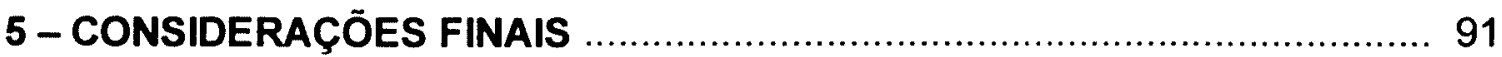

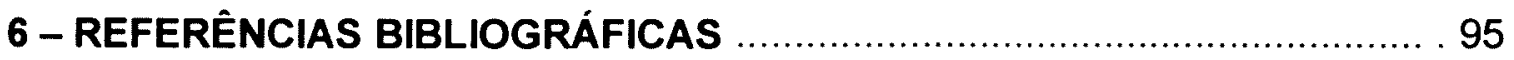

\section{ANEXOS}




\section{INTRODUÇÃO}

O instante de corola o instante de vida o instante de sentimento o instante de conclusão

o instante de memória e muitos outros instantes sem razão e sem verso.

Carlos Drummond de Andrade

"Inscrição Tumular" 


\subsection{AS ESTATÍSTICAS DE MORTALIDADE}

A análise das condições de vida e saúde de uma população é fundamental para o processo de planejamento, execução e avaliação de impacto das ações de saúde. Nesse sentido, as informações de mortalidade são uma das medidas de saúde mais acessiveis e utilizadas.

Com as estatísticas de mortalidade são construidos os indicadores de saúde que permitem o conhecimento dos agravos que afetam uma população e, como conseqüência, a elaboração de programas de prevenção, tratamento e erradicação de doenças.

A palavra estatística vem de Estado e significa "medida do Estado" ou "coisas do Estado", tendo sido usada pela primeira vez, documentalmente, em 1749, por Achenwall, referindo-se à coleção de informações sobre o Estado (4. 58. 59) . Atualmente, ela diz respeito a toda a elaboração que vai desde o planejamento e coleta de dados, até a análise e interpretação dos resultados ${ }^{(27)}$.

O desenvolvimento da estatistica, como ciência, é relativamente recente, embora algumas tarefas do trabalho estatístico tenham sido realizadas pelo homem há milhares de anos. Os levantamentos gerais populacionais, os Censos, vêm sendo realizados desde a Antiguidade, por diversos povos, tais como os egípcios, romanos, gregos, hebreus e chineses. No ano 100 da era cristã, em Roma, as declarações de nascimentos e de mortes tornaram-se obrigatórias ${ }^{(4,27)}$.

No entanto, as primeiras análises de dados de mortalidade só apareceram no século XVII. John Graunt, um comerciante londrino de roupas masculinas, foi o pioneiro, publicando "Natural and political observations mentioned in a following index, and made upon the Bills of Mortality", em 1662. Graunt, estudando as mortes do último terço do século, em Londres, demonstrou a regularidade de certos fenômenos como a supremacia das mortes masculinas sobre as femininas, o excesso de mortalidade da cidade sobre o campo e a variação das taxas de mortes, segundo as estações ${ }^{(58,59,60)}$.

No século XVIII, vários estados europeus sentiram a necessidade das informações estatisticas para determinar o número e as características de suas 
populações, cabendo à Suécia, em 1748, a primazia das coletas estatísticas oficiais, com a publicação, em 1766, das tabelas de mortalidade dos anos de 1756 a 1763 , as primeiras para todo o país ${ }^{(59)}$.

Em meados e fins do século XIX, William Farr, médico inglês, considerado o criador das estatísticas da moderna saúde pública, que criara, em 1839, um registro anual de mortalidade e morbidade para a Inglaterra e o País de Gales, analisou detalhadamente diversos aspectos relacionados à saúde da população inglesa, a partir de dados de mortalidade, marcando uma precoce institucionalização dos sistemas de informação em saúde. Farr mostrou as deficiências das estatísticas vitais e os métodos necessários para melhorá-las, para que pudessem cumprir as suas finalidades nas áreas de demografia e saúde pública $^{(27,58,59)}$.

No Brasil, nas últimas décadas do Império, os estudos de mortalidade eram feitos com informações colhidas nos jornais, que publicavam os óbitos ocorridos a cada dia. Os levantamentos estatísticos se tornaram mais confiáveis, somente após a proclamação da República, com a implantação de serviços de demografia sanitária em vários estados ${ }^{(3)}$.

O Decreto Imperial $n^{\circ} 9.886$ regulamentou o registro civil de nascimentos, casamentos e óbitos, no Rio de Janeiro, estipulando a obrigatoriedade do Atestado de Óbito. No entanto, só em 21 de novembro de 1891, o Decreto $n^{\circ} 680$, assinado por Deodoro da Fonseca e Alencar Araripe, padronizou um formulário único com os dados necessários para atender às necessidades da demografia sanitária, tais como: sexo, estado civil, profissão e nacionalidade. Dentre os itens a serem preenchidos pelo médico estava a causa mortis. O texto legal do Decreto, publicado no Diário Oficial, incluía um longo trecho justificando essa medida como importante instrumento para a administração sanitária ${ }^{(3)}$.

Apesar dos benefícios a serem obtidos pela análise das estatísticas vitais na organização dos serviços de Saúde Pública e do decreto abranger apenas o Distrito Federal, o doutor Nina Rodrigues, de Salvador, iniciou uma mobilização contra a inclusão obrigatória da causa de morte nos atestados de óbito, tendo 
como argumento o segredo profissional a que todos os médicos estariam obrigados pelos princípios do Código de Ética Médica ${ }^{(3)}$.

Em São Paulo, a organização das estatísticas demógrafo-sanitárias se iniciou em 1892, sendo divulgadas as primeiras informações apenas em 1894. Até esta época, não havia registro sistemático de mortalidade geral, causas de morte ou nascimentos, sendo os dados levantados junto aos cartórios. As informações eram pouco precisas devido à irregularidade com que os cartórios do interior enviavam os dados ao Serviço Sanitário. Somente em 1896 , pela Lei $n^{\circ} 432$, foi criada a Seção de Estatistica Demógrafo-Sanitária, responsável pela organização de boletins mensais de mortalidade geral para todo o Estado, pela divulgação de boletins meteorológicos que explicassem o aumento ou declínio das endemias, epidemias e a freqüência de certas causas de óbitos, além da análise das informações que servissem para avaliar o grau de sanidade da Capital e do interior $^{(56)}$.

Nos anos de 1898 e 1899, o doutor Eudóxio de Oliveira, um dos pioneiros da estatística vital no Brasil, divulgava na Gazeta Médica da Bahia, suas análises dos dados do registro civil, colhidos nos distritos urbanos e suburbanos de Salvador, quantificando e classificando os óbitos segundo sexo, idade, nacionalidade, raça, estado civil, profissão, causa de morte, mês de ocorrência, entre outros. Desta forma, eram apresentadas informaçōes importantes para os serviços de saúde, tais como: os meses em que aumentava a incidência de febre amarela e variola na cidade, as principais causas de morte em cada periodo, sexo e faixa etária e o cálculo do coeficiente da mortalidade infantil. Além destes estudos, dedicou-se também a uma apreciação crítica quanto à qualidade dos dados analisados, apontando para a falta de empenho das autoridades na melhoria do sistema de registro civil $^{(3)}$.

Nesta época, a imprensa médica, além dos estudos de mortalidade geral, destacava alguns aspectos especificos destas estatisticas. No Rio de Janeiro, o doutor Ismael Rocha relatava o crescimento das mortes devidas aos acidentes da "via urbana", em que carros, carroças, bondes e tilburis contribuiriam de forma importante para os desastres e atropelamentos. O periódico médico paulista 
Gazeta Clinica publicava comparações entre as taxas de mortalidade segundo profissões $^{(3)}$.

O registro civil dos atestados de óbito, além de permitir o levantamento e a análise dos dados para a demografia sanitária, possibilitou também a identificação de problemas referentes à organização dos serviços de saúde. O doutor Carlos Castro, em 1908, apontou para uma questão relativa ao exercicio ilegal da medicina: os falsos médicos e curandeiros, impossibilitados de assinar o atestado de óbito, contavam com a conivência de clínicos amigos que atestavam por eles, mesmo não tendo assistido ao doente. Desta forma, os certificados emitidos seriam destituídos de valor e impediam o conhecimento das reais condições de saúde da população ${ }^{(3)}$.

Em 1912, o doutor Theóphilo Torres apresentou à Academia Nacional de Medicina um estudo da estatística mortuária do Rio de Janeiro, mostrando a imprecisão dos dados quanto à causa de morte. Diante da exigência legal, para a realização do sepultamento, do atestado de óbito declarando a natureza da doença, muitos profissionais expediam o certificado com o "diagnóstico de ocasião". Assim, dependendo das circunstâncias, aumentavam sem fundamento as taxas de óbitos devidos ao paludismo, ou à gripe, ou a outras enfermidades. Essas observações fizeram com que o doutor Torres solicitasse, à Diretoria Geral de Saúde Pública, a criação de um corpo de médicos habilitados para as perícias necroscópicas, responsáveis pela verificação de óbito, sempre que os clínicos tivessem dúvidas sobre o diagnóstico ${ }^{(3)}$.

Outro fator que impedia o real conhecimento da realidade dizia respeito a um erro de preenchimento dos atestados de óbitos. Segundo apontou, em 1919, o doutor Luiz de Rezende Puech ${ }^{(53)}$, da Santa Casa de Misericórdia de São Paulo, havia uma confusão entre a causa direta da morte e a doença que deflagrava este evento patológico. Deste modo, por exemplo, os clínicos atestavam óbitos de crianças ocorridos por broncopneumonia, em conseqüência do sarampo, sem mencionarem este último nas declarações. Assim, nas estatísticas, o sarampo aparecia como doença de pequena gravidade ${ }^{(3)}$. 
Em 1944, inicia-se a divulgação regular dos dados de mortalidade das capitais brasileiras. Neste ano, o Serviço Federal de Bioestatistica do Departamento Nacional de Saúde, do Ministério da Educação e Saúde, publicou o primeiro Anuário Bioestatístico, com dados de mortalidade por causa, referentes aos óbitos das capitais brasileiras, nos anos de 1929 e $1932^{(37)}$.

A implantação do modelo internacional de atestado de óbito, proposto pela Organização Mundial de Saúde (OMS), em 1948, ocorreu em todo território nacional, em 1950. Porém, embora a parte relativa à causa de morte obedecesse a critério internacional, os dados de identificação e outras informações não seguiam um modelo uniforme, havendo impressos de formatos e cores diferentes, nos vários Estados ${ }^{(28)}$.

Em novembro de 1975, frente à necessidade de dados de mortalidade mais abrangentes e confiáveis, o Ministério da Saúde promoveu a primeira Reunião Nacional sobre Sistemas de informação em Saúde. Nesta reunião foi discutido um modelo para o subsistema de informações sobre mortalidade, com a aprovação de um formulário único de declaração de óbito $(\mathrm{DO})$ e declaração de óbito fetal, e a definição dos fluxos e da periodicidade dos dados a serem computados ${ }^{(37)}$.

O Sistema de Informações de Mortalidade do Ministério da Saúde (SIM/MS) foi implantado, em nivel nacional, em 1975, possuindo bases de dados disponiveis para análise desde o ano de 1979. O Anuário "Estatísticas de Mortalidade - Brasil" vem sendo publicado desde 1977, com informações sobre os óbitos dos residentes no pais, em nivel de estados, municípios e capitais brasileiras, segundo sexo, idade e causa básica ${ }^{(37)}$.

\subsection{USOS E LIMITAÇÕES DAS INFORMAÇÕES DE MORTALIDADE}

As informações de mortalidade estão entre as mais importantes na área de saúde. Classicamente, vêm sendo utilizadas para a análise das condições de vida, através dos indicadores de saúde, definição de atividades da vigilância 
epidemiológica, avaliação do impacto das ações de saúde, análises de tendência ao longo do tempo e comparação entre regiões, entre outras.

Na mensuração do nível de vida das coletividades humanas, a saúde é o primeiro componente a ser avaliado. Paradoxalmente, os dados de morte e de doença são os mais freqüentemente utilizados na avaliação do nível de saúde de uma população, dadas as dificuldades encontradas em se medir sua "saúde". A obtenção de informações sobre as doenças, feita através de estatisticas ambulatoriais, hospitalares ou de inquéritos, costuma ser parcial e onerosa. As estatisticas de mortalidade, embora sejam o mais antigo e tradicional meio utilizado para se medir a saúde de uma coletividade, ainda hoje, são indispensáveis, quando o registro é satisfatório. Assim, a quantificação de óbitos, por meio dos chamados "indicadores de saúde", representa uma medida indireta da saúde coletiva ${ }^{(61)}$. Os mais freqüentemente utilizados são: a mortalidade proporcional, os coeficientes de mortalidade geral e mortalidade infantil, esperança de vida, coeficientes de mortalidade segundo causas, sexo e idade, entre outros.

Segundo Barata ${ }^{(6)}$, o uso das informações de mortalidade baseia-se em algumas considerações de ordem prática e em outras, de ordem teórica. Assim, 0 fato de inúmeros estudos epidemiológicos demonstrarem que as informações de mortalidade refletem, de maneira apropriada, o nivel de saúde de populações fornece a sustentação teórica para a utilização destas nos diagnósticos de saúde. As facilidades de uso destas informaçōes, dentre as quais a característica de ser um evento único, a obrigatoriedade, a centralização e a relativa confiabilidade dos dados, respondem pelas considerações de ordem prática.

Os diagnósticos de nivel de saúde, baseados em indicadores, são a etapa introdutória para a elaboração dos planos nacionais, estaduais ou municipais de saúde. Portanto, partem da avaliação da situação inicial onde são identificados os principais problemas.

Entretanto, com a expansão dos serviços de assistência primária, a utilização tradicional destes diagnósticos vem sendo questionada pela inadequação entre as informações de mortalidade e as práticas assistenciais no nível primário de atenção e pela incapacidade dos valores médios em revelar as 
desigualdades existentes entre frações de classe, ocultando situações diversas do ponto de vista epidemiológico.

Desta maneira, houve um movimento de desprestígio das informações de mortalidade, consideradas como pouco úteis para o planejamento dos serviços de saúde, entre outras razões por seu caráter genérico, pela demora na elaboração e pelo nivel de agregação dos dados ${ }^{(6)}$.

Neste sentido, a implantação de bancos municipais de dados de óbito, que tem sido realizada em vários municípios, responde à necessidade de obtenção de informação de forma mais rápida e adequada às necessidades locais, sendo úteis para a elaboração de práticas de saúde e na avaliação do desempenho dos serviços $^{(2,6,7)}$.

O estudo das desigualdades em saúde, evidenciadas pelos diferenciais de mortalidade entre classes sociais segundo variáveis sócio-econômicas, tem auxiliado a compreensão do complexo processo de determinação das doenças e possibilitado a utilização destas informações para a adoção de estratégias de intervenção, visando a ampliação da equidade em saúde ${ }^{(7,65)}$.

Nessa linha, a análise das diferenças nos padrões de mortalidade dos moradores de diferentes setores ou bairros de uma cidade pode se constituir em importante instrumento para a apreensão das desigualdades em saúde e subsidiar propostas de trabalho mais adequadas para as equipes das unidades locais.

$\mathrm{O}$ dado de mortalidade também pode ser utilizado como evento-sentinela, "indicador das condições particulares de produção de doenças, mas também como indicador das características dos próprios serviços de saúde e, de maneira mais ampla, da organização do setor, como um todo". Desta forma, a ocorrência de óbitos classificados como evitáveis passa a ser vista como injustificável, desencadeando uma investigação para detectar suas determinações, implementando ações, passíveis por parte do setor saúde, capazes de modificar esses determinantes ${ }^{(6)}$.

O sistema de informação de mortalidade por ser universal, de base populacional e de codificação padronizada, permite a avaliação de tendências e a comparações com outros locais ${ }^{(1)}$. 
Nas atividades da vigilância epidemiológica, $\bigcirc$ acompanhamento permanente de um problema de saúde (doença ou agravo) requer informações que possibilitem surpreender, o mais precocemente possivel, as mudanças nos padrões de morbidade e de mortalidade, a fim de permitir, em tempo oportuno, as medidas de controle pertinentes. O conhecimento das estatisticas de mortalidade orienta ainda a implantação de modelos de atenção, de promoção de saúde e das ações de prevenção e controle, revelando sua importância desde o planejamento até a avaliação de impacto destas últimas. Desta forma, é possivel estabelecer prioridades, com a alocação de recursos de forma direcionada para a modificação positiva das condições de saúde da população ${ }^{(61)}$.

As limitações do uso das informações sobre mortalidade devem-se a fatores como:

1. fornecerem informações insuficientes para o conhecimento da real ocorrência das doenças de menor letalidade;

2. dificuldade para o conhecimento da verdadeira causa básica de morte, uma vez que, geralmente, há um longo período de tempo entre o aparecimento da doença e a morte, exceto nas doenças agudas e acidentes;

3. trabalharem, em geral, só com a causa básica, uma vez que a morte, na maioria das vezes, é multicausal;

4. a precária qualidade do preenchimento das declarações de óbito, geralmente, por falta de treinamento dos médicos, e

5. as dificuldades na definição da causa básica por baixa disponibilidade de apoio diagnóstico.

A limitação a que se refere o item 3, poderia ser superada com o uso de estatísticas de mortalidade por causas múltiplas, onde se classificam todas as causas citadas na DO, a básica e as associadas. Laurenti ${ }^{(24)}$ refere que para certos tipos de óbitos, entre os quais, algumas doenças infecciosas agudas e de acidentes, pode-se aceitar uma só causa. No entanto, em grande parte das mortes, um complexo de causas contribui para o óbito. 
Assim, o estudo das causas múltiplas permitiria que se conhecesse, para cada causa básica, quais as conseqüências e complicações mais freqüentes ou ainda, os tipos de associação, no caso de duas ou mais causas específicas.

\subsection{A QUALIDADE DAS INFORMAÇÕES DE MORTALIDADE}

A utilidade das informações de mortalidade depende da fidedignidade da sua fonte de dados. A qualidade e a confiabilidade das declarações de óbito vêm sendo analisadas e questionadas em todo o mundo, com a realização de diversos estudos ${ }^{(5,14,22,35,45,46,48,57)}$ que procuram aferir a precisão das informações aí contidas.

Além da causa de morte, de importância fundamental, os outros itens constantes da declaração de óbito permitem revelar relações entre ocupação, sexo, idade, escolaridade ou local de residência e taxas diferenciadas de mortalidade.

Uma revisão da literatura, realizada por Maudsley ${ }^{(31)}$, com o objetivo de documentar e analisar os aspectos relevantes da DO para a saúde pública, entre eles a questão da precisão, mostrou estudos realizados no periodo de 1981 a metade do ano de 1995. Sua conclusão foi que, embora houvesse uma perspectiva de melhora da qualidade da informação de mortalidade, esta não aconteceu.

Laurenti ${ }^{(23)}$, também em uma revisão bibliográfica de trabalhos que discutiam a precisão dos certificados de óbito, analisou 40 estudos produzidos entre 1923 e 1996, agrupando-os em 5 classes: os que utilizam os achados de autópsia como medida da precisão de diagnósticos, os que comparam as informações da DO com os dados clínicos, os que comparam a precisão das informações quando diferentes médicos preenchem a DO, os que estudam as diferenças na codificação da causa básica de óbito e outros tipos de estudos para a avaliação da precisão dos dados de mortalidade. Na classe dos que comparam 
as informações da DO com os dados clínicos, cita trabalhos que, de uma maneira geral, elaboraram uma nova DO, buscando os dados em prontuários médicos hospitalares e ambulatoriais, entrevistas com o médico que atendeu ao paciente, resultados de exames complementares, entrevista com a familia e, quando existentes, resultados de autópsia. As diferenças encontradas entre as DO (original e refeita) variaram de estudo para estudo. Em um dos trabalhos brasileiros compilados ${ }^{(24)}$ encontrou-se um grau de discordância que afetava a causa básica e seu agrupamento, sendo as duas causas básicas classificadas em diferentes grupos, em $37,7 \%$ dos casos. Nos casos em que houve concordância, em $51,1 \%$ esta foi dos quatro algarismos do código de doença, em $6,0 \%$ dos três primeiros algarismos e, em $5,2 \%$, de apenas dois algarismos.

Nas investigações interamericanas de mortalidade ${ }^{(54)}$ e de mortalidade infantil ${ }^{(55)}$, os dados para a cidade de São Paulo mostraram que, nos indivíduos de 15 a 74 anos, em $67 \%$ das vezes a causa básica de morte foi corretamente preenchida nos atestados de óbito e em $52 \%$, para os óbitos de menores de 5 anos.

\section{- O SISTEMA DE INFORMAÇÕES SOBRE MORTALIDADE (SIM)}

No Brasil, a utilização do SIM, em todo o seu potencial, esbarra em muitos problemas, sendo o principal deles o que se refere à cobertura. Apesar da melhora gradativa apresentada ao longo dos anos, a análise quantitativa dos dados do SIM para o Brasil, quando comparados às estimativas do número de óbitos, realizadas pelo IBGE, mostra uma cobertura incompleta dos óbitos ${ }^{(12,33)}$. Segundo a publicação da Fundação Nacional de Saúde -Estudos Epidemiológicos- de agosto/2000, algumas unidades da federação chegam a um sub-registro superior a $70 \%$, sendo $40,2 \%$ na região Norte, $45,1 \%$ no Nordeste e $12,7 \%$ no CentroOeste. As regiões Sudeste e Sul apresentam um sub-registro bem menor ou inexistente $^{(39)}$. 
Como dificuldade adicional à cobertura do SIM, têm-se os problemas relativos à qualidade dos dados, particularmente no que diz respeito às causas de morte. Os dados sócio-demográficos, tais como o sexo, a idade, local de residência, ocupação, grau de instrução, entre outros, não apresentam problemas importantes quanto ao preenchimento ${ }^{(49)}$.

O aspecto mais relevante na análise qualitativa das Declarações de Óbito (DO) é o que mede a fidedignidade das informações relativas à mortalidade por causa, sendo vários os trabalhos publicados no Brasil que tratam deste tema ${ }^{(14 .}$ 22,24,35,48,52,62). Um dos estudos pioneiros, realizado em São Paulo, nos anos de $1962 / 1963$, mostrou que apenas $67,6 \%$ dos atestados apresentavam a verdadeira causa da morte anotada na DO ${ }^{(36)}$. Trabalho semelhante, realizado em 1971/1972, utilizando uma amostra de óbitos ocorridos nos hospitais da cidade São Paulo, revelou que em $37,9 \%$ dos casos não havia concordância entre a causa anotada e a verdadeira, evidenciando que, em 10 anos, não houve melhora na certificação médica da causa de morte, na cidade de São Paulo ${ }^{(22)}$.

A exatidão do diagnóstico clínico da causa básica do óbito, muitas vezes, é determinada por sua comparação com os resultados da necropsia $(9,44,63,64)$. Carvalho e colaboradores ${ }^{(13)}$, analisando 910 laudos de autópsias realizadas em um hospital universitário de Salvador, Bahia, entre os anos de 1970 e 1982 , encontraram $31 \%$ de diagnósticos clínicos incorretos quanto à causa da morte e $34 \%$ parcialmente corretos. Foram considerados como parcialmente corretos aqueles em que a doença básica identificada pelo patologista foi mencionada pelo clínico, dentre outras doenças, sem ter sido apontada como sendo a principal causa da morte.

E sabido que esta baixa qualidade da informação se expressa, principalmente, na falta de exatidão nos diagnósticos da causa básica da morte e das causas conseqüenciais, gerando, como produto principal, uma grande proporção de óbitos registrados como devidos a causas mal definidas. Outras vezes, esta mesma inexatidão só permite a classificação da causa básica em categorias residuais dos capitulos das causa naturais definidas, podendo ser consideradas como "mal definidas" dentro dos capitulos "bem definidos". No caso 
de mortes violentas são muito freqüentes a não conceituação do tipo da violência e a definição inexata da causa básica da morte, constando apenas o tipo de lesão. Além disso, tem sido referido que as estatísticas de mortalidade por AIDS e pelas causas maternas são bastante subestimadas ${ }^{(32)}$.

Diante desta realidade, é importante entender-se mais profundamente cada um destes aspectos.

\section{- Óbitos por causas mal definidas e sem assistência médica}

A utilização das informações sobre a mortalidade de uma determinada população pode ser prejudicada pelo mau preenchimento da $\mathrm{DO}$, levando a um elevado número de óbitos codificados no capítulo das causas mal definidas da Classificação Internacional de Doenças (cap. XVIII, CID-10), que, por sua vez, inclui, os sem assistência médica. Por representarem uma lacuna no conhecimento da distribuição das mortes segundo causas, dificultam 0 planejamento de ações preventivas e assistenciais nas diversas áreas, já que podem alterar significativamente os coeficientes de mortalidade por doenças específicas.

Esta situação engloba tanto os óbitos sem assistência médica e as mortes em que não se chegou a um diagnóstico mais preciso, como os casos de mau preenchimento da DO por desconhecimento ou negligência dos médicos acerca da forma correta de se atestar o óbito.

A proporção de mortes mal definidas em relação ao total de óbitos costuma ser usada como um indicador da qualidade dos dados de mortalidade ${ }^{(52)}$.

No Brasil, no período de 1979 a 1997, as proporções de óbitos codificados neste grupo de causas oscilaram entre $20,1 \%$ e $14,7 \%$, com uma variação importante entre as diferentes regiōes do pais. As Regiões Sul e Sudeste apresentaram, em 1997, os valores mais baixos, próximos de $10 \%$, enquanto 0 Norte e Nordeste mostraram proporções de 24,45 e $31,2 \%$, respectivamente ${ }^{(38)}$. 
- Óbitos com diagnósticos incompletos (categorias residuais dos capítulos)

A inexatidão no preenchimento de algumas $D O$ só permite classificar a causa básica do óbito em categorias residuais ("lixões") dos capitulos da CID que compõem as causas naturais definidas. Essas causas com diagnósticos incompletos, poderiam ser consideradas como "mal definidas" dentro de capitulos "bem definidos". Como exemplo, podem ser enumeradas: Carcinomatose, Neoplasia, Insuficiência Cardiaca, Doença do Coração, Doença do Aparelho Respiratório, Hemorragia Gastrointestinal, Insuficiência Renal, Anomalia Congênita sem outra especificação etc. ${ }^{(32)}$.

A atual descentralização da produção da informação, pela proximidade com os serviços de saúde onde ocorreu o evento, poderá contribuir para melhorar o preenchimento da $\mathrm{DO}$, através de atividades de consulta ao prontuário médico ou entrevista com o médico que assinou o atestado.

\section{- Óbitos por causas externas}

No Brasil, as mortes provocadas por acidentes ou violências, denominadas pela Organização Mundial de Saúde (OMS) como causas externas, representam um sério problema de saúde pública, ocupando o segundo lugar na ordenação dos principais grupos de causas de morte (excluindo-se as "mal definidas"), em 1998, sendo superadas apenas pelas doenças do aparelho circulatório (em todas as regiões do país) ${ }^{(38)}$.

Por ser um fenômeno de conceituação complexa e de determinação múltipla, assume-se como violência "o evento representado por açōes realizadas por individuos, grupos, classes ou nações que ocasionam danos fisicos, emocionais, morais e ou espirituais a si próprio ou a outros - por exemplo: agressão física, abuso sexual, violência psicológica, violência institucional" (42). 
Acidente é entendido como o evento não intencional e evitável, causador de lesões físicas e ou emocionais ${ }^{(42)}$.

Por determinação legal, no Brasil, para as mortes suspeitas ou decorrentes de causas não naturais, por acidentes ou violência, as DO devem ser fornecidas somente por perito legista, após realização de necropsia.

Segundo a Organização Mundial de Saúde (OMS), sempre que a causa da morte for uma lesão ou outro efeito de uma causa externa (capítulo XIX da CID10), deverão ser selecionadas como causas básicas as circunstâncias que deram origem a essa afecção (capítulo $X X$ da CID-10), já que do ponto de vista da prevenção há necessidade de se conhecerem os tipos de agravos que ocasionaram as lesões ${ }^{(51)}$.

As informações de mortalidade por causas externas têm como fontes oficiais as Secretarias de Segurança Pública e as Secretarias Estaduais e Municipais de Saúde, órgãos com atribuições e funções sociais distintas. Assim, as responsabilidades diversas e a falta de articulação entre essas instituições acarreta, logo na geração dos dados, uma considerável perda. Para os peritos dos Institutos de Medicina Legal, o objetivo principal do esclarecimento das circunstâncias em que ocorreu a morte é determinar a causa médica do óbito, que pode ser utilizada para fins judiciais. Já para os serviços de saúde interessa conhecer o início do processo que levou à morte, ou seja, o tipo de acidente/violência que ocasionou as lesões, que é o fator mais importante para fins de prevenção ${ }^{(47)}$. Desta forma, contribuiriam para o desenvolvimento de ações preventivas nas diversas áreas relacionadas ao fenômeno da violência (saủde, educação, segurança pública, emprego etc.) e para o planejamento das ações assistenciais, desde o atendimento das emergências até a reabilitação e reintegração social. Além disso, seriam essenciais para o monitoramento da violência, ou seja, para a avaliação das tendências e o acompanhamento do impacto das intervenções voltadas para sua redução ${ }^{(20)}$.

O que tem se verificado é que, freqüentemente, ao preencherem as $\mathrm{DO}$, os médicos legistas referem apenas os tipos de lesões encontradas no exame necroscópico (politraumatismo, traumatismo crânio-encefálico, perfuração de alças 
intestinais, entre outras), sem assinalar o tipo de violência (acidentes, homicídios, suicídios etc.) e a definição exata da causa básica de morte (enforcamento, afogamento, agressão etc). Desta forma, as estatisticas apresentam um resíduo de causas codificadas como eventos cuja intenção é ignorada se acidental ou intencional e de acidentes não especificados ${ }^{(20,28,42,43,49)}$.

Esta situação não é privilégio do Brasil. Castilho, analisando as 26.886 mortes por causas externas ocorridas no Chile, no triênio 1992-1994, encontrou uma proporção de causas externas mal definidas de $41,7 \%{ }^{(15)}$.

A alegação dos médicos, de desconhecimento do tipo de acidente ou violência que levou à morte, poderia ser tomada como verdadeira se os Institutos de Medicina Legal não dispusessem de informações policiais a respeito de cada caso. Em geral, estes recebem cópia do Boletim Policial de Ocorrência ou ao menos uma informação policial sobre cada caso, devendo esta informação ser anotada no atestado. O novo modelo da DO já traz a especificação relativa ao tipo de causa externa e qual a fonte de informação utilizada para o preenchimento deste item, eximindo o médico de qualquer avaliação subjetiva quanto a esse aspecto ${ }^{(28)}$.

Souza e colaboradores ${ }^{(67)}$, discutindo a qualidade da informação sobre mortalidade por causas externas, salientam a deficiente formação dos profissionais envolvidos na geração dos dados e a desconexão com o uso social esta informação.

Um bom exemplo é o que acontece em São Paulo, onde o Programa de Aprimoramento das Informações de Mortalidade no Município de São Paulo (PROAIM) incorporou na sua rotina, desde 1996, a busca de informações adicionais, junto ao IML, em todos os casos de mortes por causas externas atestadas como acidentes sem a especificação da causa e como lesões de intenção indeterminada. Assim, vem obtendo como resultado, o esclarecimento de grande parte dos casos investigados, o que tem permitido o aprimoramento da qualidade da sua informação, com conseqüente ampliação da sua utilização (21) 


\section{- Óbitos de mulheres em idade fértil}

A mortalidade materna -morte de mulheres em idade fértil por causas ligadas à gravidez, aborto, parto ou puerpério- è um importante indicador da qualidade de vida de um país e da determinação política de realizar ações de saúde coletiva. Segundo definição internacional, a mulher em idade fértil é aquela entre 15 e 49 anos de idade. No Brasil, levando-se em conta as idades que constam das estatísticas de registros vitais e de procedimentos médicos realizados, e a experiência dos Comitês de Mortes Maternas, recomenda-se considerar a faixa etária de 10 a 49 anos para mulher em idade fértil ${ }^{(41)}$.

A Organização Mundial de Saúde (OMS), em estudo realizado em 1990 , estimou que 580.000 mulheres morrem por ano, no mundo, por complicações ligadas ao ciclo gravídico-puerperal, sendo que $95 \%$ destas mortes ocorrem em paises em desenvolvimento.

No Brasil, em 1998, foram registrados 2.039 óbitos maternos. No entanto, é difícil identificar os niveis e tendências da mortalidade materna, estando esta bastante subestimada, em razão do sub-registro e da sub-informação das DO. $O$ sub-registro, mais comum nas regiōes Norte, Nordeste e Centro-Oeste, consiste da omissão do registro do óbito em cartório. Já a sub-informação se dá por um preenchimento incorreto das DO pelos médicos, que omitem tratar-se de uma morte por causa ligada à gestação, parto e puerpério, por desconhecimento de como preencher corretamente e da importância deste documento como fonte de dados, entre outras causas. Isto leva a falhas na seleção da causa básica da morte e afeta a comparabilidade dos dados, além de resultar em um quadro epidemiológico falso. Assim, freqüentemente a causa básica é mascarada, já que as causas declaradas registram apenas as afeç̧ões ou lesões que sobrevieram por último na sucessão de eventos que culminou com a morte, o que impede a identificação do óbito materno. Estas causas, que ocultam o estado gestacional, são conhecidas como máscaras ${ }^{(41)}$. 
No entanto, estudos demonstraram que em certos óbitos declarados como não devidos a causas maternas, poder-se-ia presumir que os mesmos fossem devidos a estas causas. Em função disso, recomenda-se a elaboração de uma lista de causas que comumente mascaram mortes maternas (causas presumiveis) e induzem a sub-informação, para que sejam pesquisadas quando ocorrerem em mulheres em idade fértil ${ }^{(41)}$.

Outro método utilizado para corrigir a sub-informação consiste na análise dos óbitos de mulheres em idade fértil, investigando a presença de gravidez no momento da morte ou nos doze meses anteriores e, em caso positivo, tentar estabelecer um nexo causal entre a gestação, parto e puerpério e a causa da morte. Em São Paulo, o uso deste procedimento praticamente duplicou o coeficiente de mortalidade materna em relação aos dados oficiais ${ }^{(25,26,66)}$.

\section{- Óbitos presumíveis de AIDS}

Assim como para as causa maternas, é possivel presumir a existência de AIDS, mesmo quando médico não a informa na DO. A instituição "Centers for Diseases Control“ publicou, em 1992, uma lista de causas presumiveis, que devem gerar uma investigação para cada caso suspeito, para a possivel correção dos dados e melhor conhecimento da situação de mortalidade ${ }^{(16)}$.

Refere-se que a mortalidade por AIDS é bastante sub-estimada, em razão da não declaração desta patologia pelos médicos. Em Marilia, um levantamento junto à Vigilância Epidemiológica do município mostrou que do total de 24 óbitos por AIDS e Tuberculose associados, ocorridos entre os anos 1996 e 2000, três DO $(12,5 \%)$ não declaravam a existência de AIDS ou Tuberculose, referindo causa desconhecida de óbito, $12(50 \%)$ atestavam apenas AIDS e $9(37,5 \%)$ continham a informação de AIDS e Tuberculose ${ }^{(19)}$.

Por outro lado, Matida e colaboradores ${ }^{(30)}$ mostraram que no Estado de São Paulo, no periodo de 1984 a 1994, o programa de DST/AIDS havia recebido a 
notificação de 762 óbitos por AIDS em menores de 13 anos, sendo constatada, através de um levantamento junto aos dados do SIM, a sub-notificação de cem mortes. Isto demonstra a importância do uso de mais de um sistema de informação para a obtenção de dados mais fidedignos sobre a saúde da população ${ }^{(2)}$.

\subsection{ESTE ESTUDO}

Este trabalho é parte do projeto "O Sistema de Informação sobre Mortalidade: problemas e propostas para seu enfrentamento", que tem como objetivos avaliar o Sistema de Informação de Mortalidade do Ministério da Saúde dos pontos de vistas quantitativo e qualitativo, e testar técnicas fáceis e uniformes capazes de minimizar as possiveis distorções ${ }^{(32)}$.

Foi realizada a vigilância dos óbitos de municipios dos estados de São Paulo, Sergipe e Mato Grosso, visando a obtenção do aprimoramento da informação estatística por meio de metodologia específica, que será abordada com maiores detalhes em tópico adiante.

Considerando-se que o estado de São Paulo foi uma das UF selecionadas e que os dados de mortalidade, por sua acessibilidade, são os mais utilizados na elaboração da maioria dos indicadores de saúde, cuja análise subsidia as ações de saúde, e que as limitações do SIM/MS, no que diz respeito à qualidade das informações, justifica uma avaliação deste sistema, assim como o desenvolvimento de metodologias uniformes e fáceis que possibilitem seu aprimoramento. 
2. OBJETIVOS 


\subsection{GERAIS}

1. Avaliar o Sistema de Informação de Mortalidade do Ministério da Saúde (SIM) do ponto de vista qualitativo, em alguns municípios da Regional de Saúde de Marília, estado de São Paulo, no período de 15 de agosto a 15 de dezembro de 1999 .

2. Testar metodologias simples e uniformes, capazes de minimizar as distorções do SIM.

\subsection{ESPECÍFICOS}

1. Conhecer as reais causas de morte, nos casos de óbitos classificados como mal definidos.

2. Melhorar a qualidade da informação quanto às causas de morte classificadas nas categorias residuais dos capítulos da CID-10, causas externas, causas presumiveis de AIDS e dos óbitos de mulheres em idade fértil.

3. Mensurar o ganho obtido com a aplicação da metodologia proposta.

4. Analisar a concordância entre as causas de morte obtidas em prontuário e em visita domiciliar. 


\section{MATERIAL E MÉTODOS}




\subsection{POPULAÇÃO DE ESTUDO}

Este estudo, como parte projeto "O Sistema de Informação sobre Mortalidade: problemas e propostas para seu enfrentamento" , já citada anteriormente, apresentou as mesmas características metodológicas. No entanto, para o Estado de São Paulo foi realizada apenas a análise qualitativa - verificação da fidedignidade das informações das causas de morte - por se considerar que as estatísticas de mortalidade para este estado não apresentam problemas do ponto de vista quantitativo.

O material de análise foi composto pelas declarações de óbito (DO) das mortes ocorridas em cinco municípios do Estado de São Paulo, pertencentes à Regional de Saúde de Marília (DIR-14) - Marília, Tupã, Garça, Osvaldo Cruz e Echaporã - sendo relativas ao periodo de 15 de agosto a 15 de dezembro de 1999 (Figuras 1 e 2).

Figura 1: Localização dos municípios da Regional de Saúde de Marília, Estado de São Paulo, 1999.

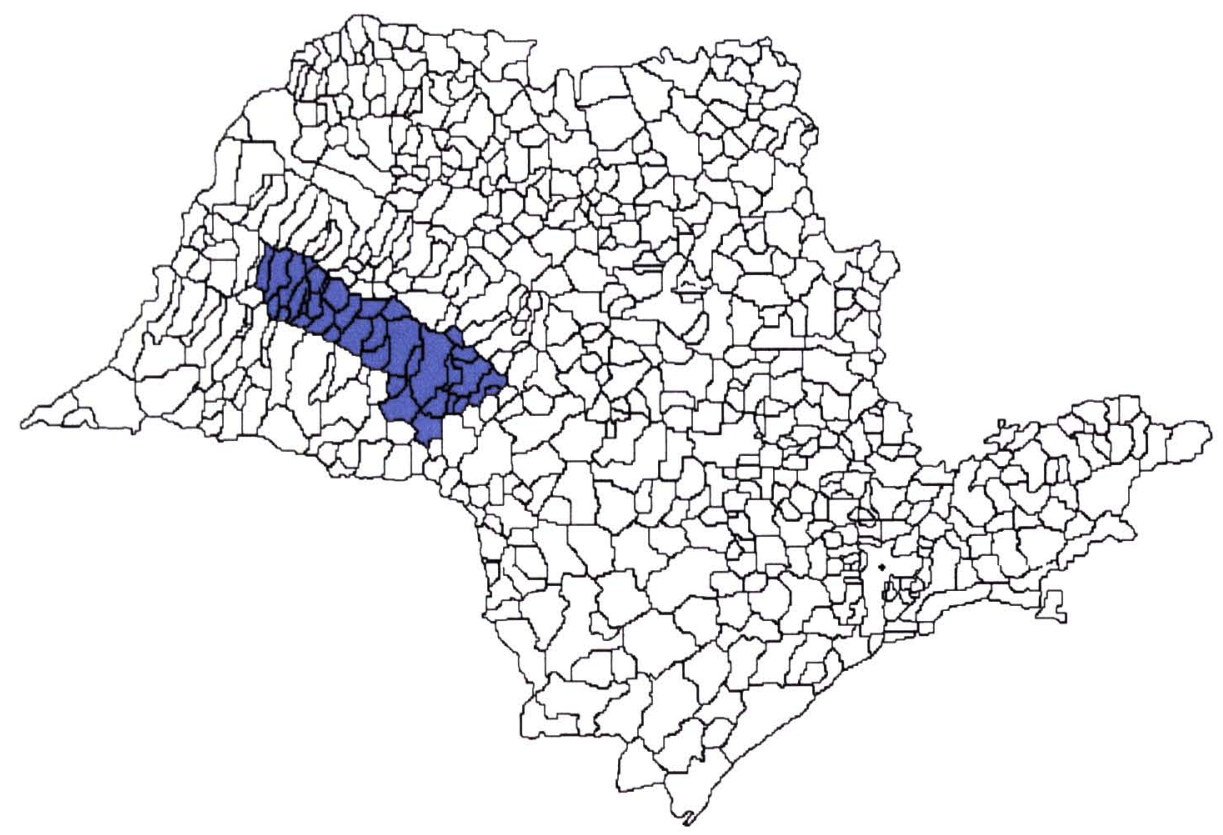


Figura 2: Municípios da Regional de Saúde de Marília - DIR-14 - 1999.

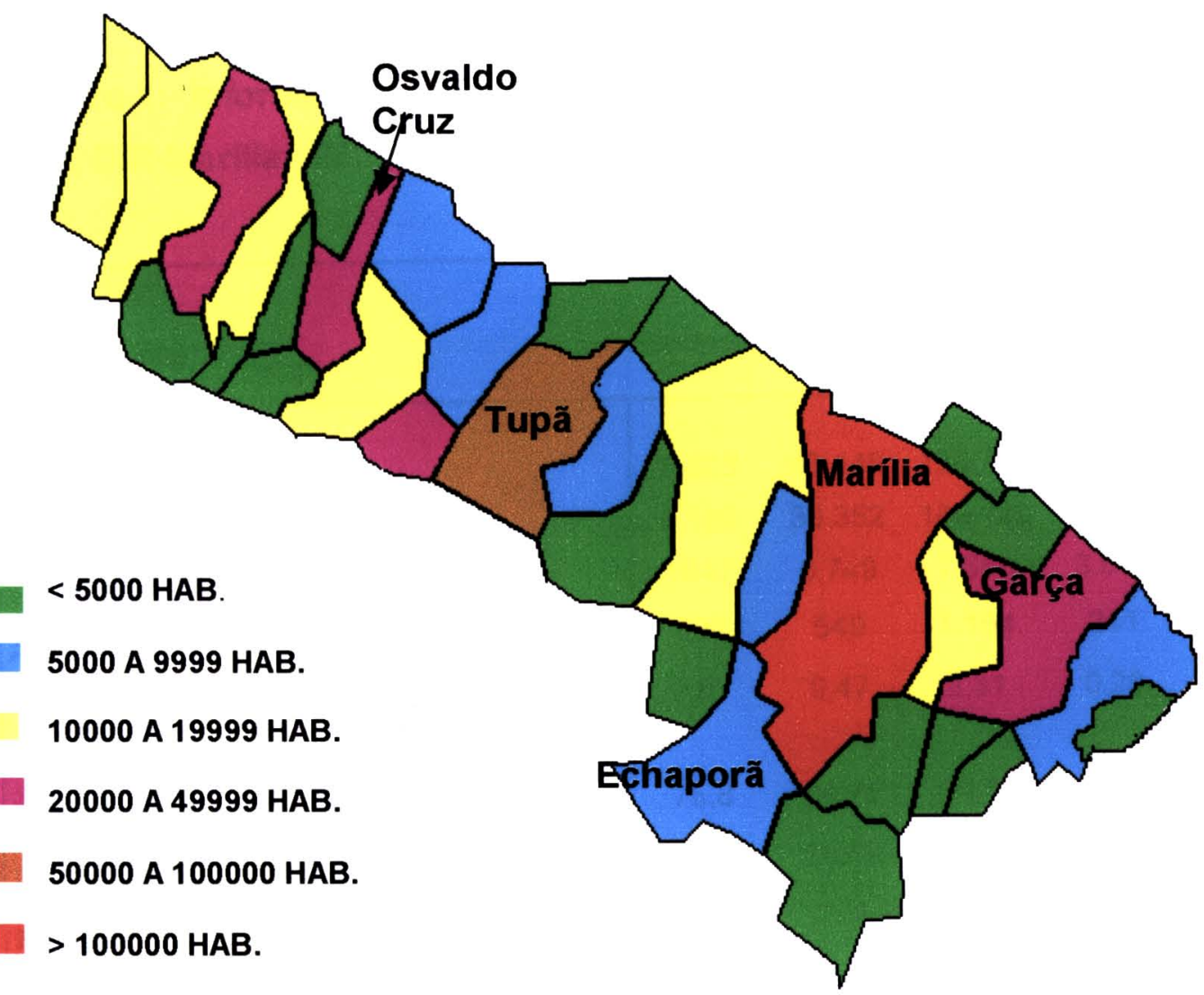

Fonte: Fundação SEADE 
Estes municipios foram escolhidos em função do número de habitantes, de forma que na amostra houvesse representantes dos vários tamanhos, e pela presença de pessoal do setor saúde competente e interessado no aprimoramento das informações.

Na Quadro1 podem ser apreciadas algumas características dessas áreas.

Quadro 1: Informaçōes relativas aos municipios selecionados segundo área, DIR-Marilia, 2000.

\begin{tabular}{|c|c|c|c|c|c|}
\hline Informaçōes & Echaporã & Garça & Marilia & Osv. Cruz & Tupã \\
\hline População & 6.805 & 43.146 & 196.778 & 29.628 & 63.253 \\
\hline - urbana & 5.185 & 36.352 & 189.122 & 26.112 & $60 .{ }^{27} 6$ \\
\hline - rural & 1647 & 6.749 & 7.656 & 3.516 & 2.977 \\
\hline Área $\left(\mathrm{em} \mathrm{km}{ }^{2}\right)$ & 507 & 549 & 1.154 & 241 & 625 \\
\hline $\begin{array}{l}\text { Taxa Geom. Cresc. Anual da População - } \\
\text { 1991/2000 (\% a.a.) }\end{array}$ & 0,87 & 0,47 & 2,31 & 0,28 & 0,85 \\
\hline Taxa de urbanização (\%) & 75,8 & 84,25 & 96,11 & 88,13 & 95,29 \\
\hline Densidade demográfica (hab $/ \mathrm{km}^{2}$ ) & 13,42 & 78,59 & 170,52 & 122,94 & 101,2 \\
\hline No de nascidos vivos (residentes) & 135 & 778 & 3.278 & 403 & 941 \\
\hline Coef. De natalidade (x1000 habit.) & 19,84 & 18,03 & 16,66 & 13,6 & 14,88 \\
\hline Coef. De natimortalidade ( $\times 1000$ nasc.) & 21,74 & 11,44 & 5,16 & 14,67 & 13,63 \\
\hline Coef. geral de mortalidade ( $\times 1000$ hab.) & 5,44 & 8,04 & 6,22 & 7,32 & 7,56 \\
\hline Coef.de mortalidade infantil(x1000 n.v.) & 7,41 & 16,71 & 18,61 & 12,41 & 17,0 \\
\hline $\mathrm{N}^{\circ}$ de hospitais gerais & 1 & 2 & 3 & 1 & 2 \\
\hline$N^{0}$ de leitos SUS & 44 & 134 & 451 & 43 & 194 \\
\hline$N^{0}$ de hospitais psiquiátricos & - & 1 & 1 & - & 3 \\
\hline $\mathrm{N}^{\circ}$ de leitos psiquiátricos - SUS & - & 276 & 260 & - & 654 \\
\hline$N^{\circ}$ de UBS/PSF & 1 & 9 & 25 & 3 & 9 \\
\hline
\end{tabular}

Fontes: F. SEADE

DIR-Marilia 
A região da DIR-Marília, em movimento oposto ao que vem acontecendo no Brasil, apresentou um aumento da proporção de óbitos por causas mal definidas (incluindo os "sem assistência médica"), entre 1993 e 2000 (Tabela 1). O aumento significativo do número de óbitos, a partir do ano de 1995, deve-se à incorporação dos municipios dos antigos Escritórios Regionais de Saúde de Adamantina e Tupã, pela DIR-Marília.

Tabela 1 : $\mathbf{N}^{0}$ total de óbitos e por causas mal definidas ( $\mathrm{n}^{\circ} \mathrm{e} \%$ ), na DirMarília, Estado de São Paulo, 1993-2000.

\begin{tabular}{cccc}
\hline ANO & Óbitos totais & $\begin{array}{c}\text { Óbitos por causas mal definidas } \\
\mathbf{N}^{\mathbf{0}}\end{array}$ \\
\hline 1993 & 1909 & 236 & 12,4 \\
1994 & 1998 & 255 & 12,8 \\
1995 & 3707 & 558 & 15,1 \\
1996 & 3907 & 582 & 14,9 \\
1997 & 3918 & 538 & 13,7 \\
1998 & 3826 & 583 & 15,2 \\
1999 & 3912 & 620 & 15,8 \\
2000 & 3752 & 618 & 16,5 \\
\hline
\end{tabular}

Fonte: SIM/DIR-Marilia

A figura 3 mostra que os cinco municípios do estudo, também, apresentaram um aumento nos percentuais de óbitos por causas mal definidas, em relação ao total de óbitos, para o período de 1993/2000. Marilia, município polo da região, apresenta as mais altas proporções, tendo passado de $13,7 \%$ a $20 \%$. 
Figura 3 : Proporção (\%) de óbitos por causas mal definidas, em relação ao total de óbitos, nos Municípios de Echaporã, Garça, Marília, Osvaldo Cruz e Tupã, no período de 1993/2000.

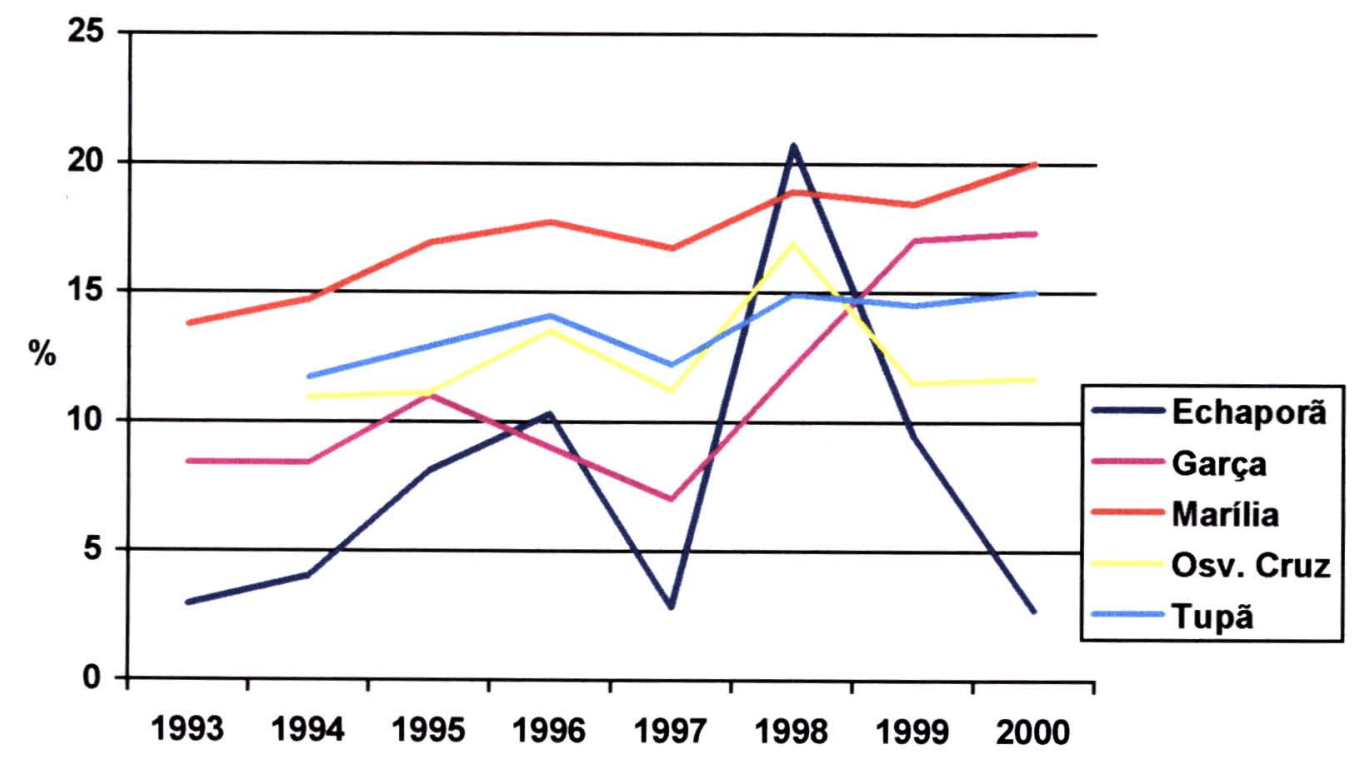

\subsection{VARIÁVEIS DE ESTUDO}

As variáveis analisadas foram:

- sexo

- idade

- local de ocorrência

- tipo de hospital (universitário/não universitário)

- municipio de ocorrência

- município de residência

- assistência médica

- óbito feminino em idade fértil

- causa da morte 
- morte não natural - tipo causa externa

- médico que assina

- fonte de dados

\subsection{MÉTODOS}

Foram coletadas, junto às Secretarias Estadual e Municipais de Saúde e aos Cartórios de Registro Civil, as DO de todos os óbitos ocorridos no período de 15 de Agosto a 15 de Dezembro de 1999, nos Municipios de Marilia, Tupã, Garça, Osvaldo Cruz e Echaporã. Destes, foram investigados os que tiveram como causa de morte uma ou mais das seguintes situações:

- causa mal definida

- diagnósticos incompletos, casos considerados como "lixões" ou categorias residuais de capítulos da CID-10.

- causas externas

- causas presumíveis de AIDS (Anexo 1)

- mortes de mulheres em idade fértil (10 a 49 anos).

A escolha destes critérios para a investigação dos óbitos deveu-se ao fato de serem eles os que mais freqüentemente expressam a má qualidade da informação.

Foram elaborados formulários específicos para a coleta de dados dos óbitos investigados, com o objetivo de permitir a obtenção de informações nas diferentes instituições: hospitais, unidades de saúde, Institutos de Medicina Legal, Delegacias de Polícia, consultórios médicos e domicílios (Anexo 2: F2, F3, F4 e F5). Estes formulários foram os mesmos que os utilizados na pesquisa nacional.

O inicio da investigação dependia do local de ocorrência do óbito. Assim, os procedimentos relativos à coleta de dados obedeceram aos seguintes fluxos: 
- Óbito ocorrido em hospital: foram realizadas visitas aos hospitais para análise e cópia dos prontuários, com o objetivo de melhorar a informação e/ou determinar a causa da morte. A análise foi feita por duas médicas que registraram os dados no Formulário para Coleta de Informações Hospitalares sobre óbitos - F3.

- Óbito ocorrido em domicílio: foram realizadas visitas domiciliárias, por pessoal treinado, com a aplicação de um formulário -F2- com o objetivo de localizar o Hospital, Unidade Básica de Saúde (UBS) ou o médico que assistiu ao doente. Nas entrevistas também foram levantadas informações sobre a doença que levou à morte e, no caso de mulheres em idade fértil, a presença ou não de gravidez no momento da morte ou nos 12 meses que precederam a morte. Caso o doente tivesse recebido assistência hospitalar, foi feita a consulta ao prontuário médico do hospital, com o preenchimento do formulário apropriado (F3). Nos casos de assistência ambulatorial, visitas foram feitas às UBS ou ao consultório médico, com o preenchimento do instrumento $\mathrm{F} 4$, através de consulta ao prontuário ou entrevista com o médico.

- Óbito por causa externa: foram examinados os laudos do Instituto Médico Legal (IML) e, quando necessário, os Boletins de Ocorrência das Delegacias de Polícia, com o preenchimento do formulário F5, com o objetivo de precisar o tipo de causa externa que levou à morte.

As mortes por causas externas foram classificadas em 3 subgrupos: causas externas bem definidas, com diagnóstico incompleto e mal definida. Para esta subdivisão, foram consideradas:

- Causa externa mal definida:

- Eventos de intenção ignorada - códigos Y10 a Y 34

- Causa externa com diagnóstico incompleto:

- nos acidentes de transporte: 
V87 = acidente de trânsito tipo especificado, mas sendo desconhecido o modo de transporte da vítima

V88= acidente não - de - trânsito de tipo especificado, mas sendo desconhecido o modo de transporte da vítima

V89= acidente com um veiculo a motor ou não-motorizado, tipo(s) de veículo(s) não especificado(s)

V98= Outros acidentes de transporte especificados

V99= Acidente de transporte não especificado

- nos demais acidentes:

$\mathbf{W 1 9}=$ Queda sem especificação

W49= Exposição a outras forças mecânicas inanimadas e às não especificadas

W64= Exposição a outras forças mecânicas animadas e às não especificadas

W74= Afogamento e submersão não especificados

$\mathbf{X 0 9}=$ Exposição a tipo não especificado de fumaça, fogo ou chamas

X19= Contato com outras fontes de calor ou com substâncias quentes não especificadas

X29= Contato com animais ou plantas venenosos, sem especificação

X49= Envenenamento [intoxicação] acidental por e exposição a outras substâncias quimicas nocivas e às não especificadas

X59 $=$ Exposição a fatores não especificados

- nos suicídios:

X84=Lesão autoprovocada intencionalmente por meios não especificados

- nos homicidios

Y09= Agressão por meios não especificados

Com as informações levantadas na aplicação dos diversos formulários, foi preenchida, para cada óbito, uma DO-Nova. Este preenchimento seguiu as orientações do livro "O atestado de óbito" ${ }^{(28)}$, publicado pelo Centro da OMS para 
a Classificação de Doenças em Português (Centro Brasileiro de Classificação de Doenças).

Em relação à definição, à classificação e à codificação da causa da morte, usou-se a $10^{a}$ Revisão da Classificação Internacional de Doenças (CID-10) ${ }^{(51)}$, em vigor desde 1996

A DO-Nova foi considerada como o "documento-verdade", uma vez que representa nova causa básica gerada com a transcrição das informações dos

prontuários hospitalares e ambulatoriais, dos laudos do IML, dos Boletins de Ocorrência e das entrevistas realizadas.

As autoridades locais dos municípios foram contatadas, no sentido de informar os objetivos e importância da pesquisa, assim como para a solicitação de autorização para a busca dos dados em prontuários e arquivos pertencentes às instituições de saúde.

\subsection{ANÁLISE DE GANHOS}

A mensuração dos ganhos foi feita através da comparação entre as causas básicas observadas na DO original e na DO-Nova, atribuindo-se os seguintes pesos nos diferentes graus de ganho:

a) para as causas mal definidas na DO original:

peso 2 - quando se chegou a uma causa bem definida.

peso 1 - quando se chegou a uma nova causa básica, mas apenas considerada como diagnóstico incompleto.

peso 0 - quando a causa básica não se alterou, mantendo-se como mal definida, apesar da busca de informações.

b) para diagnósticos incompletos na DO original: 
peso 2 - quando se chegou a uma causa bem definida (dentro ou fora do capítulo original).

peso 0 - quando a causa básica não se alterou ou se alcançou outro diagnóstico incompleto (dentro ou fora do capítulo).

c) para as causas externas:

- mal definidas:

peso 2 - quando se chegou a uma nova causa básica bem definida.

peso 1 - quando a nova causa básica foi um diagnóstico incompleto.

peso 0 - quando a causa básica original não se alterou.

- com diagnósticos incompletos:

peso 2 - quando se alcançou uma causa básica bem definida.

peso 0 - quando a causa básica não se alterou ou se alcançou outro diagnóstico incompleto.

d) para os óbitos de mulheres em idade fértil, o ganho foi analisado pela alteração do número de óbitos por causas maternas.

e) para os óbitos presumiveis de AIDS, o ganho foi analisado em função do número de casos novos descobertos.

\subsection{MEDIDAS E TÉCNICAS UTILIZADAS}

Os dados foram digitados e analisados, utilizando o programa EPI INFO 6 , versão $6.04 b^{\left({ }^{(17)} \text {. }\right.}$

Para a verificação de relação entre as variáveis, foram realizados testes de associação (Qui-quadrado e teste de Fisher), sendo estabelecido um nivel de significância de $5 \%$, isto é, $\alpha=0,05^{(10)}$. 
$\mathrm{Na}$ comparação entre os dados levantados em diferentes fontes (prontuários e visitas domiciliares), foram analisadas as concordâncias ou não das causas básicas da morte, através do coeficiente Kappa, valor preditivo positivo e testes de sensibilidade e especificidade ${ }^{(4)}$.

Considerou-se, nas tabelas 26 e 27 :

\section{Doença segundo prontuário médico}

\begin{tabular}{|c|c|c|c|c|}
\hline & & Sim & Não & \\
\hline Doença & Sim & $A$ & b & $a+b$ \\
\hline Segundo & Não & $\mathrm{C}$ & d & $c+d$ \\
\hline V.D. & & $a+c$ & $b+d$ & \\
\hline
\end{tabular}

- Valor preditivo (positivo): a probabilidade de que as doenças de um determinado capítulo da CID-10 estejam presentes quando informadas pela VD. $V P+=a /(a+b)$.

- Sensibilidade: a capacidade da VD para detectar casos de determinado capítulo da CID-10. $S=a /(a+c)$.

- Especificidade: proporção de indivíduos sem doenças de determinado capitulo da CID-10 que foram assim classificados pela VD. $E=d /(b+d)$.

\subsection{ASPECTOS ÉTICOS}

O Projeto de Pesquisa "O Sistema de Informação de Mortalidade: problemas e propostas para seu enfrentamento", do qual este estudo faz parte, foi analisado e homologado por meio de parecer emitido pelo Comitê de Ética em Pesquisa da Faculdade de Saúde Publica, em 17/02/98 (Anexo 3). O termo de consentimento também está apresentado em anexo (Anexo 4). 
4. RESULTADOS E DISCUSSÃO 
Ocorreram 800 óbitos nos municípios de Marília, Tupã, Garça, Osvaldo Cruz e Echaporã, no período de 15 de agosto a 15 de dezembro de 1999. Destes, 302 satisfizeram os critérios de seleção e foram investigados (Tabela 2), tendo as proporções de óbitos estudados para cada cidade, variado de 27,9 a $50,5 \%$. Considerando-se o total de municípios, verificou-se que mais de um terço do total de óbitos foi selecionado para investigação. É importante lembrar que estas DO foram selecionadas do conjunto de óbitos ocorridos nos diversos municípios, e não apenas de residentes, já que o objetivo era verificar a qualidade dos dados do SIM, através da atuação junto à fonte que preencheu a DO, especificamente a causa básica.

Tabela 2: Número de óbitos por local de ocorrência e número e percentual de óbitos investigados, nos municípios selecionados da DIR-Marília, agosto/ dezembro, 1999.

\begin{tabular}{l|c|cc}
\hline \multicolumn{1}{c|}{ Município } & Óbitos ocorridos & \multicolumn{2}{c}{ Óbitos investigados } \\
& & No $^{\circ}$ & $\%$ \\
\hline Marilia & 465 & 180 & 38,7 \\
Tupã & 154 & 43 & 27,9 \\
Garça & 107 & 54 & 50,5 \\
Osvaldo Cruz & 63 & 21 & 33,3 \\
Echaporã & 11 & 4 & 36,4 \\
\hline TOTAL & $\mathbf{8 0 0}$ & 302 & $\mathbf{3 7 , 8}$ \\
\hline
\end{tabular}

Para a elaboração das DO-novas foram realizadas 111 visitas domiciliares e consultados: 192 prontuários hospitalares, 69 laudos do IML, 4 boletins de ocorrência, 13 prontuários de UBS, 14 médicos e 3 laudos de patologia, totalizando 406 procedimentos. Em alguns casos (13), foram consultadas até 3 fontes. 
Embora a metodologia proposta não contemplasse a consulta a laudos em laboratórios de patologia, este recurso foi usado em 3 casos, cujos prontuários não continham informações que permitissem determinar a causa de morte, mas faziam menção a exames de anatomia patológica.

A DO-nova não pode ser elaborada em 18 casos (perdas) por não se conseguir localizar o prontuário nos hospitais e unidades de saúde ou pela impossibilidade da realização da visita domiciliária, em decorrência de endereços errados na DO e/ou prontuário, ou mudança da família. Em apenas um caso, a perda se deveu a recusa da família em responder ao formulário.

\subsection{CARACTERIZAÇÃO DOS ÓBITOS}

A tabela 3 mostra a distribuição dos 302 óbitos segundo o motivo de inclusão na pesquisa e o município de ocorrência. O total de casos apresentados (317) é maior do que o total de óbitos investigados (302), devido ao fato de 15 deles terem sido incluidos em duas situaçōes (dois motivos de entrada).

Das 302 mortes analisadas, 185 (61,3\%) eram de homens e $117(38,7 \%)$ de mulheres. Quanto à faixa etária, 36, 4\% tinham 70 anos ou mais e $33,8 \%$ de 20 a 49 anos (Tabela 4). O grande número de óbitos na faixa de 20 a 49 anos é explicado pela maior ocorrência de mortes por causas externas nestas idades e pelo critério de seleção: óbitos de mulheres em idade fértil e presumiveis de AIDS (Figura 4). As causas mal definidas foram o motivo de inclusão mais freqüente nas faixas etárias de 50 a 69 anos e 70 e mais. 
Tabela 3: Número de óbitos analisados segundo município de ocorrência e motivo de inclusão, DIR-Marília, agosto/dezembro, 1999.

\begin{tabular}{|c|c|c|c|c|c|c|c|}
\hline \multirow[b]{2}{*}{ Municipios } & \multirow{2}{*}{\begin{tabular}{c|} 
Mal \\
Definidos
\end{tabular}} & \multirow{2}{*}{$\begin{array}{l}\text { Diagnósticos } \\
\text { Incompletos }\end{array}$} & \multirow{2}{*}{$\begin{array}{c}\text { Causas } \\
\text { Externas }\end{array}$} & \multirow{2}{*}{$\begin{array}{l}\text { Mulher em } \\
\text { idade fértil }\end{array}$} & \multirow{2}{*}{$\begin{array}{l}\text { Presum. } \\
\text { De AIDS }\end{array}$} & \multicolumn{2}{|c|}{ Total } \\
\hline & & & & & & $\mathbf{N}^{\circ}$ & $\%$ \\
\hline Marília & 79 & 26 & 47 & 20 & 17 & 189 & 59,6 \\
\hline Tupã & 13 & 13 & 7 & 12 & 2 & 47 & 14,8 \\
\hline Garça & 29 & 12 & $6^{*}$ & 7 & 1 & 55 & 17,4 \\
\hline Osv.Cruz & 10 & 3 & 8 & 1 & - & 22 & 6,9 \\
\hline Echaporã & 1 & - & 1 & 1 & 1 & 4 & 1,3 \\
\hline Total & 132 & 54 & 69 & 41 & 21 & 317 & 100,0 \\
\hline
\end{tabular}

Tabela 4: Número e porcentagem de óbitos segundo faixa etária e sexo, nos municípios selecionados da DIR-Marília, agosto/dezembro, 1999.

\begin{tabular}{c|cc|rc}
\hline Faixa etária (anos) & \multicolumn{2}{|c|}{ Sexo } & \multicolumn{2}{c}{ Total } \\
& Masc. & Fem. & \multicolumn{1}{c}{$N^{\circ}$} & \multicolumn{1}{c}{} \\
\hline$<1$ & 7 & 5 & 12 & 4,0 \\
1 a 9 & 2 & 1 & 3 & 1,0 \\
10 a 19 & 9 & 4 & 13 & 4,3 \\
20 a 49 & 64 & 38 & 102 & 33,8 \\
50 a 69 & 46 & 16 & 62 & 20,5 \\
70 e mais & 57 & 53 & 110 & 36,4 \\
\hline Total & 185 & 117 & 302 & 100,0 \\
\hline
\end{tabular}


Figura 4: Número de óbitos investigados segundo faixa etária e motivo de inclusão, nos municípios selecionados da DIR-Marília, agosto/dezembro, 1999.

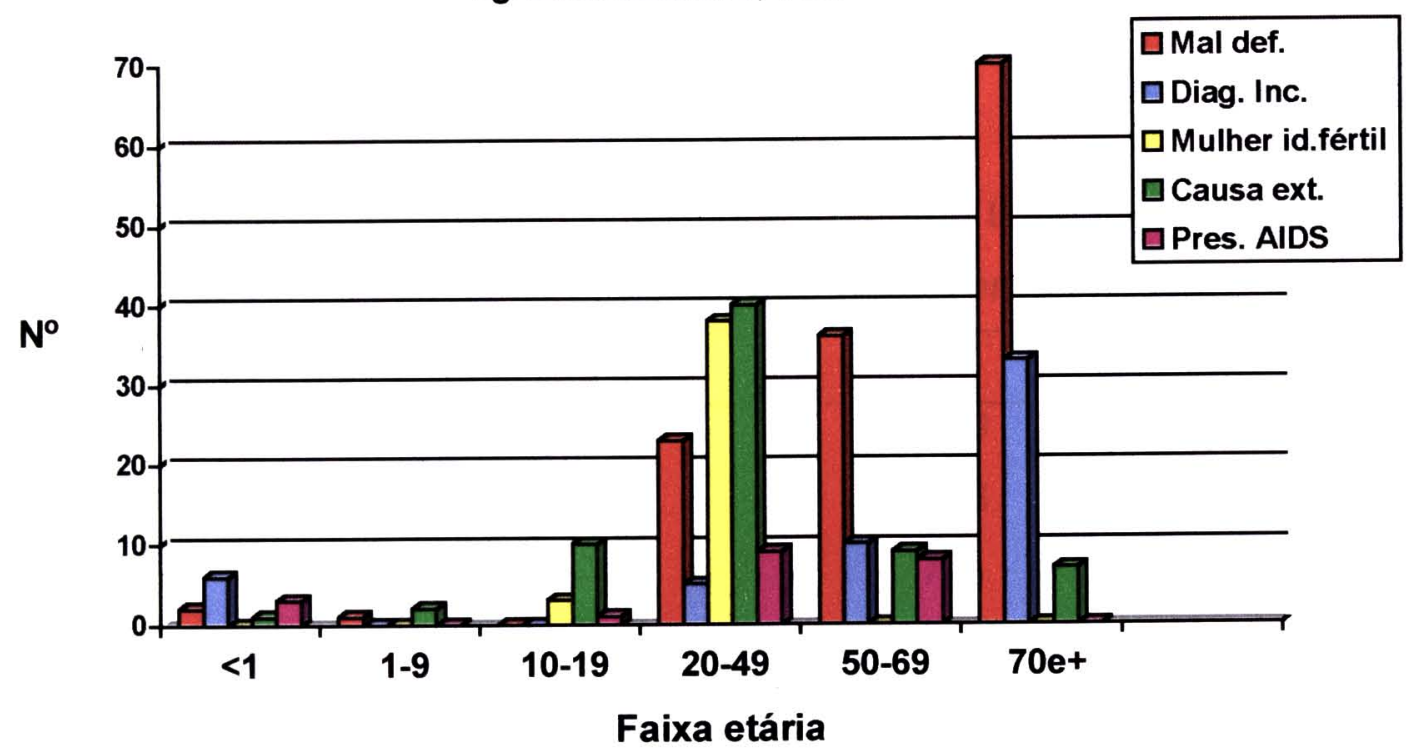

A tabela 5 mostra a distribuição dos óbitos segundo município de residência. Embora 180 das mortes tenham ocorrido em Marília, o número de residentes neste município é menor (135), provavelmente pelo fato de seus serviços de saúde serem referência para toda a região.

Tabela 5: Número e porcentagem de óbitos segundo município de residência, DIR-Marília, agosto/dezembro, 1999.

\begin{tabular}{l|cc}
\hline Município de residência & $\mathbf{N}^{\circ}$ & $\%$ \\
\hline Marília & 135 & 44,7 \\
Tupã & 32 & 10,6 \\
Garça & 57 & 18,9 \\
Osvaldo Cruz & 18 & 6,0 \\
Echaporã & 4 & 1,3 \\
Outros & 53 & 17,5 \\
lgnorado & 3 & 1,0 \\
\hline Total & $\mathbf{3 0 2}$ & $\mathbf{1 0 0 , 0}$ \\
\hline
\end{tabular}


A maioria dos óbitos, 53,9\%, ocorreu em hospitais e 30,8\% em domicílios (Tabela 6). As declarações de óbito foram assinadas em $31,2 \%$ das vezes pelo médico que assistia ao falecido e $22,9 \%$ por médicos do IML (Tabela 7).

Tabela 6: Número e porcentagem de óbitos segundo local de ocorrência, nos municipios selecionados da DIR-Marília, agosto/dezembro, 1999.

\begin{tabular}{l|cc}
\hline Local & $\mathbf{N}^{\circ}$ & $\%$ \\
\hline Hospital & 163 & 53,9 \\
Domicílio & 93 & 30,8 \\
Via pública & 21 & 7,0 \\
Em trânsito & 10 & 3,3 \\
Outros & 9 & 3,0 \\
Ignorado & 6 & 2,0 \\
\hline Total & 302 & $\mathbf{1 0 0 , 0}$ \\
\hline
\end{tabular}

Tabela 7: Número e porcentagem de declarações de óbito segundo médico que assina, nos municípios selecionados da DIR-Marilia, agosto/dezembro, 1999.

\begin{tabular}{|c|c|c|}
\hline Médico que assina: & $\mathbf{N}^{0}$ & $\%$ \\
\hline Atendeu ao falecido & 94 & 31,2 \\
\hline Substituto & 35 & 11,6 \\
\hline IML & 69 & 22,9 \\
\hline Outros & 58 & 19,3 \\
\hline Ignorado & 45 & 15,0 \\
\hline Total & $301^{\star}$ & 100,0 \\
\hline
\end{tabular}

* Incluido um óbito por causa externa registrado sem DO, por determinação judicial 


\subsection{CAUSAS DE MORTE}

\subsubsection{Causas mal definidas}

Foram investigados 132 casos que se enquadraram como óbitos por causas mal definidas (capítulo XVIII da CID-10), correspondendo a $43,7 \%$ do total analisado.

No período estudado, a proporção destas mortes em relação ao total de óbitos ocorridos nos municípios variou de 8,4 a 27,1\% (Tabela 8). Apenas Echaporã e Tupã encontram-se com valores compatíveis aos da região Sudeste $(9,9 \%)^{(40)}$.

Dos 132 óbitos, 81 foram de homens e 51 de mulheres, com idades que variaram de menor de 1 a 98 anos, sendo $53 \%$ na faixa etária de 70 anos e mais (Tabela 9).

Quanto ao local do óbito, de forma diferente do ocorrido com o total de mortes, onde a maioria se deu no hospital, verificou-se que, para as mal definidas, $79(59,8 \%)$ aconteceram nos domicílios. Destes, 43 DO foram assinadas por médicos que não haviam atendido ao falecido, provavelmente plantonistas de prontos-socorros de hospitais (Tabela 10).

Tabela 8: Número de óbitos ocorridos e número e porcentagem de óbitos por causas mal definidas segundo município da DIR-Marília, agosto/dezembro, 1999.

\begin{tabular}{l|c|cc}
\hline \multicolumn{1}{c|}{ Município } & Óbitos ocorridos & \multicolumn{2}{c}{ Óbitos por causas mal definidas } \\
& & $\mathbf{N}^{\mathbf{0}}$ & $\%$ \\
\hline Marília & 465 & 79 & 17,0 \\
Tupã & 154 & 13 & 8,4 \\
Garça & 107 & 29 & 27,1 \\
Osvaldo Cruz & 63 & 10 & 15,9 \\
Echaporã & 11 & 1 & 9,1 \\
\hline TOTAL & $\mathbf{8 0 0}$ & $\mathbf{1 3 2}$ & $\mathbf{1 6}, \mathbf{5}$ \\
\hline
\end{tabular}


Tabela 9: Distribuição dos óbitos por causas mal definidas, segundo faixa etária e sexo, nos municípios selecionados da DIR-Marília, agosto/dezembro, 1999.

\begin{tabular}{l|cc|cc}
\hline Faixa etária (anos) & \multicolumn{2}{|c|}{ Sexo } & \multicolumn{2}{c}{ Total } \\
& Masculino & Feminino & No & $\%$ \\
\hline$<1$ & 2 & - & 2 & 0,8 \\
1 a 9 & 1 & - & 1 & 1,5 \\
20 a 49 & 18 & 5 & 23 & 17,4 \\
50 a 69 & 26 & 10 & 36 & 27,3 \\
70 e + & 34 & 36 & 70 & 53,0 \\
\hline Total & $81(61,4 \%)$ & $51(38,6 \%)$ & 132 & 100,0 \\
\hline
\end{tabular}

Para a elaboração das DO-novas foram realizadas 80 visitas domiciliares, consultados 95 prontuários hospitalares, 5 laudos do IML, 11 prontuários das Unidades de Saúde, 4 médicos e 1 laudo de anatomia patológica.

Ao se analisar a distribuição das mortes mal definidas, segundo categorias da CID, observa-se que $81(61,4 \%)$ foram codificadas como causa desconhecida, pertencente à categoria outras causas mal definidas e as não especificadas de mortalidade e que $28(21,2 \%)$ foram classificadas como óbitos sem assistência médica (Tabela 11). Considerando-se que o total de mortes no conjunto dos municípios foi de 800 , observa-se que, em $3,5 \%$ das vezes, a morte foi declarada como sem assistência médica. É importante destacar que esta situação ocorreu, em sua maior parte, por preenchimento inadequado das $D O$, já que estas mortes se deram em locais onde existem médicos e equipamentos de saúde e cerca de $20 \%$ dos médicos que atestaram declararam ter atendido ao falecido (Tabela 10).

$\mathrm{Na}$ investigação destes óbitos, visando à melhoria da informação, houve 13 perdas, correspondentes aos casos em que não se conseguiu localizar o 
prontuário nos hospitais ou unidades de saúde e/ou a entrevista domiciliar não pode ser realizada, por mudança da família ou endereço errado.

Tabela 10: Número e porcentagem de óbitos por causas mal definidas segundo o tipo de médico que assinou a DO, nos municípios selecionados da DIR-Marilia, agosto/dezembro, 1999.

\begin{tabular}{l|rrrr|rc}
\hline $\begin{array}{l}\text { Médico que assinou } \\
\text { a DO }\end{array}$ & H & D & VP & O & No & $\%$ \\
\hline Atendeu ao falecido & 15 & 6 & 1 & 4 & 26 & 19,7 \\
Substituto & 8 & 9 & - & 1 & 18 & 13,6 \\
IML & 2 & 1 & - & 2 & 5 & 3,8 \\
Outros & 5 & 43 & 2 & 4 & 54 & 40,9 \\
Ignorado & 8 & 20 & - & 1 & 29 & 22,0 \\
\hline Total & $\mathbf{3 8}$ & $\mathbf{7 9}$ & $\mathbf{3}$ & $\mathbf{1 2}$ & $\mathbf{1 3 2}$ & $\mathbf{1 0 0 , 0}$ \\
\hline
\end{tabular}

* H: hospital D: domicílio VP: via pública O: outros 
Tabela 11: Distribuição dos óbitos por causas mal definidas, segundo categorias e subcategorias da CID-10, nos municípios selecionados da DIRMarília, agosto/dezembro, 1999.

\begin{tabular}{|c|c|c|}
\hline Categorias e subcategorias & $\mathbf{N}^{\circ}$ & $\%$ \\
\hline $\begin{array}{l}\text { Sint. Sinais Rel. Ap. Circ. E Resp. (R00-R09) } \\
\text { - Dor precordial } \\
\text { - Parada respiratória }\end{array}$ & $\begin{array}{l}1 \\
15\end{array}$ & 12,1 \\
\hline $\begin{array}{l}\text { Sint. Sinais Rel. Ap. Dig. e Abdome (R10-R19) } \\
\text { • Abdome agudo }\end{array}$ & 2 & 1,5 \\
\hline $\begin{array}{l}\text { Sint. e Sinais Gerais (R50-R69) } \\
\text { - Senilidade } \\
\text { - Outras convulsões e as não espec. } \\
\text { - Outros sintomas e sinais gerais espec. }\end{array}$ & $\begin{array}{l}1 \\
1 \\
3\end{array}$ & 3,8 \\
\hline $\begin{array}{l}\text { Causas Mal Definidas e Desconhecidas } \\
\text { - Morte sem assistência } \\
\text { - Outras causas mal def. e as não espec. }\end{array}$ & $\begin{array}{ll} & 109 \\
28 & \\
81 & \end{array}$ & 82,6 \\
\hline Total & 132 & 100,0 \\
\hline
\end{tabular}

A redistribuição dos 119 óbitos por causas mal definidas após a investigação, segundo os capitulos da CID-10, para todos os municipios, pode ser vista na tabela 12. Esta re-alocação baseou-se sobretudo em dados de prontuários e de entrevistas com médicos, confirmados ou não pelos familiares. Quando estes dados não foram localizados, em raras ocasiōes, utilizaram-se apenas dados obtidos nos domicilios.

Observou-se que permaneceram na categoria de causas mal definidas $21 \%$ dos casos (25 óbitos), geralmente por ausência ou indefinição das informações contidas nos prontuários ou, ainda, por informação insuficiente dada no domicilio para a elaboração de qualquer diagnóstico. 
É importante observar que dos 94 casos restantes, 90 tiveram a nova causa bem definida e 4 tornaram-se diagnósticos incompletos.

Tabela 12: Número e porcentagem de óbitos por causas mal definidas redistribuidos, após investigação, segundo causas*, nos municípios selecionados da DIR-Marília, agosto/dezembro, 1999.

\begin{tabular}{ll|cc}
\hline \multicolumn{2}{l|}{ Capítulos } & $\mathbf{N}^{\mathbf{0}}$ & $\%^{\star *}$ \\
\hline I. $\quad$ Algumas doenças infecciosas e parasitárias & 11 & 9,2 \\
II. $\quad$ Neoplasias & 17 & 14,3 \\
IV. Doenças das gland. endócr., nutric. e metabólicas & 6 & 5,0 \\
V. Transtornos mentais e comportamentais & 12 & 10,1 \\
VI. Doenças do sistema nervoso & 2 & 1,7 \\
IX. Doenças do aparelho circulatório & 31 & 26,1 \\
X. Doenças do aparelho respiratório & 8 & 6,7 \\
XI. Doenças do aparelho digestivo & 4 & 3,4 \\
XVIII. Mal definidos & 25 & 21,0 \\
XX. Causas externas & 3 & 2,5 \\
Perdas & 13 & \\
\hline Total & 132 & 100,0 \\
\hline
\end{tabular}

* segundo capitulos da CID-10

*" porcentagem calculada excluindo-se as perdas.

Considerando-se as DO que puderam ser investigadas, verificou-se que $26,1 \%$ foram re-alocadas entre as doenças do aparelho circulatório, sendo $30 \mathrm{com}$ causas bem definidas e 1 com diagnóstico incompleto.

$E$ interessante notar que o segundo lugar foi ocupado pelas neoplasias (14,3\%), o que chama a atenção, já que estas, em geral, costumam ser bem diagnosticadas. Foram adicionados aos 128 casos bem definidos de neoplasias outros 17 , o que representou um aumento de 13,3\%. Estes dados mostram haver 
uma subestimação do número de mortes por câncer. Schnitman ${ }^{(62)}$, em estudo realizado para avaliar a fidedignidade da DO em relação à causa básica por câncer, investigando DO cujas causas de morte eram outras que não as neoplasias, também concluiu que o número de mortes por câncer estava subestimado nas estatisticas oficiais.

Mais surpreendente ainda è a porcentagem dos transtornos mentais e comportamentais que ocuparam a terceira posição, com uma proporção de $10,1 \%$. Este dado confirma a tendência apontada na pesquisa "O Sistema de Informação sobre Mortalidade: problemas e propostas para seu enfrentamento", da qual este estudo é parte, onde os transtornos mentais e comportamentais, que eram representados em apenas $0,7 \%$ do total de óbitos, passaram a $6,6 \%{ }^{(32)}$.

As causas externas, que não deveriam aparecer na redistribuição das causas mal definidas, já que estas deveriam se restringir apenas às causas naturais, tiveram uma freqüência de $2,5 \%$. As declarações de óbito por causas externas, por determinação da legislação do país, teriam que ser preenchidas por médico legista ou, na ausência deste, em Delegacias de Polícia ou Cartórios.

A distribuição original do total de óbitos segundo causas, incluindo as mal definidas, referentes às 800 mortes ocorridas no conjunto dos municipios selecionados, no periodo estudado, foi:

10) Doenças do aparelho circulatório - 30,9\%

$\left.2^{\circ}\right)$ Mal definidas - $16,8 \%$

$\left.3^{\circ}\right)$ Neoplasias $-16,0 \%$

$4^{\circ}$ ) Causas externas $-8,6 \%$

$5^{\circ}$ ) Doenças do aparelho respiratório $-6,9 \%$

$6^{\circ}$ ) Doenças do aparelho digestivo $-5,5 \%$

$7^{\circ}$ ) Doenças das glândulas endócrinas, nutricionais e metabólicas $-3,6 \%$

$8^{\circ}$ ) Doenças infecciosas e parasitárias $-3,6 \%$

$9^{\circ}$ ) Afecções originadas no periodo perinatal $-3,3 \%$

10\%) Doenças do sistema nervoso - $2,1 \%$

$11^{\circ}$ ) Doenças do aparelho geniturinário $-0,8 \%$ 
12\%) Transtornos mentais e comportamentais $-0,6 \%$

13\%) Demais capitulos $-1,3 \%$

Comparando-se esta situação à da tabela 12, percebe-se que a redistribuição das causas mal definidas não é igual a das causa bem definidas, para o mesmo período.

Com a redistribuição das mal definidas, nas mesmas proporções da distribuição das causas conhecidas, conforme propõe a Organização Panamericana de Saude (OPS) ${ }^{(32)}$, tem-se:

$\left.1^{\circ}\right)$ Doenças do aparelho circulatório - $37,1 \%$

$2^{\circ}$ ) Neoplasias - $19,2 \%$

$3^{\circ}$ ) Causas externas $-10,4 \%$

$4^{\circ}$ ) Doenças do aparelho respiratório $-8.3 \%$

$\left.5^{\circ}\right)$ Doenças do aparelho digestivo $-6,6 \%$

$6^{\circ}$ ) Doenças das glândulas endócrinas, nutricionais e metabólicas - 4,5\%

$7^{\circ}$ ) Doenças infecciosas e parasitárias $-4,4 \%$

$\left.8^{\circ}\right)$ Afecções originadas no período perinatal $-3,9 \%$

$9^{\circ}$ ) Doenças do sistema nervoso $-2,5 \%$

$10^{\circ}$ ) Doenças do aparelho geniturinário - $0,9 \%$

$11^{\circ}$ ) Transtomos mentais e comportamentais - $0,7 \%$

$1^{\circ}$ ) Demais capítulos $-1,5 \%$

$\mathrm{Na}$ redistribuição dos 94 casos, originalmente classificados como mal definidos, mas alocados em causas bem definidas dentro dos capítulos da CID-10 após a investigação, obteve-se:

$\left.1^{\circ}\right)$ Doenças do aparelho circulatório $-34,8 \%$

$2^{\circ}$ ) Neoplasias $-18,1 \%$

$\left.3^{\circ}\right)$ Causas externas $-9,0 \%$

$4^{\circ}$ ) Doenças do aparelho respiratório $-7,9 \%$ 
$5^{\circ}$ ) Doenças do aparelho digestivo - 6,0\%

$6^{\circ}$ ) Doenças infecciosas e parasitárias $-5,0 \%$ Mal definidas $-5,0 \%$

$7^{\circ}$ ) Doenças das glândulas endócrinas, nutricionais e metabólicas - 4,5\%

$\left.8^{\circ}\right)$ Afecções originadas no período perinatal - 3,3\%

$\left.9^{\circ}\right)$ Doenças do sistema nervoso $-2,4 \%$

$\left.10^{\circ}\right)$ Transtornos mentais e comportamentais $-2,1 \%$

$1^{\circ}$ ) Demais capitulos $-1,9 \%$

Colocando-se, lado a lado, as três situações citadas, pré-investigação, pósinvestigação e a que propõe a OPS (Tabela 13), nota-se a existência de pequenas alterações nos percentuais das principais causas de morte, estando as cinco primeiras superestimadas na terceira hipótese apresentada (OPS). Levando-se em conta que a situação pós-investigação é a correta, pode-se constatar uma subestimação dos Transtornos mentais e comportamentais, que passaram de 0,6 e 0,7 a $2,1 \%$, assumindo a $10^{\mathrm{a}}$ posição entre as causas de morte. 
Tabela 13: Porcentagem e ordenação das causas de morte, segundo situação pré e pós-investigação e a que propõe a OPS, nos municípios selecionados da DIR-Marília, agosto/dezembro, 1999.

\begin{tabular}{l|rc|ccc|cc}
\hline \multicolumn{1}{c|}{ Capítulos } & \multicolumn{3}{c}{ Pituação } & \multicolumn{2}{c}{ Pós } & \multicolumn{2}{c}{ OPS } \\
& $\%$ & ordem & $\%$ & ordem & $\%$ & ordem \\
\hline Doenças do aparelho circulatório & 30,9 & $1^{\mathbf{a}}$ & 34,8 & $1^{\mathbf{a}}$ & 37,1 & $1^{\mathbf{a}}$ \\
Neoplasias & 16,0 & $3^{\mathbf{a}}$ & 18,1 & $2^{\mathbf{a}}$ & 19,2 & $2^{\mathbf{a}}$ \\
Causas externas & 8,6 & $4^{\mathbf{a}}$ & 9,0 & $3^{\mathbf{a}}$ & 10,4 & $3^{\mathbf{a}}$ \\
Doenças do aparelho respiratório & 6,9 & $5^{\mathbf{a}}$ & 7,9 & $4^{\mathbf{a}}$ & 8,3 & $4^{\mathbf{a}}$ \\
Doenças do aparelho digestivo & 5,5 & $6^{\mathbf{a}}$ & 6,0 & $5^{\mathbf{a}}$ & 6,6 & $5^{\mathbf{a}}$ \\
Doenças infecciosas e parasitárias & 3,6 & $7^{\mathbf{a}}$ & 5,0 & $6^{\mathbf{a}}$ & 4,4 & $7^{\mathbf{a}}$ \\
Mal definidas & 16,8 & $2^{\mathbf{a}}$ & 5,0 & $6^{\mathbf{a}}$ & - & \\
Doenças das glândulas endócrinas, & 3,6 & $7^{\mathbf{a}}$ & 4,5 & $7^{\mathbf{a}}$ & 4,5 & $6^{\mathbf{a}}$ \\
nutricionais e metabólicas & & & & & & \\
Afecções originadas no período perinatal & 3,3 & $9^{\mathbf{a}}$ & 3,3 & $8^{\mathbf{a}}$ & 3,9 & $8^{\mathbf{a}}$ \\
Doenças do sistema nervoso & 2,1 & $10^{\mathbf{a}}$ & 2,4 & $9^{\mathbf{a}}$ & 2,5 & $9^{\mathbf{a}}$ \\
Transtornos mentais e comportamentais & 0,6 & $12^{\mathbf{a}}$ & 2,1 & $10^{\mathbf{a}}$ & 0,7 & $11^{\mathbf{a}}$ \\
Doenças do aparelho geniturinário & 0,8 & $11^{\mathbf{a}}$ & 0,8 & $11^{\mathbf{a}}$ & 0,9 & $10^{\mathbf{a}}$ \\
Demais capítulos & 1,3 & & 1,9 & & 1,5 & \\
\hline Total & 100,0 & 100,0 & & 100,0 \\
\hline
\end{tabular}

\subsubsection{Causas com diagnósticos incompletos}

Foram estudadas 54 DO classificadas como óbitos com causa básica com diagnóstico incompleto, pertencente às categorias residuais dos capítulos da CID10. Destes, $53,7 \%$ eram do sexo masculino e $46,3 \%$ do feminino, sendo que 
$55,6 \%$ dos falecidos se encontravam na faixa etária de 70 anos e mais (Tabela 14). O local do óbito foi o domicílio em $94,4 \%$ das vezes (Figura 3 ).

Quanto ao médico que assina a declaração, verificou-se que, em $61,1 \%$, o médico que tratou o falecido foi o que atestou a morte (33 casos). Esse dado é bastante diferente dos $19,7 \%$ encontrado para as causas mal definidas, verificando-se uma associação estatisticamente significativa entre a causa de morte ser mal definida e o médico que atesta não ter atendido ao falecido. $\left(X^{2}=13,00 ; p<0,05\right)$.

Tabela 14: Número e porcentagem de óbitos com diagnóstico incompleto, segundo faixa etária e sexo, nos municipios selecionados da DIR-Marilia, agosto/dezembro, 1999.

\begin{tabular}{|c|c|c|c|c|}
\hline \multirow[b]{2}{*}{ Faixa etária (anos) } & \multicolumn{2}{|c|}{ Sexo } & \multicolumn{2}{|c|}{ Total } \\
\hline & Masculino & Feminino & $N^{\circ}$ & $\%$ \\
\hline$<1$ & 2 & 4 & 6 & 11,1 \\
\hline 20 a 29 & 3 & 2 & 5 & 9,3 \\
\hline 50 a 69 & 6 & 4 & 10 & 18,5 \\
\hline $70 e^{+}$ & 18 & 15 & 33 & 61,1 \\
\hline Total & $29 \quad(53,7 \%)$ & $25(46,3 \%)$ & 54 & 100,0 \\
\hline
\end{tabular}

A distribuição dos diagnósticos incompletos que constavam na DO original pode ser vista na tabela 15 . Os capítulos que concentraram o maior número de diagnósticos incompletos foram: IX - Doenças do aparelho circulatório (22 casos 40,7\%); XI - Doenças do aparelho digestivo (12 casos - 22,2\%); I - Algumas doenças infecciosas e parasitárias (5 casos - 9,3\%) e XVI - Algumas afecções originadas no periodo perinatal ( 5 casos $-9,3 \%$ ). 
Tabela 15: Número de diagnósticos incompletos, segundo a DO original e a situação após a investigação, nos municípios selecionados da DIR-Marilia, agosto/dezembro, 1999.

\begin{tabular}{|c|c|c|c|c|c|}
\hline \multirow{2}{*}{$\begin{array}{l}\text { DO original } \\
\text { Diagnóstico incompleto: }\end{array}$} & \multicolumn{5}{|c|}{ Situação pós-investigação } \\
\hline & $\begin{array}{c}\text { Bem } \\
\text { definido }\end{array}$ & $\begin{array}{l}\text { Não } \\
\text { mudou }\end{array}$ & $\begin{array}{l}\text { Outro } \\
\text { Diag } \\
\text { Incompl }\end{array}$ & \begin{tabular}{c|} 
Mal \\
definido
\end{tabular} & Total \\
\hline Outras septicemias & 3 & 1 & - & 1 & 5 \\
\hline $\begin{array}{l}\text { Neoplasias malignas de outras localizaçōes e de } \\
\text { localizações mal def. }\end{array}$ & 1 & 1 & - & - & 2 \\
\hline Neoplasias malignas, sem especificação & 1 & - & - & - & 1 \\
\hline Anemia não especificada & - & - & 1 & - & 1 \\
\hline Distúrbio metabólico não especificado & 1 & - & - & - & 1 \\
\hline $\begin{array}{l}\text { Outros transtornos do sist. nervoso, não } \\
\text { classificados em outra parte }\end{array}$ & 1 & - & - & - & 1 \\
\hline $\begin{array}{l}\text { Embolia pulmonar sem menção de cor pulmonale } \\
\text { agudo }\end{array}$ & 1 & - & - & - & 1 \\
\hline Cardiomiopatia não especificada & 4 & - & - & - & 4 \\
\hline Insuficiência cardiaca não especificada & 13 & - & 2 & - & 15 \\
\hline Hemorragia subaracnóide não especificada & - & 1 & - & - & 1 \\
\hline $\begin{array}{l}\text { Embolia e trombose de outras porçōes da aorta e } \\
\text { das não especificadas }\end{array}$ & 1 & - & - & - & 1 \\
\hline Outras doenças do esôfago & 1 & - & - & - & 1 \\
\hline Outras formas de obstrução intest., e não especif. & - & 2 & - & - & 2 \\
\hline Megacólon, nāo classificado em outra parte & - & 1 & - & - & 1 \\
\hline Peritonite & 1 & - & 1 & - & 2 \\
\hline Insuficiência hepática crônica & 1 & - & - & - & 1 \\
\hline Doença hepática sem outra especificaçāo & 1 & - & - & - & 1 \\
\hline Hemorragia gastrointestinal, sem outra especif. & 4 & - & - & - & 4 \\
\hline Insuficiência renal não especificada & 1 & - & - & - & 1 \\
\hline $\begin{array}{l}\text { Infecção do trato urinário de localização não } \\
\text { especificada }\end{array}$ & 2 & - & - & - & 2 \\
\hline Asfixia grave ao nascer & 1 & 1 & - & - & 2 \\
\hline Outras afecçōes respiratórias especif. do RN & 1 & - & - & - & 1 \\
\hline Septicemia bacteriana năo especif. do RN & 2 & - & - & - & 2 \\
\hline Total & 41 & 7 & 4 & 1 & $53^{\star}$ \\
\hline
\end{tabular}


Dos 54 casos considerados como diagnóstico incompleto, um não pode ser investigado (perda). Dos 53 restantes, $41(77,3 \%)$ passaram para um diagnóstico completo e 12 continuaram como incompletos.

As mudanças ocorridas nas causas básicas de morte, após a investigação, nos diagnósticos incompletos mais freqüentes foram:

- Septicemia (5 casos): apenas 1 se manteve sem possibilidade de alteração. Em 1 caso houve "piora" da informação, isto é, de diagnóstico incompleto passou a mal definido na nova-DO. Os outros 3 , passaram a ter as seguintes causas básicas:

- B57.2:Doença de Chagas (crônica) com comprometimento cardiaco - J18.0: Broncopneumonia não especificada.

- M51.2: Outros deslocamentos discais intervertebrais especificados

- Neoplasias malignas, sem especificação ou de localização mal definida ( 3 casos): 1 caso se manteve e dois ficaram com os seguintes diagnósticos:

- C56: Neoplasia maligna de ovário

- C85.9: Linfoma não-Hodgkin de tipo não especificado

- Cardiomiopatia não especificada (4 casos):

- E14.2: Diabetes mellitus não especificado com complicações renais

- 108.8: Outras doenças de múltiplas valvas

- 125.9: Doença isquêmica crônica do coração não especificada ( 2 casos)

- Insuficiência cardíaca (15 casos): 2 passaram para outro diagnóstico incompleto, sendo 1 do mesmo capítulo (151.9 : Doença não especificada do coração) e outro do capítulo das causas extemas (W19.9 : Queda sem especificação). Os 13 casos restantes apresentaram como causa básica: 
- C96.7: Outras neoplasias malignas especificadas dos tecidos linfático, hematopoético e tecidos correlatos (1 caso)

- 111.0: Doença cardíaca hipertensiva com insuficiência cardiaca (congestiva) - ( 3 casos)

- 125.1: Doença aterosclerótica do coração (1 caso)

- 125.9: Doença isquêmica crônica do coração não especificada (1 caso)

- 142:0: Cardiomiopatia dilatada ( 2 casos)

- 150.0: Insuficiência cardíaca congestiva (4 casos)

- 169.8: Sequelas de outras doenças cerebrovasculares e das não especificadas ( 1 caso)

- Hemorragia gastrointestinal, sem outra especificação (4 casos): passaram a ter os seguintes diagnósticos:

- 180.2: Flebite e tromboflebite de outros vasos profundos dos membros inferiores

- J18.9: Pneumonia não especificada

- K70.3: Cirrose hepática alcoólica

- Y83.9: Intervenção cirúrgica não especificada

A análise da distribuição dos casos com diagnóstico incompleto segundo capitulos da CID-10, no atestado original e na DO-nova (Tabela 16), revelou uma diminuição do número de mortes em alguns capitulos (especialmente as doenças infecciosas e parasitárias, doenças do aparelho circulatório, digestivo e geniturinário) e o aumento em outros (doenças endócrinas, do aparelho respiratório e causas externas). Em alguns capítulos, mesmo que os números original e final sejam os mesmos, estes não se referem aos mesmos casos (processo de inclusão/exclusão), tendo características diferentes quanto ao sexo, idade e outras variáveis. 
Tabela 16: Número de óbitos com diagnóstico incompleto, segundo causas (capítulos da CID-10), nas DO original e nova, nos municipios selecionados da DIR-Marilia, agosto/dezembro, 1999.

\begin{tabular}{|c|c|c|c|c|c|c|c|c|c|c|c|c|c|c|c|c|c|c|c|c|c|}
\hline \multirow[t]{2}{*}{ Original } & \multicolumn{19}{|c|}{ DO-nova } & \multirow[t]{2}{*}{ Perdas } & \multirow[t]{2}{*}{ Total } \\
\hline & $T$ & II & III & IV & V & VI & VII & VIII & IX & $x$ & $X \mid$ & XII & XIII & XIV & $\mathbf{X V}$ & $\mathbf{X V I}$ & XVII & XVIII & $\mathbf{x x}$ & & \\
\hline $\mathrm{I}$ & 2 & & & & & & & & & 1 & & & 1 & & & & & 1 & & & 5 \\
\hline II & & 3 & & & & & & & & & & & & & & & & & & & 3 \\
\hline III & & & & & & & & & & & 1 & & & & & & & & & & 1 \\
\hline IV & & & & 1 & & & & & & & & & & & & & & & & & 1 \\
\hline $\mathbf{V}$ & & & & & & & & & & & & & & & & & & & & & - \\
\hline VI & & & & & & & & & & & & & & & & & & & 1 & & 1 \\
\hline VII & & & & & & & & & & & & & & & & & & & & & - \\
\hline VIII & & & & & & & & & & & & & & & & & & & & & - \\
\hline IX & & 1 & & 1 & & & & & 19 & & & & & & & & & & 1 & 1 & 23 \\
\hline$x$ & & & & & & & & & & & & & & & & & & & & & - \\
\hline XI & 1 & & & & 1 & & & & 1 & 1 & 7 & & & & & & & & 1 & & 12 \\
\hline XII & & & & & & & & & & & & & & & & & & & & & - \\
\hline XIII & & & & & & & & & & & & & & & & & & & & & - \\
\hline XIV & & & 1 & 1 & & & & & & & & & & 1 & & & & & & & 3 \\
\hline $\mathbf{X V}$ & & & & & & & & & & & & & & & & & & & & & - \\
\hline$\overline{X V I}$ & & & & & & & & & & & & & & & & 4 & 1 & & & & 5 \\
\hline XVII & & & & & & & & & & & & & & & & & & & & & - \\
\hline XVIII & & & & & & & & & & & & & & & & & & & & & - \\
\hline$x x$ & & & & & & & & & & & & & & & & & & & & & - \\
\hline Total & 3 & 4 & 1 & 3 & 1 & - & - & - & 20 & 2 & 8 & - & 1 & 1 & - & 4 & 1 & 1 & 3 & 1 & 54 \\
\hline
\end{tabular}




\subsubsection{Causas externas}

As mortes ocorridas por causas externas (capitulo $X X$ da CID-10) foram classificadas em 3 subgrupos: causas externas bem definidas, com diagnóstico incompleto e mal definidas. Optou-se por investigar também as bem definidas para avaliar a fidedignidade da causa básica de morte e a possibilidade de ganho no detalhamento da informação, devida à importância que os acidentes e violências vêm assumindo no Brasil.

Nos municipios e periodo estudados, segundo os dados do SIM, as mortes por causas externas corresponderam a $8,6 \%$ do total de óbitos, sendo a terceira causa de morte, depois das doenças do aparelho circulatório e das neoplasias.

Das 68 DO analisadas, $43(63,2 \%)$ se apresentaram como bem definidas, $15(22,1 \%)$ tinham um diagnóstico incompleto e $10(14,7 \%)$ eram mal definidas (Tabela 18). Foi encontrado um laudo do IML, referente a um homicídio no município de Garça, cuja DO não foi encontrada. Este óbito foi registrado 60 dias após a morte, com autorização judicial, sem DO.

O conjunto das mortes foi distribuído nos seguintes tipos:

- acidentes de transporte: códigos V01 a V99;

- demais acidentes: códigos W; X01 a X59; Y40 a Y98;

- lesões auto-inflingidas (suicidios): códigos X60 a X84;

- agressões (homicídios): códigos X85 a Y09, Y 35 e Y36;

- ignorado (lesōes em que se ignora a intenção): códigos Y10 a Y34.

A distribuição dos 68 óbitos por causas externas segundo o tipo e o motivo de inclusão se encontra na tabela 17. O tipo mais numeroso foi o dos acidentes de transporte $(41,2 \%)$, seguido dos homicidios $(23,5 \%)$. 
Tabela 17: Número de óbitos por causas externas, segundo tipo e motivo de análise, nos municípios selecionados da DIR-Marília, agosto/dezembro, 1999.

\begin{tabular}{l|c|c|c|cc}
\hline Tipos & $\begin{array}{c}\text { CE bem } \\
\text { Definidas }\end{array}$ & $\begin{array}{c}\text { CE mal } \\
\text { Definidas }\end{array}$ & $\begin{array}{c}\text { CE diagnóstico } \\
\text { incompleto }\end{array}$ & \multicolumn{2}{|c}{ Total } \\
\hline Acidentes de transporte & 16 & - & 12 & 28 & 41,2 \\
Demais acidentes & 5 & - & 2 & 7 & 10,3 \\
Suicidios & 7 & - & - & 7 & 10,3 \\
Homicídios & 15 & - & 1 & 16 & 23,5 \\
Ignorado & - & 10 & - & 10 & 14,7 \\
\hline Total & 43 & 10 & 15 & 68 & 100,0 \\
\hline
\end{tabular}

Em relação à idade e ao sexo (Tabela 18), observou-se que $57,3 \%$ dos falecidos estavam na faixa etária de 20 a 49 anos e que $85,3 \%$ eram do sexo masculino.

Tabela 18: Número e porcentagem dos óbitos por causas externas, segundo faixa etária e sexo, nos municípios selecionados da DIR-Marilia, agosto/dezembro, 1999.

\begin{tabular}{|c|c|c|c|c|c|c|}
\hline \multirow{3}{*}{ Faixa etária (anos) } & \multicolumn{4}{|c|}{ Sexo } & \multirow{2}{*}{\multicolumn{2}{|c|}{ Total }} \\
\hline & \multicolumn{2}{|c|}{ Masculino } & \multicolumn{2}{|c|}{ Feminino } & & \\
\hline & $\mathbf{N}^{\circ}$ & $\%$ & $\mathbf{N}^{\circ}$ & $\%$ & $\mathbf{N}^{0}$ & $\%$ \\
\hline$<1$ & 1 & 1,7 & - & - & 1 & 1,5 \\
\hline 1 a 9 & 1 & 1,7 & 1 & 10 & 2 & 2,9 \\
\hline 10 a 19 & 8 & 13,8 & 2 & 20 & 10 & 14,7 \\
\hline 20 a 49 & 34 & 58,7 & 5 & 50 & 39 & 57,4 \\
\hline 50 a 69 & 9 & 15,5 & - & - & 9 & 13,2 \\
\hline 70 e + & 5 & 8,6 & 2 & 20 & 7 & 10,3 \\
\hline Total & 58 & 100,0 & 10 & 100,0 & 68 & 100,0 \\
\hline
\end{tabular}


Embora, no Brasil, por determinação legal, seja obrigatório que as DO por causas não naturais sejam fornecidas por médicos legistas, após realização de necropsia, em 6 casos $(8,8 \%)$ isto não ocorreu. Em relação ao local de ocorrência do óbito, verificou-se que $41,2 \%$ ocorreram no hospital e $26,5 \%$ em via pública.

\section{- Causas externas mal definidas}

Neste grupo, correspondente a $14,7 \%$ das causas extemas, a única informação sobre a causa da morte era a de que se tratava de um óbito decorrente de uma lesão e não de causa natural, ou seja, lesões em que se ignorava se foram acidental ou intencionalmente infligidas. Assim, não se sabia que tipo de causa externa levara à morte: acidente, suicidio ou homicidio.

Paula e colaboradores ${ }^{(52)}$, analisando os dados de mortalidade do Brasil, de 1979 a 1989, referem que a proporção de óbitos por causas externas não especificadas em relação ao total de óbitos por causas externas, é um indicador refinado para se avaliar a qualidade da informação da mortalidade. Nesse estudo, este percentual variou, para o total do Brasil, de $20,7 \%$ no início da série, para $13,4 \%$ em 1989 , sendo observado um decréscimo para a quase totalidade das regiōes e dos estados no último ano.

Os dados desta pesquisa apresentaram proporção ligeiramente superior à média para o Brasil, em 1989. Levando-se em consideração os onze anos decorridos entre os dois estudos, e o fato dos municípios estudados pertencerem ao estado de São Paulo, seria esperado encontrar uma melhora na qualidade da informação, ou seja, percentuais bem menores.

Dos 10 óbitos nesta situação, as informações disponiveis eram que 6 mortes foram devidas a traumatismo crânio-ncefálico (2 por objeto contundente e 1 por instrumento pérfuro contundente), 1 a asfixia mecânica e 3 a fraturas de fêmur, não sendo possivel determinar a intencionalidade destas mortes.

Após a investigação, baseada principalmente nas consultas aos laudos do IML e, secundariamente, aos Boletins de Ocorrência das Delegacias de Policia, 7 
casos se tornaram bem definidos, 1 passou para um diagnóstico incompleto e 2 permaneceram ignorados.

Das 6 DO que tinham como causa traumatismo crânio-encefálico, 2 não puderam ser esclarecidas e 4 passaram a ter como nova causa básica: suicidio por arma de fogo, agressão por meio de objeto contundente, acidente de transporte e queda da mesma altura.

A DO que apresentava como causa básica asfixia mecânica, foi re-alocada no grupo dos homicídios e as 3 fraturas de fêmur, no de quedas, sendo 2 bem definidas (acidentais do mesmo nível) e 1 queda sem especificação (diagnóstico incompleto).

Estes resultados, que mostraram um aprimoramento da informação em $70 \%$ dos casos, indicam que os dados necessários para que as mortes por causa externa sejam bem definidas estão disponíveis no IML, não sendo estes transcritos para a DO. Drumond e colaboradores ${ }^{(20)}$, em um estudo que avaliou a qualidade das informações de mortalidade por acidentes não especificados e evento com intenção indeterminada, no município de São Paulo, obtiveram esclarecimento para apenas um terço dos casos.

\section{- Causas externas com diagnósticos incompletos}

Os óbitos enquadrados nesta categoria foram em número de 15 , sendo que $80 \%$ destes eram acidentes de transporte (Tabela 17).

\section{Acidentes de transporte}

Ao tratar dos acidentes de transporte terrestre (V01-V99), a 10a Revisão da Classificação Internacional de Doenças adotou como eixo o meio de transporte utilizado pela vítima, seguido da especificação do papel da vítima ou as circunstâncias do acidente. O veículo ocupado pela pessoa traumatizada é codificado pelos dois primeiros caracteres, já que se considera o mesmo como o mais importante fator a ser identificado para fins de prevenção ${ }^{(51)}$. 
Assim,

V01 a V09: Pedestre traumatizado em acidentes de transporte

V10 a V19: Ciclista traumatizado em....

V20 a V29: Motociclista traumatizado em...

V30 a V39: Ocupante de triciclo traumatizado....

V40 a V49: Ocupante de automóvel traumatizado..

V50 a V59: Ocupante de caminhonete... etc...

O terceiro caráter , como já dito anteriormente, traz a especificação do tipo de acidente. Como exemplo, a distribuição do $3^{\circ}$ caráter no caso de motociclista traumatizado:

V20: Motociclista traumatizado em colisão com um pedestre ou um animal

V21: Motociclista traumatizado em colisão com um veículo a pedal

V22: em colisão com um veículo a motor de duas ou três rodas

V33: em colisão com um automóvel..... etc...

Portanto, para uma análise global das mortes por acidente de transporte, bastaria trabalhar o problema no nivel dos agrupamentos, conhecendo somente a qualidade da vitima que reflete o meio de transporte utilizado (pedestre, ciclista, motociclista etc.). Já para se conhecer o papel da vítima ou as circunstâncias do acidente, a análise deve ser feita no nível de categoria fundamental.

Neste estudo, os 12 acidentes de transporte com diagnóstico incompleto foram codificados, na DO original como:

- V89 - acidente com um veículo a motor ou não motorizado, tipo de veículo não especificado - 11 casos; e

- V87 - acidente de trânsito de tipo especificado, mas sendo desconhecido o modo de transporte da vitima - 1 caso.

Foi possivel tornar a causa básica bem definida em $9 \quad(80,8 \%)$ dos 12 casos, sendo que 3 permaneceram como estavam (Tabela 19). 


\section{Demais acidentes}

Este grupo era composto por 2 casos de afogamento acidental não especificado (W74). Após a investigação, ambos passaram a afogamentos bem definidos (W73).

Homicídios

O único caso deste grupo, codificado pela DO-original como "agressão por meios não especificados", pode ser mais bem detalhado passando a "agressão por meio de objeto contundente".

Estes resultados, a exemplo de outros estudos semelhantes ${ }^{(20,21)}$, mostram que é possivel melhorar em muito o detalhamento da informação, tendo como fonte os laudos do IML.

\section{- Causas externas bem definidas}

A distribuição das causas dos óbitos, segundo tipo (Tabela 17), das DO originais, mostra que 36,2 eram acidentes de transporte e $34,9 \%$ se enquadravam no grupo dos homicidios.

A caracterização das mortes por acidentes de transporte (16 casos), considerando-se os dois primeiros caracteres da codificação, ou seja, o tipo de transporte utilizado, foi:

V01-V09: Pedestres - 10 casos

V10-V19: Ciclistas - 3 casos

V20-V29: Motociclista - 1 caso

V40-V49: Ocupante de automóvel -2 casos 
Os meios empregados para matar, nos 15 casos por homicidios foram:

Enforcamento: 2 casos

Arma de fogo: 9 casos

Objeto cortante ou penetrante: 2 casos

Objeto contundente: 2 casos

Tabela 19: Número de acidentes de transporte, segundo código da CID nas DO original e nova, nos municípios selecionados da DIR-Marilia, agosto/dezembro, 1999.

\begin{tabular}{|c|c|c|}
\hline DO original & DO-Nova & Total \\
\hline V89 & $\begin{array}{l}\text { V89 } \\
\text { V29 - motociclista traumatizado em acidente de transporte } \\
\text { não especificado } \\
\text { V27 - motociclista traumatizado em colisão com objeto fixo } \\
\text { ou parado } \\
\text { V48 - ocupante de um automóvel traumatizado em um } \\
\text { acidente de transporte sem colisão } \\
\text { V63 - ocupante de um veículo de transporte pesado } \\
\text { traumatizado em colisão com um automóvel ou uma } \\
\text { caminhonete } \\
\text { V67 - ocupante de um veículo de transporte pesado } \\
\text { traumatizado em colisão com um objeto fixo ou parado } \\
\text { V68 - ocupante de um veículo de transporte pesado } \\
\text { traumatizado em um acidente de transporte sem colisão }\end{array}$ & $\begin{array}{l}1 \\
2\end{array}$ \\
\hline V87 & $\begin{array}{l}\text { V59 - ocupante de uma caminhonete traumatizado em } \\
\text { outros acidentes de transporte. }\end{array}$ & 1 \\
\hline Total & & 12 \\
\hline
\end{tabular}


O grupo de óbitos classificados como "Demais acidentes" (5 casos) era composto por 3 casos de queda, 1 de inalação de conteúdo gástrico e 1 de complicação tardia causada por procedimento cirúrgico.

Finalmente, no grupo dos suicídios, havia 2 casos de intoxicação por produtos químicos e 5 por enforcamento.

Após a investigação das 43 mortes por causas externas bem definidas, verificou-se que em $20,9 \%$ dos óbitos (9 casos) houve alteração da causa básica. Destes, um passou a ser considerado causa natural.

No quadro 2, que mostra as causas básicas de óbito na DO original e na nova-DO, pode-se verificar que existiu um ganho no detalhamento das informações, mesmo nos casos de causa externa bem definida. 
Quadro 2: $\mathbf{N}^{\circ}$ de óbitos por causas externas bem definidas que apresentaram mudança na causa básica de óbito após a investigação, nos municípios selecionados da DIR-Marília, agosto/dezembro, 1999.

\begin{tabular}{|c|c|c|}
\hline DO-original & DO-Nova & $\begin{array}{c}\mathrm{N}^{\circ} \\
\text { casos }\end{array}$ \\
\hline $\begin{array}{l}\text { V09.3 - pedestre/acidente de trânsito } \\
\text { não especificado }\end{array}$ & $\begin{array}{l}\text { V03.1- pedestre /colisão com } \\
\text { automóvel }\end{array}$ & 2 \\
\hline $\begin{array}{l}\text { V19.4 - ciclista/ acidente de trânsito não } \\
\text { especificado }\end{array}$ & $\begin{array}{l}\text { V14.9 - ciclista/colisão com } \\
\text { veículo transp. Pesado }\end{array}$ & 1 \\
\hline $\begin{array}{l}\text { V29.9 - motociclista/acidente de trânsito } \\
\text { não especificado }\end{array}$ & $\begin{array}{l}\text { V27.4 - motociclista/colisão } \\
\text { com objeto fixo ou parado }\end{array}$ & 1 \\
\hline $\begin{array}{l}\text { V49.9 - ocupante automóvel/ acidente de } \\
\text { trânsito não especificado }\end{array}$ & $\begin{array}{l}\text { V44.4 - ocupante automóvel/ } \\
\text { colisão com veículo transp. } \\
\text { Pesado }\end{array}$ & 1 \\
\hline $\begin{array}{l}\text { W17.9 - outras quedas de um nivel ao } \\
\text { outro }\end{array}$ & $\begin{array}{l}\text { V80.0 - queda de um animal } \\
\text { ou veículo de tração animal }\end{array}$ & 1 \\
\hline W78.9 - Inalação de conteúdo gástrico & $\begin{array}{l}\text { 174.4 - Embolia e trombose de } \\
\text { artérias de membros não } \\
\text { especificados }\end{array}$ & 1 \\
\hline $\begin{array}{l}\text { X69.0 - Auto-intoxicação por produtos } \\
\text { quimicos não especificados }\end{array}$ & $\begin{array}{l}\text { X68.0 - Auto-intoxicação por } \\
\text { pesticidas. }\end{array}$ & 1 \\
\hline Y83.1 - Complicação tardia de cirurgia & $\begin{array}{l}\text { W18.9 - Queda no mesmo } \\
\text { nivel }\end{array}$ & 1 \\
\hline \multicolumn{2}{|l|}{ Total } & 9 \\
\hline
\end{tabular}




\subsection{4 Óbitos de mulheres em idade fértil}

Os óbitos ocorridos em mulheres em idade fértil (10 a 49 anos) foram investigados na sua totalidade, na tentativa de verificar se as causas de morte estavam relacionadas à gestação, parto ou puerpério, o que as tornariam mortes maternas diretas ou indiretas.

Foram analisados 41casos, sendo que 28 tiveram como motivo de inclusão só o fato de pertencerem a este grupo e 13, além de estarem enquadrados nesta categoria, faziam também parte de outra (mal definida, diagnóstico incompleto, causa externa ou presumivel de AIDS).

Em 4 casos não se conseguiu realizar a entrevista domiciliar ou a consulta aos prontuários, sendo considerados perdas. Em 3 destes, havia a informação, na DO, de ausência de gravidez nos últimos 12 meses.

Nos 37 restantes (Tabela 20), em 6 óbitos a informação sobre a presença de gravidez, no momento ou nos 12 meses que precederam a morte, não pode ser obtida, pela inexistência deste dado nos prontuários ou, nos casos de visita ao domicilio, os familiares o ignorarem ou, ainda, pelo não preenchimento do campo relativo à gravidez, parto ou puerpério na DO.

Considerando-se todos os casos (41), observou-se um percentual de preenchimento dos campos da DO, relativos à presença de gravidez, de apenas $42,9 \%$.

Tabela 20: Número e porcentagem de óbitos em mulheres em idade fértil, segundo a situação após a investigação, nos municípios selecionados da DIR-Marilia, agosto/dezembro, 1999.

\begin{tabular}{lcc}
\hline DO-nova & $\mathbf{N}^{\circ}$ & $\%$ \\
\hline Morte por causa materna & 2 & 5,4 \\
Morte por causa não materna & 29 & 78,4 \\
Ignorado & 6 & 16,2 \\
\hline Total & $\mathbf{3 7}$ & $\mathbf{1 0 0 , 0}$ \\
\hline
\end{tabular}


Após a investigação, em 31 casos foi possivel saber se a gravidez esteve presente ou não, sendo estabelecido o diagnóstico de óbito por causa materna em duas mortes. Apenas em 15 casos $(48,4 \%)$ a variável da DO estava preenchida (3 respostas afirmativas e 12 negativas).

Dos 3 casos em que a DO assinalava presença de gravidez, em 2 concluiuse pelo diagnóstico de óbito por causa matema. Estes, são relatados a seguir:

Caso1: 32 anos

Na DO original:

I. a. Infarto agudo do miocárdio

b. Disseccão de coronárias

c.

d.

II.

Paciente Gesta 2, Para 1, foi admitida na matemidade com 37 semanas de gestação, com bolsa rota, sem contrações. Foi submetida à cesariana com raquianestesia, tendo alta após dois dias. Aos 17 dias do puerpério foi vitima de infarto fulminante, no domicilio.

Causa básica do óbito na DO-original: infarto agudo do miocárdio. Na DO consta que a morte ocorreu no puerpério (até 42 dias).

Causa básica na Do-nova: doença cardio-vascular complicando o puerpério (099.4).

Caso 2:37 anos

$\mathrm{Na}$ DO original:

I. a. Choque cardiogênico

b. Cor pulmonale agudo

c. Tromboembolismo pulmonar 
d.

II. Diabetes mellitus

Paciente admitida no hospital no dia 16, em mau estado geral, com diabetes mellitus insulino dependente, com retinopatia diabética, prolapso de válvula mitral e gastrite aguda. Gesta 4, Para 1, sendo que as duas primeiras gestações terminaram em aborto no segundo mês. Na terceira gestação foi submetida à cesariana no $8^{\circ}$ mês, com produto nascido vivo que morreu posteriormente. A atual gestação é de 28 semanas, sendo que o produto teve morte intra-útero. No dia 18 teve parto vaginal espontâneo, recebendo alta no dia 21. Retornou ao hospital no dia 24, sendo internada na UTI (não foi encontrada a evolução desta intemação). A morte ocorreu no dia 27.

Causa básica na DO-original: tromboembolismo pulmonar. Na DO consta que a morte ocorreu no puerpério (até 42 dias).

Causa básica na DO-nova: embolia pulmonar de origem obstétrica, portanto, morte matema direta (O88.2).

No terceiro caso onde houve a presença de gravidez, essa morte não pode ser considerada como causa materna, por inexistir o nexo causal necessário.

Os dois óbitos por causa materna ocorreram em Marília, sendo um de residente no próprio município e o outro de uma residente de Garça. Desta maneira, tendo em vista que o número de nascidos vivos para os dois municípios, no mesmo período, foi de 997 e 254, respectivamente, para Marilia e Garça, temse os coeficientes de mortalidade materna de 100,3 e 397,7 por 100.000 nascidos vivos (n.v.).

Os dados da Fundação SEADE, para Marilia e Garça, no ano de 1999, são de $61,48 / 100000 n v$ e zero, respectivamente. O valor encontrado em Marília foi, portanto, $60 \%$ (razão: 1,6) maior do que o dado "oficial", relação esta menor do que as encontradas em dois trabalhos ${ }^{(26,66)}$, realizados no municipio de São 
Paulo, de 2,22 e 2,24. Em relação à cidade de Garça, pelo seu reduzido número de habitantes, a análise do coeficiente $(397,7 / 100000$ n.v.) requer que se examinem os dados por um tempo maior do que os quatro meses desta pesquisa, tendo em vista as oscilações que ocorrem em períodos pequenos.

Pelos resultados relatados acima foi possivel verificar a existência de subinformação de óbitos por causas maternas e que a busca de informações, através de levantamentos de prontuários e em visitas domiciliares, constitui-se em importante metodologia para a recuperação das mesmas.

\subsection{5 Óbitos por causas presumíveis de AIDS}

Com o objetivo de verificar se a informação sobre a mortalidade por AIDS poderia ser melhorada, foram investigados 21 casos considerados, pela causa básica anotada na DO-original, como presumíveis de AIDS. Em 14 deles (66,7\%) não havia no prontuário qualquer informação que pudesse levar à conclusão de ser ou não um caso de AIDS.

Dos 7 óbitos restantes, em que houve pelo menos uma solicitação de sorologia para HIV, em 3 o exame foi positivo, estando anotado o diagnóstico de AIDS no prontuário de dois deles. Nos 4 restantes o exame foi negativo (Tabela 21).

Tabela 21: Número e porcentagem de óbitos com causas presumiveis, segundo a causa básica da DO-nova, nos municipios selecionados da DIRMarilia, agosto/dezembro, 1999.

\begin{tabular}{l|cc}
\hline DO-nova & $\mathbf{N}^{\circ}$ & $\%$ \\
\hline AIDS & 3 & 14,3 \\
Não AIDS & 4 & 19,0 \\
Ignorado & 14 & 66,7 \\
\hline Total & $\mathbf{2 1}$ & $\mathbf{1 0 0 , 0}$ \\
\hline
\end{tabular}


Os três casos confirmados de AIDS estavam relatados nos prontuários da seguinte forma:

Caso 1: Masculino, 22 anos

DO original:
I. a. Insuficiência Respiratória Aguda
b. Pneumonia Intersticial
C. Abcesso cerebral
d.

II. Dependência química

Andarilho, etilista e usuário de drogas. Admitido no hospital com quadro neurológico a esclarecer, febril, desidratado, com candidiase oral. Solicitada a sorologia para HIV, em dezembro de 99. A morte ocorreu no dia $7 / 12 / 99$, vindo a confirmação do resultado positivo para HIV no dia 4/1/2000.

Caso 2: Masculino, 59 anos

DO original:

I. a.

b. Insuficiência Respiratória Aguda

c. Edema agudo de pulmão

d. Tuberculose pulmonar disseminada

II.

No prontuário há informações que o paciente é portador de Tuberculose miliar, menigoencefalite, gastroenterite aguda e AIDS.

Caso 3: Masculino, 27

DO-original: 
I. a. Insuficiência Respiratória Aquda

b. Edema agudo de pulmão

c. Pneumonia bilateral

d. Tuberculose pulmonar disseminada

II.

O prontuário informa que o paciente é portador de AIDS, tuberculose, moniliase oral, meningoencefalite e gatroenterite aguda.

Dos 3 casos de AIDS, 2 ocorreram no municipio de Tupã, sendo apenas 1 de residente. O outro ocorreu em Marília, sendo a vitima não residente neste município. Os dados da Fundação SEADE, para o ano de 1999, referem a existência de 5 casos de residentes em Tupã. Portanto, houve um aumento de pelo menos $20 \%$ no número de casos, considerando-se a hipótese de não ter havido mais óbitos por AIDS, não declarados nas DO, nos outros 8 meses do ano de 1999, que ficaram fora do período de investigação desta pesquisa.

\subsection{ANÁLISE DE GANHOS}

\subsubsection{Causas mal definidas}

A mensuração dos graus de ganho para as causa mal definidas, feita através da comparação da DO original com a DO-nova, atribuiu peso 2, quando se conseguiu chegar a uma causa bem definida, peso 1, quando se alcançou um diagnóstico incompleto e peso 0 , quando não houve modificação, conforme apresentado anteriormente. 
Analisando-se o conjunto dos municipios, em $75,6 \%$ dos casos investigados, houve um ganho máximo (2), o que equivale a dizer que se alcançou uma causa bem definida (Tabela 22 ). Incluindo-se as perdas $(10,2 \%)$ no total de casos, essa proporção passa a ser $68,2 \%$.

As mortes que não puderam ser investigadas (perdas) não foram analisadas quanto a ganho, uma vez que não se poderia afirmar que grau de ganho seria possivel, caso a investigação fosse realizada.

É interessante notar a variabilidade dos percentuais de ganho 2 entre os municipios, que oscilaram entre um máximo de $81,0 \%$, em Marilia, e um mínimo de $15,4 \%$, em Tupã. O fato de esse município ter apresentado uma menor proporção de óbitos mal definidos $(8,4 \%)$ pode significar serem estes, de fato, de dificil definição, o que explicaria as diferenças encontradas e indicaria um melhor preenchimento da DO pelos médicos deste local.

As diferenças dos percentuais de ganho do município de Marilia com os de Tupã e Osvaldo Cruz foram estatisticamente significativas (Teste de Fisher, $p<0,05)$, assim como, a do municipio de Garça quando comparado com Tupã $\left(X^{2}=\right.$ 10,51, $p<0,05)$.

Quanto às perdas, que também foram maiores em Tupã e Osvaldo Cruz, respectivamente, 35 e 30\%, podem ter sido motivadas pela maior distância destas cidades em relação à Marilia, o que dificultou a pesquisa dos prontuários hospitalares, realizada por duas médicas residentes nesse municipio. As viagens para o levantamento das informações eram agendadas, sendo que, em diversas ocasiões, nos dias das visitas, os prontuários não foram localizados nos hospitais. De qualquer maneira, estes resultados não invalidam a metodologia proposta, uma vez que a mesma deverá ser desenvolvida por equipes locais de saúde que, por estarem próximas, terão o acesso ao hospital facilitado. 
Tabela 22: Número e porcentagem de óbitos mal definidos, segundo ganho de informação nas causas de morte, nos municípios selecionados da DIRMarilia, agosto/dezembro, 1999.

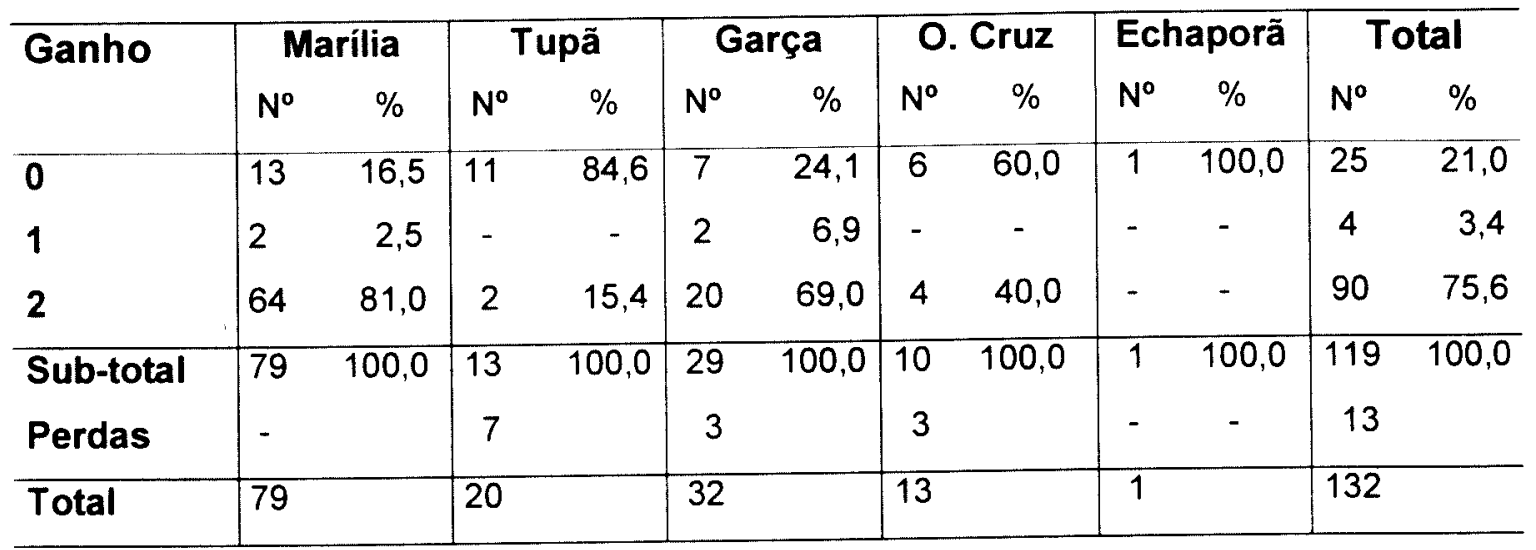

Outra observação é que não foram freqüentes os ganhos intermediários (1). Assim, em sua grande maioria, os casos passaram a bem definidos ou permaneceram como estavam.

Este resultado $(68,2 \%)$, na análise do conjunto dos municípios e incluindose as perdas no total de casos, são melhores que os apresentados pela já citada pesquisa sobre o Sistema de Informação de Mortalidade ${ }^{(32)}$ e por Oliveira ${ }^{(50)}$, na avaliação do Sistema de Informação sobre Mortalidade em Mato Grosso, que obtiveram, respectivamente, 43,9 e 50,9\% de ganho 2 .

Neste último estudo, a autora refere ter encontrado dificuldades na elucidação das causas, dada a má qualidade de alguns prontuários hospitalares e, em muitos casos, a inadequação dos meios diagnósticos. Provavelmente, esta é a razão da diferença encontrada, já que nos municipios desta pesquisa a qualidade dos prontuários, embora não fosse excelente, não se constituiu em fator limitante na grande maioria dos casos. 


\subsubsection{Causas com diagnósticos incompletos}

Para os diagnósticos incompletos, o critério na mensuração do grau de ganho foi de 2 , quando se alcançou uma causa bem definida e 0 , quando permaneceu como diagnóstico incompleto.

Os resultados obtidos foram semelhantes, no conjunto dos municípios, aos encontrados para as causas mal definidas, havendo $75,9 \%$ de ganho 2 nos casos investigados (Tabela 23). Incluindo-se no total o único caso de perda, este valor passa a 74,5. Também aqui, os resultados foram melhores dos que os apresentados nos dois estudos citados ${ }^{(32,50)}$, já que a pesquisa nacional obteve $52,3 \%$ e a do Mato Grosso, $41,0 \%$.

Tabela 23: Número e porcentagem de óbitos com diagnósticos incompletos, segundo ganho de informação nas causas de morte, nos municípios selecionados da DIR-Marília, agosto/dezembro, 1999.

\begin{tabular}{|c|c|c|c|c|c|c|c|c|c|c|c|c|}
\hline \multirow[t]{2}{*}{ Ganho } & \multicolumn{2}{|c|}{ Marília } & \multicolumn{2}{|c|}{ Tupã } & \multicolumn{2}{|c|}{ Garça } & \multicolumn{2}{|c|}{ O. Cruz } & \multicolumn{2}{|c|}{ Echaporã } & \multicolumn{2}{|c|}{ Total } \\
\hline & $N^{\circ}$ & $\%$ & $\mathrm{~N}^{\circ}$ & $\%$ & $N^{\circ}$ & $\%$ & $\mathrm{~N}^{\circ}$ & $\%$ & $N^{0}$ & $\%$ & $\mathrm{~N}^{\circ}$ & $\%$ \\
\hline 0 & 5 & 19,2 & 5 & 38,5 & 2 & 16,7 & 1 & 33,3 & - & - & 13 & 24,1 \\
\hline 2 & 21 & 80,8 & 8 & 61,5 & 10 & 83,3 & 2 & 66,7 & - & - & 41 & 75,9 \\
\hline Sub-total & 26 & 100,0 & 13 & 100,0 & 12 & 100,0 & 3 & 100,0 & - & - & 54 & 100,0 \\
\hline Perdas & - & & 1 & & - & & - & & - & - & 1 & \\
\hline Total & 26 & & 14 & & 12 & & 3 & & - & & 55 & \\
\hline
\end{tabular}

Vale destacar que, para os óbitos com diagnósticos incompletos, a variabilidade das proporções de ganho total (2) entre os municipios foi bem menor, sendo o pior resultado encontrado o do município de Tupã, com $61,5 \%$. As diferenças entre os municípios não foram estatisticamente significativas. 


\subsubsection{Causas externas}

O critério na aferição do ganho foi o mesmo utilizado para as mal definidas e para os diagnósticos incompletos das causas naturais.

O pequeno número de casos, tanto das causas externas mal definidas como das incompletas, inviabilizou uma análise específica para cada municipio.

Não houve perdas entre as causa externas.

Mal definidas: apenas 10 casos se apresentaram dentro desta categoria, sendo que $70 \%$ ( 7 óbitos) com ganho 2, 1 com ganho 1 e 2 com ganho zero.

Com diagnósticos incompletos: foram investigados 15 casos, com ganho total (2) em 11 deles (73,3\%), e nenhum ganho em 4.

\subsubsection{Análise geral dos ganhos}

A análise da situação geral mostra que foram investigados 198 casos, excluindo-se os óbitos por causas externas bem definidas, de mulheres em idade fértil e os presumiveis de AIDS. Não foi possivel realizar a investigação em 14 que foram considerados perdas (Tabela 24).

Considerando-se que para os casos classificados como perdas, a causa básica original fosse mantida, ainda assim os ganhos obtidos seriam expressivos, sendo de $68,2 \%$ para as causa mal definidas, $74,5 \%$ para as com diagnósticos incompletos, $70,0 \%$ para as externas mal definidas e $73,3 \%$ para as externas com causas incompletas.

É importante destacar que, embora para as causas externas bem definidas o ganho não seja mensurado, este de fato aconteceu já que em 9 casos $(20,9 \%)$ houve uma melhora da informação. 
Além disso, deve-se somar a esse resultado, o fato desta pesquisa ter permitido a obtenção dos coeficientes corrigidos para a mortalidade materna e AIDS.

As apresentações gráficas da situação pré e pós-investigação, para todos os casos investigados, no conjunto dos municípios e para cada um deles, se encontram nas figuras 5 a 10.

Tabela 24: Número e porcentagem de óbitos, segundo ganho de informação nas causas de morte, nos municípios selecionados da DIR-Marilia, agosto/dezembro, 1999.

\begin{tabular}{|c|c|c|c|c|c|c|c|c|c|c|}
\hline \multirow[t]{3}{*}{ Ganho } & \multirow{2}{*}{\multicolumn{2}{|c|}{$\begin{array}{c}\text { Mal } \\
\text { Definidas }\end{array}$}} & \multirow{2}{*}{\multicolumn{2}{|c|}{$\begin{array}{l}\text { Diagnósticos } \\
\text { incompletos }\end{array}$}} & \multicolumn{4}{|c|}{ Causas externas } & \multicolumn{2}{|c|}{ Total } \\
\hline & & & & & \multicolumn{2}{|c|}{ Mal definidas } & \multicolumn{2}{|c|}{ Incompletas } & \multirow[b]{2}{*}{$N^{\circ}$} & \multirow[b]{2}{*}{$\%$} \\
\hline & $N^{\circ}$ & $\%$ & $N^{0}$ & $\%$ & $\mathrm{~N}^{\circ}$ & $\%$ & $\mathrm{~N}^{\mathrm{c}}$ & $\%$ & & \\
\hline 0 & 25 & 18,9 & 13 & 23,6 & 2 & 20,0 & 4 & 26,7 & 44 & 20,7 \\
\hline 1 & 4 & 3,0 & - & - & 1 & 10,0 & - & - & 5 & 2,4 \\
\hline 2 & 90 & 68,2 & 41 & 74,5 & 7 & 70,0 & 11 & 73,3 & 149 & 70,3 \\
\hline Perdas & 13 & 9,9 & 1 & 1,8 & - & - & - & - & 14 & 6,6 \\
\hline Total & 132 & 100,0 & 55 & 100,0 & 10 & 100,0 & 15 & 100,0 & 212 & 100,0 \\
\hline
\end{tabular}


Figura 5: Situação dos óbitos, pré e pós-investigação, no conjunto dos municípios da DIR-Marília, agosto/dezembro, 1999.

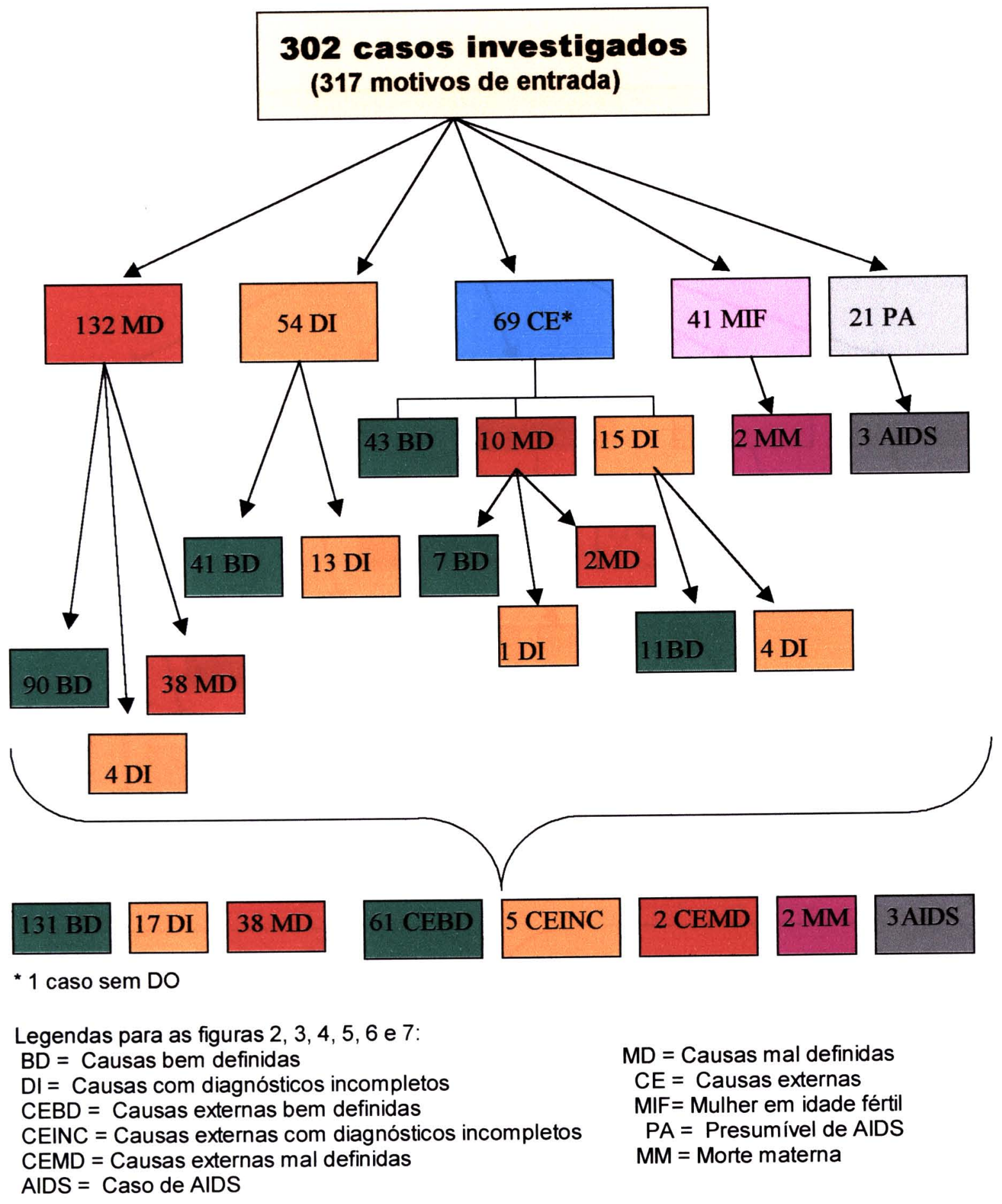


Figura 6: Situação dos óbitos, pré e pós-investigação, no município de Marília, DIR-Marília, agosto/dezembro, 1999.

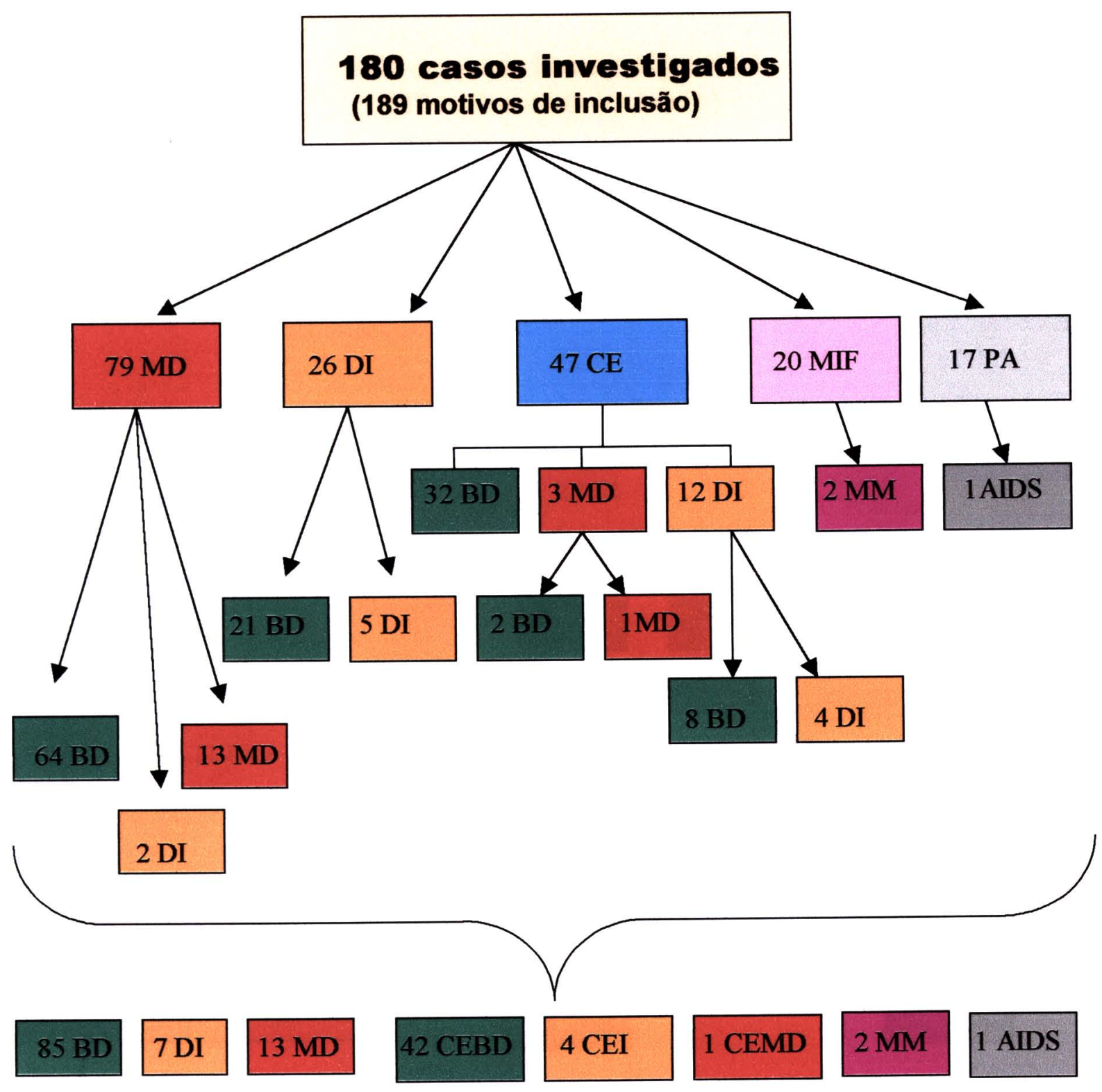


Figura 7: Situação dos óbitos, pré e pós-investigação, no município de Tupã, DIR-Marília, agosto/ dezembro, 1999.

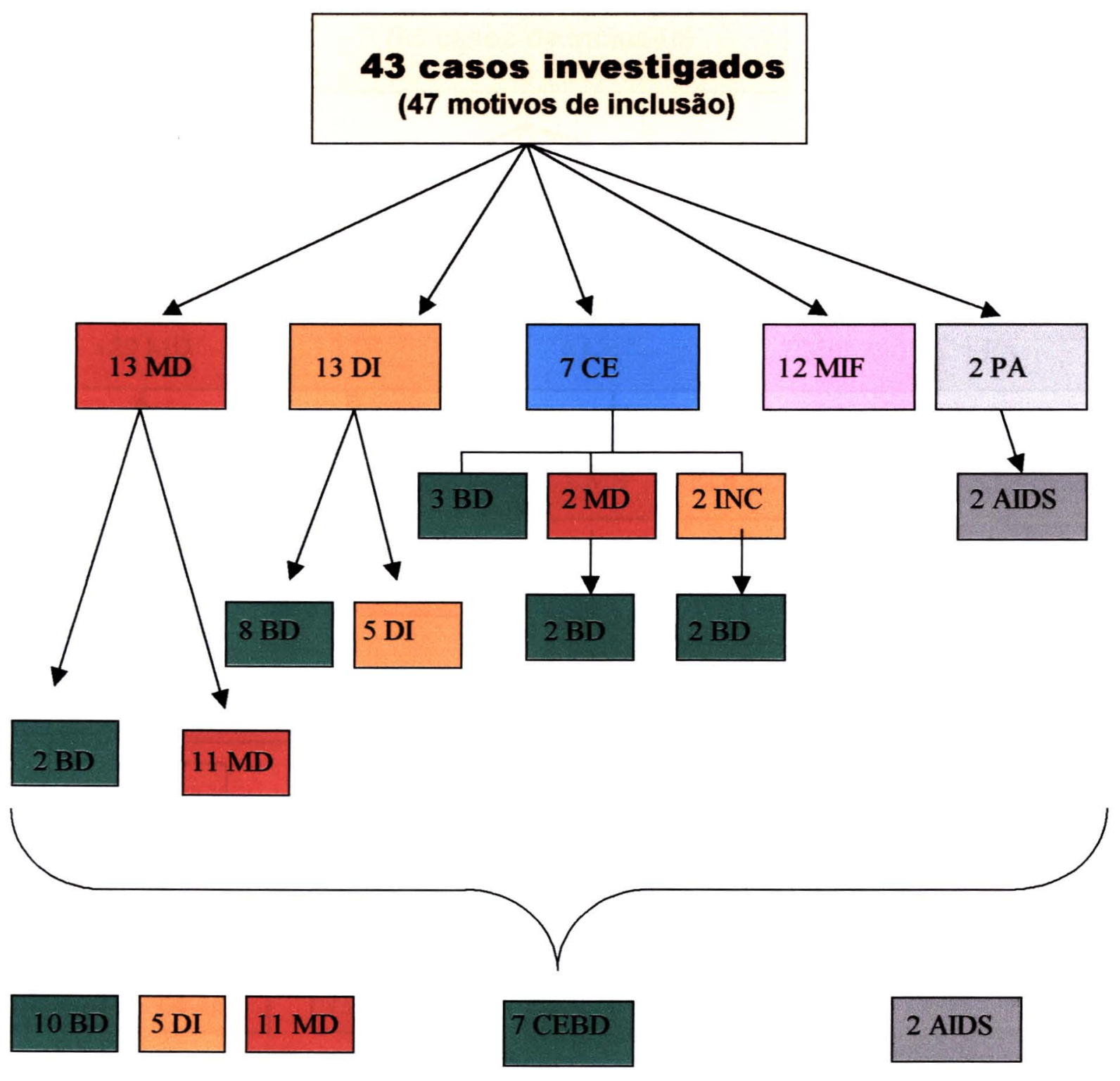


Figura 8: Situação dos óbitos, pré e pós-investigação, no município de Garça, DIR-Marília, agosto/dezembro, 1999.

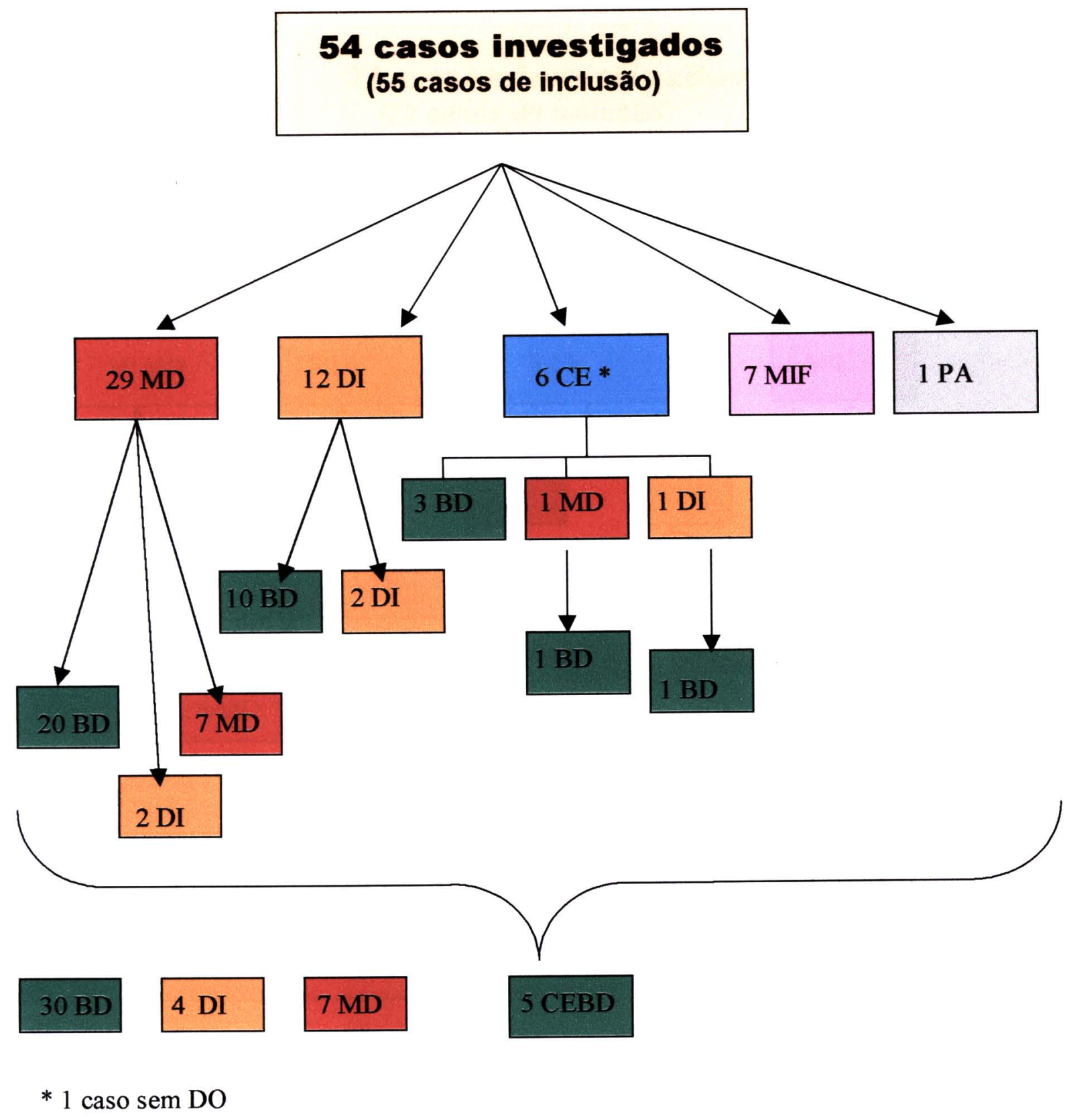


Figura 9: Situação dos óbitos, pré e pós-investigação, no município de Osvaldo Cruz, DIR-Marília, agosto/dezembro, 1999.

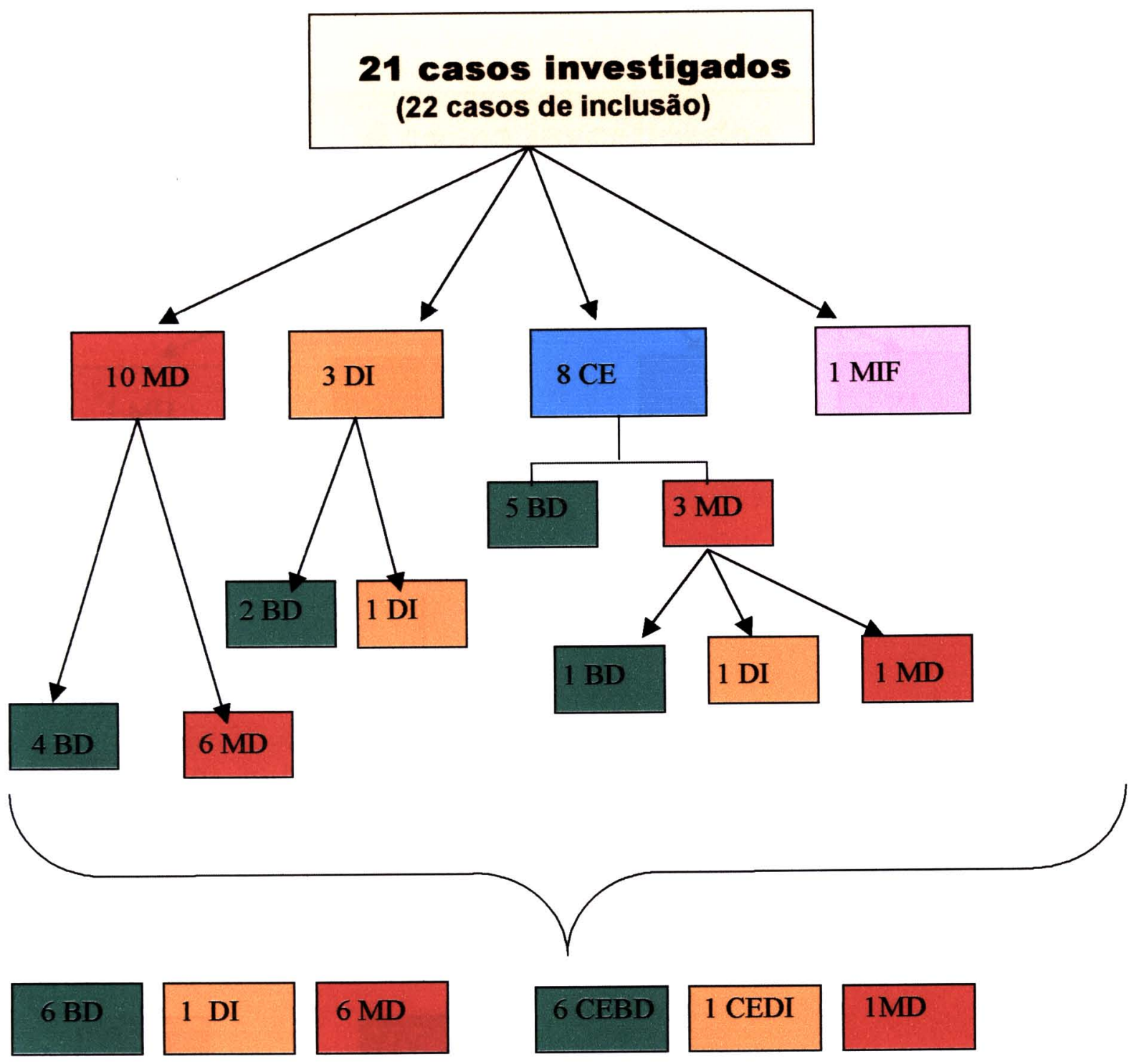


Figura 10: Situação dos óbitos, pré e pós-investigação, no município de Echaporã, DIR-Marília, agosto/dezembro, 1999.

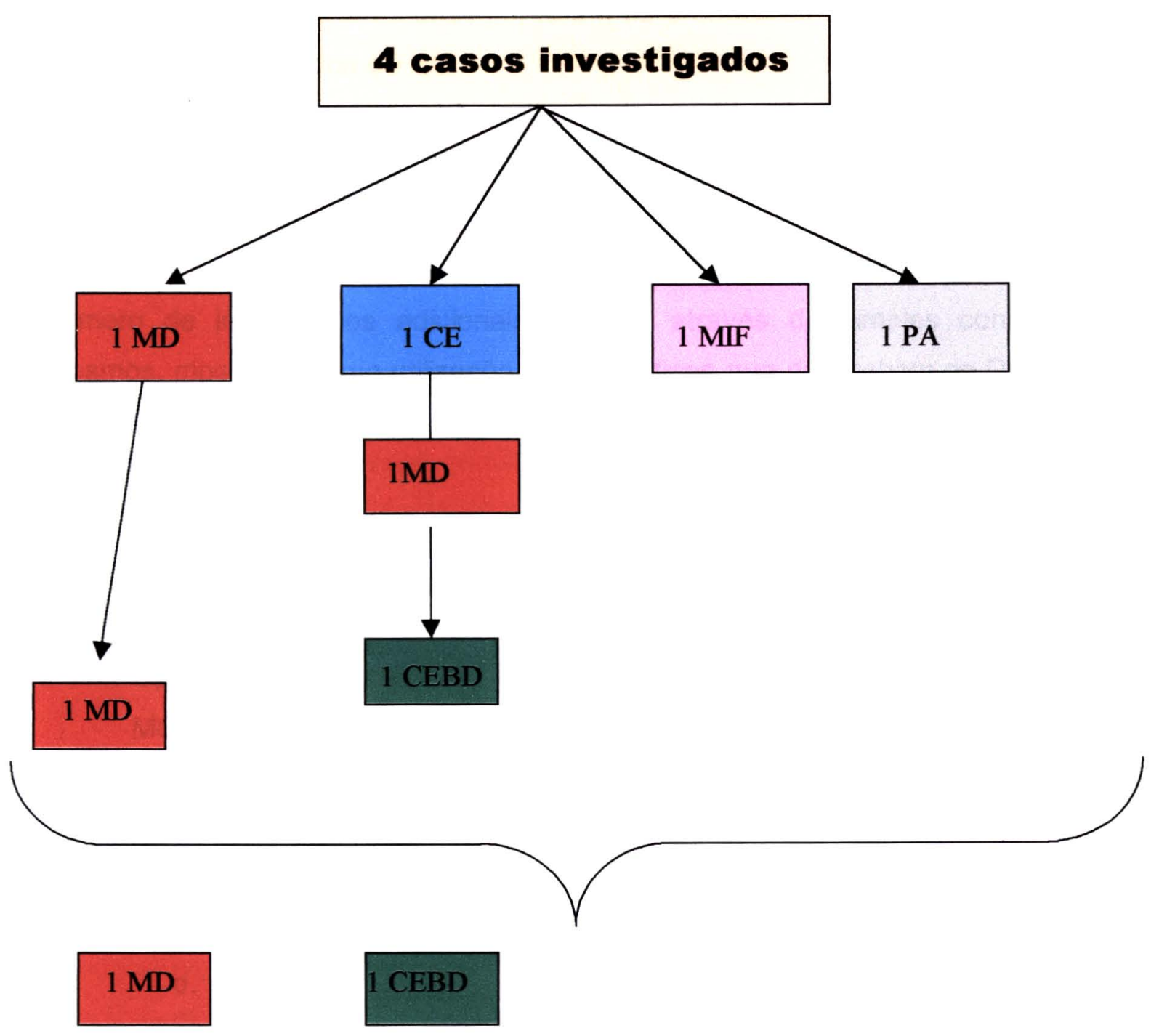




\subsection{FONTE DE DADOS}

Como pode se verificar pela análise dos dados, as fontes consultadas nesta pesquisa foram suficientes para esclarecer grande parte das causas de morte. As mais utilizadas, como já foi descrito, foram os prontuários de hospitais, as visitas domiciliares e os laudos do IML.

Em relação aos laudos do IML, muito se tem discutido na literatura sobre a não utilização dos dados disponiveis, no próprio instituto, para o preenchimento da DO ${ }^{(8,20,21,34)}$. Neste estudo a situação não foi diferente.

O mesmo se pode dizer em relação aos prontuários hospitalares. $O$ número de informações adicionais obtidas, através da simples consulta aos mesmos, mostra que sua utilização pelos médicos que preenchem as DO poderia reverter grande parte dos problemas encontrados na qualidade da informação de mortalidade.

A seguir, estão relatados alguns casos de óbitos com causa básica mal definida que, após a investigação, tornaram-se bem definidos.

Caso1: Feminino, 78 anos.

Motivo de inclusão: causa mal definida

Na DO original:

I. a. Choque por abdome agudo

b.

c.

d.

II.

Dados do prontuário hospitalar:

A paciente foi admitida em 3/10 com dor abdominal, iniciada há 3 dias, em mau estado geral, vômito, sem febre. Evolui com sudorese, vômito bilioso, palidez intensa, hipotensão, distensão abdominal, sendo submetida a uma laparotomia. 
Foi realizada uma gastrorrafia em úlcera péptica perfurada. Horas após a cinurgia, apresenta dispnéia intensa seguida de parada respiratónia. Óbito em 4/10.

Nova causa básica: Úlcera gástrica perfurada.

Caso 2: Masculino, 85

Motivo de inclusão: Causa incompleta.

Na DO original:

I. a. Insuficiência Respiratória Aguda

b. Falência de Músculo Cardíaco

c. Sepses

d.

II.

Dados do prontuário hospitalar:

Paciente com Doença de Chagas, apresenta uma miocardiopatia dilatada, com quadro de ICC. Apresenta fibrilação atrial crônica e hipertensão arterial sistêmica. Evoluiu para uma insuficiência respiratória secundária à congestão, com infecção generalizada.

Nova causa básica: Doença de Chagas.

Caso 3: Masculino, 60 anos

Motivo de inclusão: causa mal definida.

Na DO original:

I. a. Causa desconhecida

b.

c.

d.

II. 
Dados do prontuário hospitalar:

Paciente trazido pelo Resgate, após episódio de hemoptise em grande quantidade, em casa. Apresentava pele fria, ausência de pulso e pupilas midriáticas fixas. Era portador de neoplasia de pulmão (estadio IV), com metástase mediastinal.

Nova causa básica: Neoplasia maligna de pulmão.

Caso 4: Masculino, 79 anos.

Motivo de inclusão: causa incompleta.

Na DO original:

I. a. Choque por abdome agudo

b.

c. Embolia pulmonar

d. Insuficiência cardiaca

II.

Dados do prontuário:

Paciente com Insuficiência Cardíaca Congestiva descompensada, Infecção do trato uninánio e cardiomiopatia dilatada . Evoluiu com vômito, diarréia, dispnéia e bradicardia, sendo transferido para a UTI. Após melhora, volta para a enfermania, onde apresenta quadro de gastroenterite infecciosa, com dor abdominal e náuseas. No dia seguinte, fez uma parada cárdio-respiratónia.

Nova causa básica: Cardiomiopatia dilatada.

Caso 5: Feminino, 48 anos

Motivo de inclusão: causa mal definida.

Na DO original:

I. a. Causa indeterminada

b.

c.

d. 
II.

Dados do prontuário hospitalar:

Paciente chegou morta ao Pronto Socorro. Familiar relata câncer de pulmão. Esteve intemada neste mesmo hospital há um mês e meio, sendo feito diagnóstico de Neoplasia de pulmão, com metástases para Sistema Nervoso Central. Após diagnóstico foi encaminhada para a Radioterapia.

Nova causa básica: Neoplasia maligna de pulmão.

Os casos 1, 2 e 4, parecem evidenciar a falta de treinamento dos médicos para preencherem as DO, amplamente discutida em diversos trabalhos ${ }^{(14,35,46,62)}$. Geralmente, aponta-se como causa deste mau preenchimento a falta de informação do médico, desde a sua graduação, que não o capacita efetivamente, até treinamentos posteriores não disponiveis em larga escala.

Já os casos 3 e 5 parecem revelar mais que isso. Nesses dois casos, os pacientes chegaram mortos ao pronto-socorro do hospital, sendo o médico informado, pelos familiares, que os mesmos faziam tratamento naquela instituição, o que foi confirmado por esta pesquisa. Mais que uma falta de treinamento, fica evidente uma desconexão com o uso social da informação. A DO parece ser vista, pelo médico, apenas como uma exigência legal para o sepultamento e não como uma fonte geradora de dados sobre a saúde da população. A tarefa de informar está deslocada de sua função - permitir o conhecimento da realidade de saúde e contribuir para a elaboração e condução de políticas de saúde - não sendo, portanto, considerada importante.

A outra fonte de informação consultada, a visita domiciliar para entrevistas com os familiares, tem sido bastante utilizada em estudos sobre a qualidade dos dados de mortalidade, em caráter suplementar. Assim, apesar de realizada, na maioria dos trabalhos, não é considerada como fonte "confiável", sendo levada em consideração apenas para a confirmação dos diagnósticos levantados em prontuários clínicos. 
No entanto, o levantamento da morbidade referida, através de inquéritos domiciliares, tem sido bastante utilizado em estudos para a determinação do perfil de morbidade populacional, da prevalência de doenças, das representações da população sobre os problemas de saúde estudados e na análise do impacto de ações de saúde no perfil de morbidade, entre outros ${ }^{(11,18.29)}$.

Para estabelecer a precisão das informações levantadas nos domicilios, foram comparados os diagnósticos obtidos nos prontuários clínicos com os encontrados nas visitas domiciliares, nos 76 casos em que ambos os métodos foram empregados.

Ao se considerar a classificação das causas de morte, segundo os capítulos da CID-10, observa-se que em 58 dos casos (76,3\%) as informações são coincidentes.

As mudanças ocorridas na distribuição percentuais das doenças mostram um pequeno aumento para as doenças do aparelho circulatório e respiratório na informação da visita domiciliar, e um sub-dimensionamento dos transtornos mentais (Tabela 25).

O valor preditivo para cada categoria diagnóstica pode ser visto na tabela 26, assim como a especificidade e a sensibilidade das informações da visita domiciliária (VD), para detectar a classificação ou não em um dos capítulos da CID-10, considerando-se como "padrão-ouro" os diagnósticos extraídos dos prontuários.

O pequeno número de casos não permite análises pormenorizadas, porém, é possivel assinalar que as neoplasias, enquanto capítulo da CID, apresentaram sensibilidade, especificidade e valor preditivo altos, enquanto as doenças do aparelho circulatório mostraram uma sensibilidade e especificidade apenas medianas. 
Tabela 25: Número e porcentagem de óbitos investigados por meio de prontuários e visitas domiciliares, segundo capítulo da CID-10 e fonte utilizada, nos municípios selecionados da DIR-Marília, agosto/dezembro, 1999.

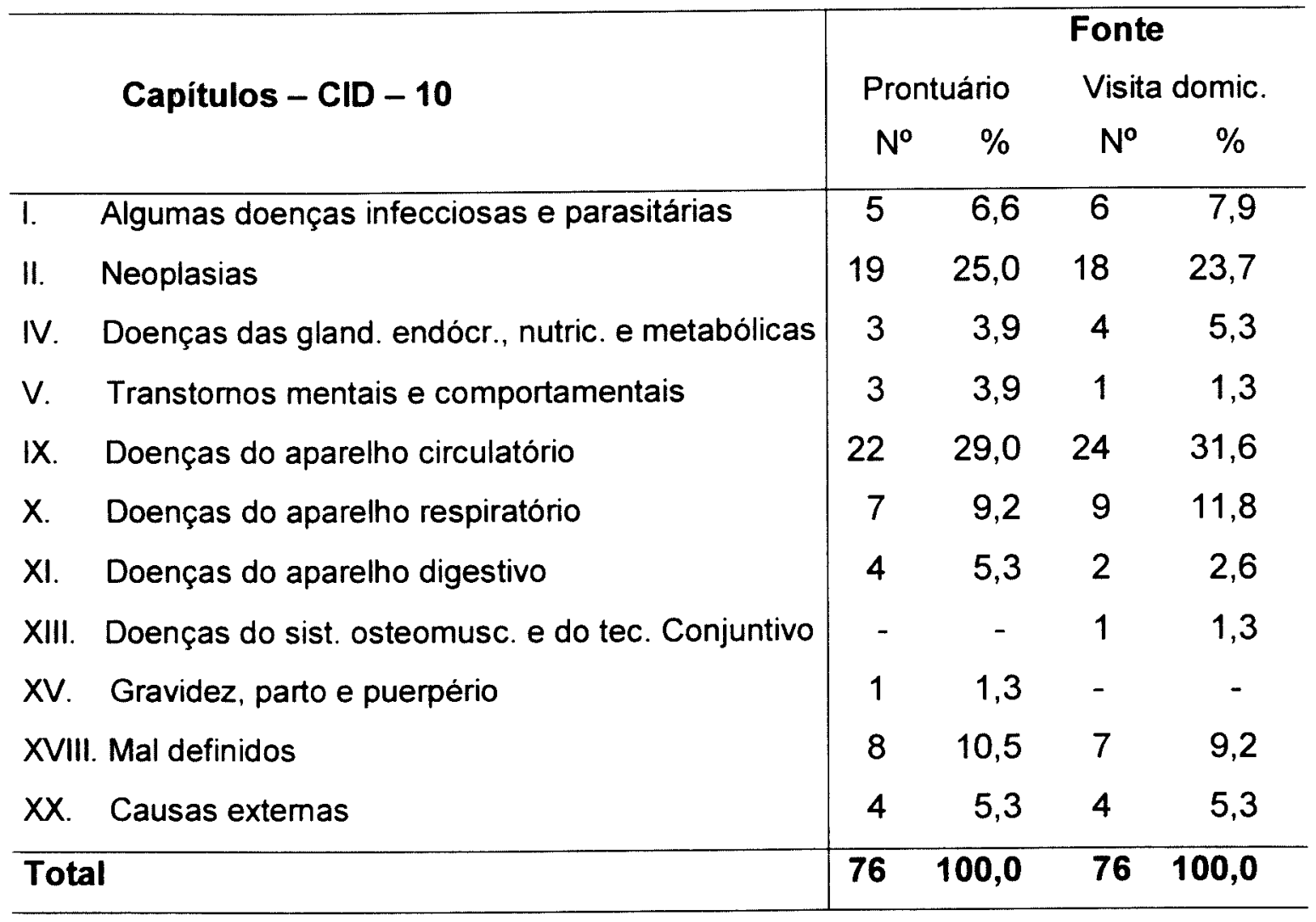

Considerando-se as informações não só por capítulo da CID-10, mas por categorias de três caracteres, as concordâncias diminuem. Dado o pequeno número de casos, esta avaliação foi feita apenas para os capitulos das neoplasias, doenças do aparelho circulatório e respiratório (Tabela 27). Nestes três casos calculou-se também o coeficiente Kappa, para avaliar a concordância. Este índice varia de zero a 1 , sendo que valores próximos de zero indicam que a 
concordância não foi maior do que aquela esperada em função do acaso. Assim, temos que Kappa: $\quad>0,75=$ altamente concordante

$$
\begin{aligned}
0,50-0,75 & =\text { concordante } \\
0,25-0,49 & =\text { fracamente concordante } \\
<0,25 & =\text { não existe concordância }
\end{aligned}
$$

Tabela 26: Valor preditivo (VP), sensibilidade (S) e especificidade (E) das informações da visita domiciliária (VD) para alguns dos capítulos da CID-10, nos municípios selecionados da DIR-Marília, agosto/dezembro, 1999.

\begin{tabular}{lrrrrrrrr}
\hline Capitulos - CID-10 & VD & a & b & c & d & VP\% & S\% & E\% \\
& & & & & & & & \\
\hline I. D. infecc.e parasit. & 6 & 4 & 2 & 1 & 69 & 66,7 & 80,0 & 97,2 \\
II. Neoplasias & 18 & 18 & 0 & 1 & 57 & 100,0 & 94,7 & 100,0 \\
III. D. gland. endócrinas & 4 & 2 & 2 & 1 & 71 & 50,0 & 66,7 & 97,3 \\
V. T. mentais & 1 & 1 & 0 & 2 & 73 & 100,0 & 33,4 & 100,0 \\
IX. D. do aparelho circulatório & 24 & 15 & 9 & 7 & 45 & 62,5 & 68,2 & 83,3 \\
X. D. do aparelho respiratório & 9 & 7 & 2 & 0 & 67 & 77,8 & 100,0 & 97,1 \\
XI. D. do aparelho digestivo & 2 & 2 & 0 & 2 & 72 & 100,0 & 50,0 & 100,0 \\
XVIII.Mal definidos & 7 & 3 & 4 & 5 & 64 & 42,9 & 37,5 & 94,1 \\
XX. Causas externas & 4 & 4 & 0 & 0 & 72 & 100,0 & 100,0 & 100,0 \\
& & & & & & & & \\
\hline
\end{tabular}

Total

75*

* Excluido um caso do capítulo de doenças osteomusc.
a) Casos em que o diagnóstico do prontuário e da VD coincidem quanto ao capitulo da CID-10.
b) Falsos positivos: a VD informa uma doença (cap.CID-10), que o paciente não tinha.
c) Falsos negativos: A VD nega uma doença (cap.CID-10)presente.
d) Negativos certos: a VD nega uma doença (cap. CID-10) que realmente não está presente. 
Tabela 27: Valor preditivo (VP), sensibilidade (S) e especificidade (E) das informações da visita domiciliária (VD) e coeficiente de Kappa para algumas das categorias da CID-10, nos municípios selecionados da DIR-Marília, agosto/dezembro, 1999.

\begin{tabular}{|c|c|c|c|c|c|c|c|c|c|}
\hline Categorias - CID-10 & VD & $\mathbf{a}$ & b & c & d & VP\% & $\mathbf{S} \%$ & $\mathrm{E} \%$ & Kappa \\
\hline II. Neoplasias & 18 & 11 & 7 & 8 & 50 & 61,1 & 58,0 & 87,7 & 0,50 \\
\hline IX. D. do ap. circulatório & 24 & 9 & 15 & 13 & 39 & 37,5 & 40,9 & 72,2 & 0,28 \\
\hline X. D. do ap.respiratório & 9 & 7 & 2 & 0 & 67 & 77,8 & 100,0 & 97,1 & 0,86 \\
\hline
\end{tabular}

Total

51

Apenas as doenças respiratórias permanecem com a mesma sensibilidade, especificidade e valor preditivo, apresentando um Kappa alto, de 0,86. As neoplasias tiveram uma redução da sensibilidade, especificidade e valor preditivo, com um Kappa moderadamente concordante $(0,50)$. Porém, em 6 casos dentre os 15 não concordantes de neoplasias, as informações obtidas na VD estavam bastante próximas das fornecidas pelos prontuários:

Prontuários:

Câncer de cólon

Linfoma de grandes células

Linfoma de estômago

Câncer de esôfago

Câncer de colo de útero

Câncer de esôfago
VD:

Câncer de intestino

Linfoma

Câncer de estômago

Câncer de estômago

Câncer de útero

Câncer de garganta

Nestes 6 casos citados, em apenas um a DO original apresentava um diagnóstico bem definido (Linfoma de células grandes). Nos outros 5 , a informação era de causa mal definida ( 4 casos) e sem assistência médica ( 1 caso). Portanto, 
nestes exemplos, o médico ao preencher a DO foi pior informante do que a família.

As doenças do aparelho circulatório foram as que apresentaram maior discordância, sendo observada uma "tendência", por parte dos familiares, de classificarem como "infarto" a maioria das mortes súbitas.

Estudos comparando os diagnósticos encontrados nas DO com os elaborados após investigação de prontuários, laudos de necropsia e entrevistas com os familiares, e médicos que atenderam aos falecidos, não mostram concordância melhor ${ }^{(44,48)}$. Trabalho realizado no Rio Grande do Sul ${ }^{(48)}$, para avaliar a qualidade da informação sobre a causa básica de óbitos infantis, usando a metodologia citada, verificou, para a grande maioria das doenças, sensibilidades abaixo de $50 \%$ e coeficientes Kappa menores que 0,35. Nava Caballero e colaboradores ${ }^{(44)}$, em estudo em que utilizaram laudos de necropsias para refazer as DO, encontraram sensibilidades entre 50 e $60 \%$ para grande parte das enfermidades.

Levando-se em conta que na grande maioria dos casos aqui tratados, a DO original assinalava causa de morte mal definida, fica a indagação do quanto, e em que tipo de doenças, se poderia valorizar a informação fornecida pelos familiares, na ausência de dados de prontuários.

Vale lembrar que as VD desta pesquisa foram realizadas por pessoal leigo, em geral, universitários de outras áreas que não a da saúde. No estudo citado no parágrafo anterior, realizado no Rio Grande do Sul , onde as entrevistas com os pais da criança eram realizadas por médicos, os autores mencionam a utilidade da VD , chamada por eles de "necropsia verbal". 


\subsection{TIPO DE HOSPITAL}

No período estudado, ocorreram 800 óbitos no conjunto dos municipios. Destes, 581 se deram nos hospitais $(72,6 \%)$, sendo 167 em um hospital universitário (Tabela 28).

A presença de um hospital universitário na área estudada fez surgir a indagação se haveria diferenças nas proporções de causas mal definidas ou com diagnósticos incompletos e nos percentuais de ganho, quando se considera o tipo de hospital em que ocorreu a morte, se universitário ou não universitário.

Desta forma, observou-se que o percentual de causas mal definidas, em relação ao total de óbitos ocorridos, foi bem menor no hospital universitário $(6,6 \%)$ do que em outros hospitais (Tabela 28). Esta diferença foi estatisticamente significativa $\left(X^{2}=28,14 ; p<0,05\right)$.

O mesmo não acontece quando se compara a freqüência de causas com diagnósticos incompletos (Tabela 29). As proporções foram próximas, sendo de 7,2 e $10,1 \%$, para o hospital universitário e hospitais não universitários, respectivamente, não havendo diferença estatisticamente significativa.

Tabela 28: № e porcentagem de óbitos hospitalares, segundo tipo de hospital e de causa, nos municípios selecionados da DIR-Marília, agosto/dezembro, 1999.

\begin{tabular}{|c|c|c|c|c|c|c|}
\hline \multirow{3}{*}{ Tipo de Hospital } & \multicolumn{4}{|c|}{ Tipo de causa } & & \\
\hline & \multicolumn{2}{|c|}{ Mal definida } & \multicolumn{2}{|c|}{ Outras causas } & \multicolumn{2}{|c|}{ Total de óbitos } \\
\hline & $\mathrm{N}^{\circ}$ & $\%$ & $\mathrm{~N}^{\circ}$ & $\%$ & $\mathbf{N}^{\circ}$ & $\%$ \\
\hline Universitário & 11 & 6,6 & 156 & 93,4 & 167 & 28,7 \\
\hline Não universitário & 111 & 26,8 & 303 & 73,2 & 414 & 71,3 \\
\hline Total & 122 & 21,0 & 459 & 79,0 & 581 & 100,0 \\
\hline
\end{tabular}


Tabela 29: $\mathrm{N}^{\circ}$ e porcentagem de óbitos hospitalares, segundo tipo de hospital e tipo de causa, , nos municípios selecionados da DIR-Marilia, agosto/dezembro, 1999.

\begin{tabular}{|c|c|c|c|c|c|c|}
\hline \multirow{3}{*}{ Tipo de Hospital } & \multicolumn{4}{|c|}{ Tipo de causa } & & \\
\hline & \multicolumn{2}{|c|}{ Diag. incompleto } & \multicolumn{2}{|c|}{ Outras causas } & \multicolumn{2}{|c|}{ Total de óbitos } \\
\hline & $N^{o}$ & $\%$ & $\mathrm{~N}^{0}$ & $\%$ & $\mathbf{N}^{\circ}$ & $\%$ \\
\hline Universitário & 12 & 7,2 & 155 & 92,8 & 167 & 28,7 \\
\hline Não universitário & 42 & 10,1 & 372 & 89,9 & 414 & 71,3 \\
\hline Total & 54 & 9,3 & 527 & 90,7 & 581 & 100,0 \\
\hline
\end{tabular}

Em relação aos ganhos, não foi observada diferença significativa entre os percentuais dos hospitais, tanto quando se consideram as causas mal definidas, como quando se analisam as causas com diagnóstico incompleto.

Desta forma, neste estudo, o fato do hospital ser universitário está associado a uma menor proporção de ocorrência de causas atestadas como mal definidas. Esta associação vai ao encontro da hipótese de ter-se um melhor preenchimento das DO em instituições voltados ao ensino médico. Por outro lado, o mesmo não foi observado em relação ao ganho, o que parece indicar que grande parte das causas classificadas como mal definidas ou com diagnósticos incompletos era, de fato, ainda não esclarecida. Poder-se-ia pensar que a qualidade dos prontuários, em relação ao conteúdo de informações, justificasse esta ausência de diferença nos ganhos. Porém, o observado durante a pesquisa foi que o conteúdo de informações nos prontuários do hospital universitário é muito superior ao do encontrado no outros hospitais. 


\section{CONSIDERAÇÕES FINAIS}


$\mathrm{Na}$ avaliação da qualidade da informação de mortalidade dos municipios selecionados, chamam a atenção as altas proporções de óbitos por causas mal definidas, representando o segundo lugar na distribuição das mortes de acordo com as causas básicas agrupadas em capitulos da CID-10. Tais valores são maiores do que os observados para as regiōes Sul e Sudeste do país. A análise para os últimos anos mostra tendência de aumento, movimento este contrário ao que vem se verificando em todo o país.

Considerando-se que as causas de morte que foram objeto de estudo neste trabalho foram apenas as que representavam os principais problemas, no que diz respeito à qualidade dos dados, e que as codificadas como bem definidas, segundo vários estudos, também apresentam limitações relativas à fidedignidade das causas básicas, é possivel dimensionar a falha na adequação do sistema de informação e as dificuldades encontradas para o conhecimento da realidade de saúde e das condições de vida desta população.

A descentralização da produção da informação, com a construção de bancos municipais de dados de óbitos, a exemplo do Programa de Aprimoramento das Informaçōes de Mortalidade da Prefeitura do Municipio de São Paulo - PROAIM do municipio de São Paulo, pode permitir um aperfeiçoamento da qualidade da informação, por meio do desenvolvimento de metodologias específicas de correção de suas distorções, com a possibilidade de ampliação de seu uso para a definição das prioridades locais.

Nesse sentido, os resultados aqui obtidos confirmam essa expectativa. Com o emprego de técnicas simples e acessiveis, alcançou-se a melhoria da qualidade da informação, uma vez que, na maioria dos óbitos por causas mal definidas ou por diagnósticos incompletos, naturais e externos, foi possivel detectar as reais causas de morte.

A metodologia utilizada mostrou-se adequada para a realidade dos municípios, já que as fontes de dados consultadas, de maneira geral, possibilitaram, suficientemente, a correção de grande parte das $\mathrm{DO}$, no que diz respeito às causas de morte. 
Embora muitos estudos, a exemplo deste trabalho, tragam informações sobre as causa de óbito obtidas em entrevistas com familiares, sempre em caráter complementar às outras fontes, poucos analisam a validade destas. Nesta pesquisa, o pequeno número de óbitos por determinadas causas de morte impediu a análise da concordância para todas as causas informadas. No entanto, indicou bons indices de concordância para as neoplasias e as doenças respiratórias, sugerindo considerável grau de validade da informação fornecida nas entrevistas com os familiares.

Assim, fica a indagação já formulada anteriormente, do quanto e em que tipo de doenças poder-se-ia valorizar a informação obtida com os familiares, na ausência de dados de prontuários.

Porém, mais do que "tratar" a má informação, é necessário que se evite sua ocorrência. Para isso é preciso uma melhor compreensão de suas causas. Um dos motivos apontados por grande parte dos estudos é a falta de treinamento dos médicos no preenchimento da DO e que certamente é um fator a ser considerado. Entretanto, a não valorização da informação, por parte do corpo médico e das instituições, como instrumento importante na identificação de problemas e na orientação de ações para seu enfrentamento, parece ser causa anterior à falta de capacitação. Assim, a incompreensão da importância da informação de mortalidade e a sua não utilização como instrumento de trabalho no gerenciamento dos hospitais acaba transformando o preenchimento dos atestados de óbito em uma rotina burocrática e desestimulante.

Há ainda outras possiveis hipóteses para explicar o comportamento dos profissionais frente a este documento. Sentimentos como medo, pelas implicações jurídicas do atestado, são freqüentemente relatadas. Alem disso, sabe-se que o médico é treinado apenas para diagnosticar e restabelecer a saúde. Suas reações em relação à morte e ao morrer são pouco conhecidas. O que se observa é que na formação acadêmica não há espaços para as discussões que o habilitem a lidar com a morte e, portanto, com os sentimentos de impotência e de consciência da própria finitude. 
Outro fator a ser considerado é se as mortes ocorridas em domicílio, neste trabalho cerca de $60 \%$ das mal definidas, não refletem a falta de acesso aos serviços de saúde e, em geral, a ausência de equipamentos importantes para o diagnóstico, não havendo, portanto, como definir sua causa.

Finalmente, parte da responsabilidade pela má qualidade da informação pode ser atribuida à ausência de um serviço de verificação de óbito nos municipios estudados, fato este que contribui para a manutenção de um resíduo permanente de mortes sem possibilidade de esclarecimento.

Concluindo, pretende-se discutir estas e outras questões levantadas, tais como o fato de $8 \%$ das DO por causas não naturais não terem sido fornecidas por médicos legistas, junto aos diversos atores envolvidos, entre eles a Secretaria Estadual e as Secretarias Municipais de Saúde, para a elaboração e operacionalização das possíveis soluções dos problemas detectados. 
6. REFERÊNCIAS BIBLIOGRÁFICAS 
1. Abreu $\mathrm{DMX}$, Rodrigues $\mathrm{RN}$. Diferenças de mortalidade entre as regiões metropolitanas de Belo Horizonte e Salvador, 1985 - 1995. Rev Saúde Pública 2000; 34: 514-21.

2. Almeida MF. Descentralização de sistemas de informação e o uso das informações a nivel municipal. Inf Epidemiol SUS 1998; 3:27-33.

3. Antunes JLF. Medicina, Leis e Moral: pensamento médico e comportamento no Brasil (1879-1930). São Paulo: Fundação Editora da UNESP, 1999. Cap 5, p. 234-270 : Morte.

4. Arango HG. Bioestatística : teórica e computacional. Rio de Janeiro : Editora Guanabara Koogan S.A., 2001.

5. Arrundale J. Death Certification and Mortality Statistics. Health Bull 1991; 49:82-90.

6. Barata RB. Uso epidemiológico das informações de mortalidade no planejamento e avaliação dos serviços. [Apresentado no Seminário "Usos das informações de mortalidade em nivel municipal"; 1992; São Paulo].

7. Barros MBA, Araujo M. Espacialização dos óbitos de menores de um ano no município de Campinas.[Trabalho apresentado no Seminário "Usos das informações de mortalidade em nivel municipal"; 1992; São Paulo].

8. Barros MDA, Ximenes $R$, Lima MLC. Preenchimento de variáveis nas declarações de óbitos por causas extemas de crianças e adolescentes no Recife, de 1979 a 1995. Cad Saúde Pública 2001; 17: 71-8. 
9. Bauer FW, Robbins SL. An autopsy study of cancer patients. I - Accuracy of the Clinical Diagnoses (1955 to 1965). Boston City Hospital. JAMA 1972; 221: 1471-74.

10.Berquó ES, Souza JMP, Gotlieb SLD. Bioestatística. São Paulo: EPU, $1^{\text {a }}$ ed.rev.; 1981

11.Campos GJ, Reis Filho AS, Silva AGM, Novochadio MAS, Silva RA, Galvão, CE. Morbimortalidade infantil por diarréia aguda em área metropolitana da região Nordeste do Brasil, 1986-1989. Rev Saúde Pública 1995; 29:132-9.

12.Carvalho, DM. Grandes sistemas nacionais de informação em saúde: revisão e discussão da situação atual. Inf Epidemiol SUS 1997; 4:7-46.

13.Carvalho, FM, Oalomo V, Widmer MR, Cruz M, Cruz C. Diagnóstico clínico versus autópsia. Bol Oficina Sanit Panam 1991; 110: 213-18.

14. Carvalho ML, Niobey FML, Miranda NN, Sabroza PC. Concordância na determinação da causa básica de óbito em menores de um ano na região metropolitana do Rio de Janeiro, 1986. Rev Saúde Pública 1990; 24: 20-7.

15.Castillo B, González J, Schiattino I. Certificación médica de las defunciones por traumatismos en los Servicios de Salud de Chile. Rev Méd Chile 1997; 125 : 1389-98.

16.CENTERS FOR DISEASES CONTROL. Lista de causas presumiveis de AIDS. MMWR, 41 (RR, 17), 1992.

17.CENTERS FOR DISEASES CONTROL. Epi Info. Versão 6.04b. Atlanta, 1997. 
18.Cesar CLG, Figueiredo GM, Westphal MF, Cardoso MRA, Costa MZA, Gattás VL. Morbidade Referida e utilização de serviços de saúde em localidades urbanas brasileiras: metodologia. Rev Saúde Pública 1996; 30:153-60.

19.Corrêa MHSH, Baggio MCR. A freqüência de doentes com co-infecção HIVIAIDS e Tuberculose, no município de Marília, no periodo de 1996 a 2000. [Mimeo]. Marilia, 2001.

20.Drumond Jr. M, Lira MMTA, Freitas M, Nitrini TMV, Shibao K. Avaliação da qualidade das informações de mortalidade por acidentes não especificados $e$ eventos com intenção indeterminada. Rev Saúde Pública 1999; 33: 273-80.

21.Drumond Jr. M. Homicidios e desigualdades sociais na cidade de São Paulo: uma visão epidemiológica. Saúde e Sociedade 1999. 8: 63-81.

22.Fonseca LAM, Laurenti R. A Qualidade da Certificação Médica da Causa de Morte em São Paulo, Brasil. Rev Saúde Pública 1974; 8: 21-9.

23.Laurenti R. Accuracy of cause of death statements of death certificates and the international comparability of the mortality statistic. [Mimeo]. 1999.

24.Laurenti R. A análise da mortalidade por causa básica e por causas múltiplas. Rev Saúde Pública 1974; 8 : 421-35.

25.Laurenti R, Buchalla CM, Lólio CA, Santo AH, Mello Jorge MHP. Mortalidade de mulheres em idade fértil no municipio de São Paulo (Brasil), 1986 - I Metodologia e Resultados Gerais. Rev Saúde Pública 1990; 24: 128-33. 
26.Laurenti R, Buchalla CM, Lólio CA, Santo AH, Mello Jorge MHP. . Mortalidade de mulheres em idade fértil no município de São Paulo (Brasil), 1986 - II Mortes por causas matemas. Rev Saúde Pública 1990; 24: 468-72.

27.Laurenti R, Mello Jorge MHP, Lebrão ML, Gotlieb SLD. Estatísticas de Saúde. $2^{a}$ edição revista. São Paulo : EPU, 1987

28.Laurenti R., Mello Jorge MHP. O Atestado de Óbito. $3^{a}$ ed. revista e ampliada. São Paulo: CDCB; 1996.

29.Lauridsen EPP, Tanaka OY. Morbidade referida e busca de ajuda nos transtomos mentais na infância e na adolescência. Rev Saúde Pública 1999; 33: $586-92$.

30.Matida LH, Guibu IA. Análise crítica do sistema de informação dos óbitos por AIDS. Resumos do IV Congresso Brasileiro de Epidemiologia, Rio de Janeiro, p.199, 1998.

31.Maudsley G, Williams EMI. "Inaccuracy" in death certifications - where are we now? J Publ Hlth Med 1996; 18: 59-66.

32.Mello Jorge MHP , Gotlieb SLD. O Sistema de Informação em Mortalidade : problemas e propostas para seu enfrentamento. [Mimeo]. São Paulo; 1998. [Projeto de Pesquisa enviado ao CNPq, MS e FAPESP; em andamento].

33.Mello Jorge MHP. Registro dos Eventos Vitais : sua importância em Saúde Pública. CBCD, São Paulo, 1990 (Série Divulgação n 5).

34.Mello Jorge MHP. Situação atual das estatisticas oficiais relativas à mortalidade por causas externas. Rev Saúde Pública 1991; 24: 217-23. 
35.Mendonça, EF, Goulart EMA, Machado, JAD. Confiabilidade da declaração de causa básica de mortes infantis em região metropolitana do sudeste do Brasil. Rev Saúde Pública 1994; 28: 385-91.

36.Milanesi ML, Laurenti R. O estudo interamericano de mortalidade em São Paulo. I - Estado atual da certificação médica da causa de óbito no distrito da Capital. Rev Ass Med Bras 1964;10:11-16.

37.Ministério da Saúde. Mortalidade Brasil - 1995, Brasília, 1998.

38.Ministério da Saúde. DATASUS. Informações de Saúde/ Mortalidade, Brasil, 1979/97/98 (online). Disponivel: http://wnw.datasus.gov.br (dez 2001)

39.Ministério da Saúde. Fundação Nacional de Saúde. Estudos Epidemiológicos - Vigilância Epidemiológica. Agosto/2000.

40.Ministério da Saúde. Fundação Nacional de Saúde. Sistema de Informação sobre Mortalidade 1979-1998. Dados de declaração de óbito. [CD ROM]. CENEPI/DATASUS. TABWIN versão 1.4 para WINDOWS. Brasilia:2000.

41. Ministério da Saúde. Manual dos Comitês de Mortalidade Materna. 2 ed. Brasília, 2001.

42. Ministério da Saúde. Secretaria de Políticas de Saúde. Política Nacional de Redução de Morbimortalidade por Acidentes e Violência. Rev Saúde Pública 2000; 34:427-30.

43.Ministério da Saúde. Política nacional de redução da morbimortalidade por acidentes e violências. Brasília, 2001 (Série E, n.8). 
44.Nava Caballero JM, Huguet Recasens M, Carrasco, MA. Certificado médico de defunción. Su fiabilidad. Rev San Hig Pub 1985; 59: 667-675.

45. Nielsen GP, Björnsson J, Jonasson JG. The accuracy of death certicates. Virchows Archiv A Pathol Anat 1991; $419: 143-46$.

46. Niobey FML, Cascão AM, Duchiade MP, Sabroza PC. Qualidade de preenchimento de atestados de óbitos de menores de um ano na região metropolitana do Rio de Janeiro. Rev Saúde Pública 1990; 24: 311-8.

47.Njaine K, Souza ER, Minayo MSC, Assis, SG. A produção da (des)informação sobre violência: Análise de uma prática discriminatória. Cad Saúde Pública $1997 ; 13: 405-14$.

48. Nobre LC, Victora CG, Barros FC, Lombardi C, Teixeira AMB, Fuchs SC. Avaliação da qualidade da informação sobre a causa básica de óbitos infantis no Rio Grande do Sul (Brasil). Rev Saúde Pública 1989; 23: 207-13.

49. Oliveira $H$, Pereira IPA. Estatísticas de mortalidade e nascidos vivos: considerações sobre principais problemas. Inf Epidemiol SUS 1997; $6: 15$ 19.

50. Oliveira LR. Avaliando o Sistema de Informações sobre Mortalidade em Mato Grosso. São Paulo, 2001. [Dissertação de Mestrado, FSP/USP].

51.Organização Mundial da Saúde. Classificação Estatística Internacional de Doenças e Problemas Relacionados à Saúde Décima Revisão, 1996. São Paulo:Centro Colaborador da OMS para a Classificação de Doenças e Português; 2000. 
52.Paula AMC, Evangelista Filho D, Pereira IPA, Albano AHBL, Fernandes RM. Avaliação dos dados de mortalidade, Brasil - 1979 a 1989. Inf Epidemiol SUS 1994. Jan/Fev/ Mar.

53.Puech LR. Atestados de óbito. Anais Paul. Med. Cirurgia 1919. 277-83.

54.Puffer RR, Griffith GW. Características de la mortalidad urbana. Washington (DC): Organización Panamericana de la Salud; 1968 (Publicación científica, 151).

55.Puffer RR, Serrano CV. Caracteristicas de la mortalidad en la niñez. Washington (DC): Organización Panamericana de la Salud; 1973 (Publicación cientifica, 262).

56.Ribeiro MAR. História sem fim... inventário da saúde pública. São Paulo 1880-1930. São Paulo : Editora da UNESP, 1993.

57.Rigdon RH. Problems in a statistical study of disease based on death certificates. Southern Med J 1981; 74: 1104-6-1111.

58.Rosen G. Da polícia médica à medicina social : ensaios sobre a história da assistência médica ; Rio de Janeiro : Edições Graal, 1979.

59.Rosen G. Uma história da Saúde Pública. $2^{\mathrm{a}}$ ed. São Paulo: Editora UNESP, Rio de Janeiro :HUCITEC; 1994.

60.Rothman KJ. Lessons from John Graunt. Lancet 1996. 347: 37-39.

61.Rouquayrol MZ, Almeida Filho N. Epidemiologia \& Saúde. 5 ed. Rio de Janeiro : MEDSI, 1999. 
62.Schnitman A. Análise da fidedignidade da causa de morte por câncer em Salvador, Brasil. Rev Saúde Pública 1990; 9:811-15.

63.Schottenfeld D, Muzza E, Sommers SC, Alonso DR, Wilkinson C. The autopsy as a measure of accuracy of death certificate. Bull N Y Acad Med 1982; 58 : 778-89.

64.Serra CA, Martellotto G. Correlación entre necropsias y certificados de defunción. Rev Fac Cienc Med Cordoba 1985; 43: 26-31.

65.Silva LMV, Paim JS, Costa MCN. Desigualdades na mortalidade, espaço e estratos sociais. Rev Saúde Pública 1999; 33:187-97.

66.Siqueira AAF, Rio BEM, Tanaka ACDA, Schor N, Alvarenga ATA, Almeida CL. Mortalidade feminina na região sul do município de São Paulo : qualidade da certificação médica dos óbitos. Rev Saúde Pública 1999; 33: 499-504.

67.Souza ER, Njaine K, Minayo MCS. Qualidade da informação sobre violência: um caminho para a construção da cidadania. Cadernos do Programa de Pósgraduação em Ciência da Informação 1996; 2:104 -12. 
ANEXOS 
ANEXO 1: Lista de Causas Presumíveis de AIDS 


\section{LISTAS DAS DOENÇAS CONSIDERADAS COMO PRESUMIVEIS DE AIDS E UTILIZADAS PARA A SELEÇÃO DE CASOS DO ESTUDO}

A - Síndrome de Imunodeficiência Adquirida, AIDS, SIDA, deficiência de imunidade adquirida ou imunodeficiência sem outra especificação (em qualquer parte do atestado).

Foram excluidos os casos referentes à deficiência de imunidade conseqüente a hemofilia, transplante renal, doenças do colágeno ou demais entidades bem definidas, cuja terapêutica (desde que houvesse essa informação no atestado). Esta exclusão se deve ao fato destas causas raramente serem omitidas nas DO, sendo que sua inclusão apenas aumentaria a quantidade de atestados revisados, sem, no entanto, enriquecer a análise.

B - As doenças relacionadas à AIDS, listadas abaixo:

- Aspergilose pulmonar;

- Criptococose;

- Infecção por citomegalovirus;

- Infecções por herpes simples;

- Linfoma não-Hodgkin

- Linfoma de Burkitt;

- Micobacteriose atípica;

- Moniliase;

- Pneumonia por Pneumocystis caninii ou pneumocistose;

- Sarcoma de Kaposi;

- Toxoplasmose;

- Tuberculose

- e a menção de "infecção oportunista". 
Estas doenças com determinadas especificações como, por exemplo, tuberculose disseminada, esofagite por Cândida, pneumonia por Cândida, constituem o elenco de doenças relacionadas à AIDS pelo CDC, em 1987. No Brasil, embora o critério estabelecido tenha sido baseado no dos EUA, não há determinadas restrições ao tipo histológico do órgão atingido pela infecção. Exemplificando, atualmente, aceita-se a tuberculose pulmonar ou apenas a menção de tuberculose, em individuos HIV positivos, como critério de caso de AIDS.

C - Outras causas de morte selecionadas para o estudo:

- Abcesso cerebral;

- Bacteremia;

- Blastomicose;

- Broncopneumonia, quando esta era a causa básica ou a única causa anotada na parte médica do atestado;

- Carcinomatose;

- Desnutrição, quando informada como causa básica;

- Doença linfoproliferativa;

- Doenças do pulmão (outras que não as especificadas);

- Donovanose;

- Edema pulmonar;

- Enterite crônica;

- Enterocolite aguda;

- Estafilococcia;

- Gastroenterite;

- Leucemia;

- Leucose linfóide aguda;

- Linfoma;

- Linfossarcoma; 
- Meningoencefalite;

- Meningite e outras doenças inflamatórias do Sistema Nervoso Central;

- Neoplasia do encéfalo;

- Paracoccidioidomicose;

- Pneumonia Lobar (devida à dificuldade de se diagnosticar Pneumocystis carinii em nosso meio);

- Pneumopatia infecciosa;

- Pneumopatia intersticial;

- Processo pneumônico;

- Sarampo;

- Septicemia;

- Suicidio e

- Varicela.

Optou-se por selecionar os óbitos devidos a este grupo de causas por serem processos infecciosos, micose ou câncer que podem ocorrer como quadro terminal em casos de infecção pelo vírus da imunodeficiência adquirida e por terem sido identificadas como causa básica, em atestados de óbito de indivíduos com AIDS. O suicidio foi selecionado por ocorrer, com alguma freqüência, em indivíduos com certos tipos de doenças graves e nos quadros clínicos com alteração do sistema nervoso, comum em várias patologias, inclusive a AIDS. 
ANEXO 2: Formulários F2, F3, F4 e F5 
F2. FORMULÁRIO PARA COLETA dE INFORMAÇÃo SOBRE ÓBITOS EM DOMICÍlIO (para causas mal definidas, residuais dos capítulos e presumiveis)

Para preenchimento em nivel central

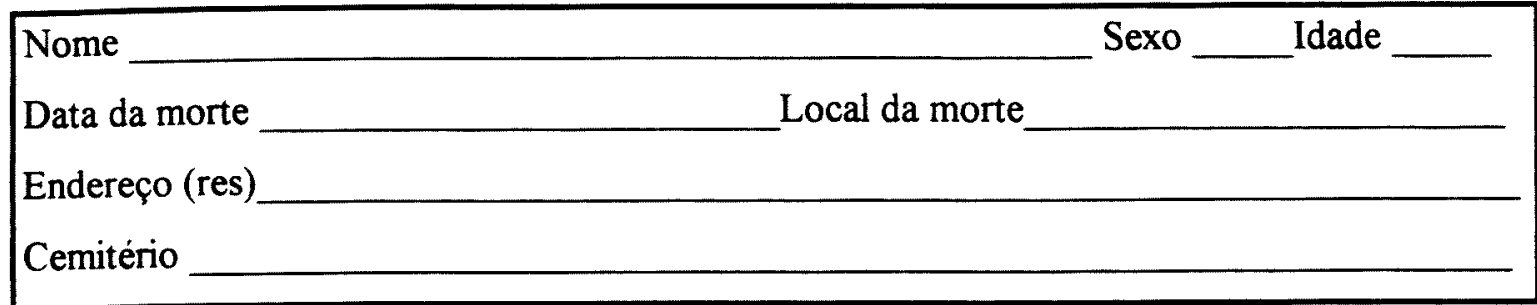

\section{Para o início da entrevista, ver instrutivo}

Para preenchimento em domicílio

Nome $\_$Data de nascimento
Sexo $\_$Idade $\_$Local da morte
Data da morte $\_$
Endereço (res)

Durante o ano que passou (um ano antes da morte), ... foi atendido por médico, hospital ou Posto de Saúde? $\operatorname{Sim} \square$ Não $\square$ Ignora $\square$

Se Sim, preencha o quadro abaixo

\begin{tabular}{|l|l|l|l|l|l|l|}
\hline $\begin{array}{c}\text { Nome do hospital, clínica, } \\
\text { médico, etc. }\end{array}$ & $*$ & Data & $\begin{array}{c}\text { Dias no } \\
\text { hospital }\end{array}$ & Motivo & $* * * *$ \\
\hline 1$)$ & & & & & & \\
\hline 3$)$ & & & & & & \\
\hline 4) & & & & & & \\
\hline
\end{tabular}

* Tipo: $\mathbf{M}=$ médico particular, convênio $\mathbf{H}=$ hospital $\mathbf{P S}=$ Posto de Saúde, Centro de Saúde

** Número de consultas

*** Esses atendimentos tinham algo a ver com a doença que levou à morte? $\mathbf{S}=\operatorname{SIM} \mathbf{N}=\mathrm{N} \tilde{O} O$

- Se mulher entre 10 e 49 anos:

Estava grávida no momento da morte? Sim $\square \quad$ Não $\square \quad$ Ignora $\square$ Se sim, duração da gestação: meses

Esteve grávida nos 12 meses que precederam a morte? Sim $\square$ Não $\square$ Ignora $\square$ Se sim, o produto foi ?

$\square$ Nascido vivo $\square$ Nascido morto $\square$ Aborto $\square$ Ignorado Onde foi atendida? Data 
Vamos falar um pouco sobre a doença que levou à morte

- Como começou a doença

- Descrição da doença (detalhar)

Se se tratar de acidente/violência, detalhar ao máximo o tipo de acidente e o tipo de lesão.

- Quanto tempo ficou doente?

- Fez tratamento caseiro? Sim $\square \quad$ Não $\square \quad$ Ignora $\square$ Qual?

- Teve assistência médica? Sim $\square \quad$ Não $\square$ Ignora $\square \quad$ Se sim, onde? Endereço

- E o que mais foi feito?

- Tomou remédio? Sim $\square \quad$ Não $\square \quad$ Ignora $\square$ Se sim, qual?

- Que doença levou à morte?

- Onde morreu? Domicílio $\square \quad$ Hospital $\square \quad$ Ignora $\square \quad$ Outro lugar $\square$

Se hospital, qual e onde?

- A Sra. acha que essa morte poderia ter sido evitada?

Se sim, como?

Data Entrevistador

\section{CONCLUSÃo}

Encaminhamento: Fazer outro formulário? Sim $\square \quad$ Não $\square$

Se sim, qual? 
F3. FORMULÁRIO PARA COLETA DE INFORMAÇÕES HOSPITALARES SOBRE ÓBTTOS (causas mal definidas, residuais dos capítulos e presumíveis)

Para preenchimento em nível central

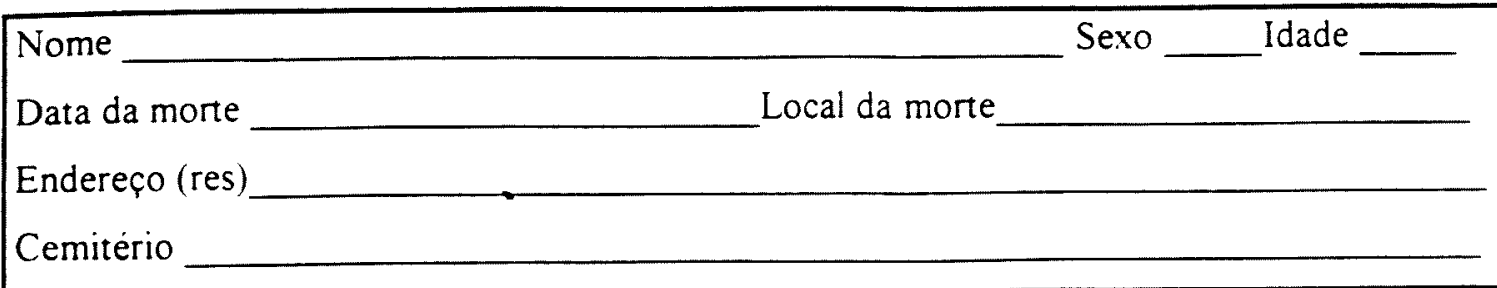

\section{Para o início da entrevista, ver instrutivo}

Para preenchimento no hospital

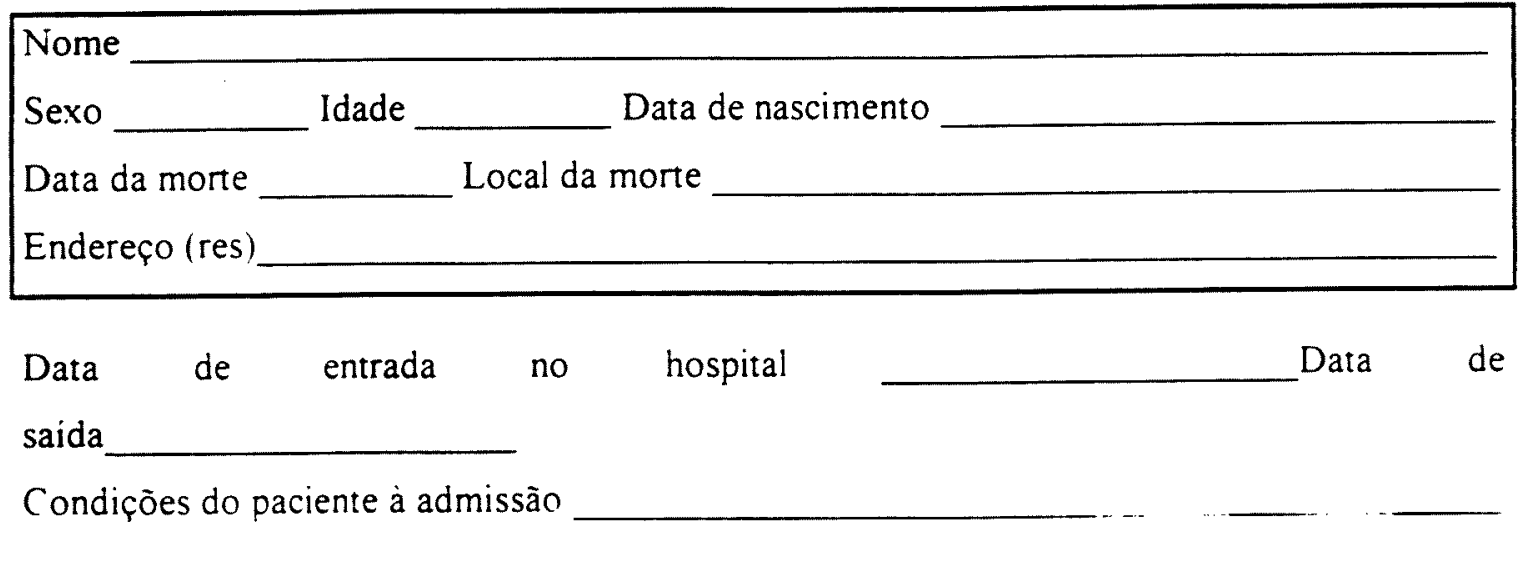

Resumo da anamnese (sintomas)

Resumo da evolução do paciente

\section{Exames}

a) Laboratório

\begin{tabular}{|l|l|l|}
\hline Tipo & Data & Resultado \\
\hline & & \\
& & \\
\hline
\end{tabular}


b) Raio $X$

\begin{tabular}{|l|l|l|}
\hline Tipo & Data & Resultado \\
\hline & & \\
& & \\
\hline
\end{tabular}

c) Citologia/biópsia (descrever o material e resultado)

d) Operações e achados

\begin{tabular}{|l|l|l|}
\hline Tipo & Data & Resultado \\
\hline & & \\
& & \\
\hline
\end{tabular}

e) Diagnósticos clínicos

f) Autópsia? Sim - Não - Resultado:

Para óbitos femininos de 10 a 49 anos, verificar se consta informação sobre a presença de gravidez, parto e puerpério nos 12 meses que precederam a morte.

- Se mulher entre 10 e 49 anos:

Estava grávida no momento da morte? Sim = Não = Ignora =

Se sim, duração da gestação: meses

Esteve grávida nos 12 meses que precederam a morte? Sim $=$ Não $=$ Ignora Se sim, o produto foi?

モ Nascido vivo こ Nascido morto こ Aborto こIgnorado

Onde foi atendida? Data

Condições da mãe momento da alta

\section{DADOS SOBRE O ÓBITO:}

O que consta no Prontuário:

Data _ _ _ I Entrevistador

\section{CONCLUSĀO}

Encaminhamento: Fazer outro formulário? Sim $\square \quad$ Não $\square$

Se sim, qual? 
F4. FORMULÁRIO PARA COLETA DE INFORMAÇÃO SOBRE ÓBITOS DOMICILIARES QUE TIVERAM ALGUMA ASSISTÊNCIA MÉDICA ANTERIOR COM MÉDICO, CS, PS OU ASSEMELHADO.

Para preenchimento em nivel central

Nome Sexo Idade

Data da morte Local da morte

Endereço (res)

Cemitério

\section{Para o início da entrevista, ver instrutivo}

\section{Para preenchimento no local do atendimento}

Nome

Sexo Idade

Data da morte Local da morte

Endereço (res)

1. Houve atendimento a essa pessoa?

2. Se sim,

Quando?

Quantas vezes?

Qual o diagnóstico?

Houve confirmação por exames complementares? $\quad \operatorname{Sim} \square$ Não $\square$

Quais?

Qual foi a doença responsável pela morte? Ignora $\square$

Entrevista feita com (anotar nome do médico ou Centro de Saúde que fez o atendimento)

Data Entrevistador 
F5. FORMULÁRIo PARA COLETA DE INFORMAÇÃo SOBRE CAUSAS EXTERNAS (IML - DP)

Para preenchimento em nível central

\begin{tabular}{|ll}
\hline Nome & Sexo ___ Idade __ Local da morte__ \\
Data da morte & \\
Endereço (res) & \\
Cemitério & \\
\hline
\end{tabular}

\section{Para o início da entrevista, ver instrutivo}

Para preenchimento em instituição

Nome $\_$Sexo $\_$Data de nascimento $\_$Local da morte
Data da morte $\_$__
Endereço (res)

\section{INFORMAÇÃO DA DP}

Data do evento Data da morte

Tipo de causa externa (o mais detalhado possivel)

\section{OBS}

\section{INFORMAÇÃO DO IML}

Data da morte

Natureza da lesão

Tipo de causa externa (descrição do acidente/violência)

OBS

Data _ _ _ Entrevistador 
ANEXO 3: Parecer do Comitê de Ética em Pesquisa 


\section{UNIVERSIDADE DE SÃO PAULO}

FACULDADE DE SAÚDE PÚBLICA

COMITÊ DE ETICA EM PESQUISA DA FSP/USP - COEP

Av. Dr. Amaldo, 715 - CEP 01246-904 - São Paulo - Brasil

Telefones: (55-11) 30667742 - fax (55-11) 30647314

\section{Of.COEP/09/98}

18 de fevereiro de 1998.

Pelo presente, informo que o Comitê de Ética em Pesquisa, homologou, em sua 1. a $/ 98$, realizada em 17.02 .98 , de acordo com os requisitos da Resolução CNS/196/96, o Projeto de Pesquisa "O SISTEMA DE INFORMAÇÃO DE MORTALIDADE: PROBLEMAS E PROPOSTAS PARA SEU ENFRENTAMENTO", apresentado pelas pesquisadoras Maria Helena Prado de Mello Jorge e Sabina Léa Davidson.

Atenciosamente,

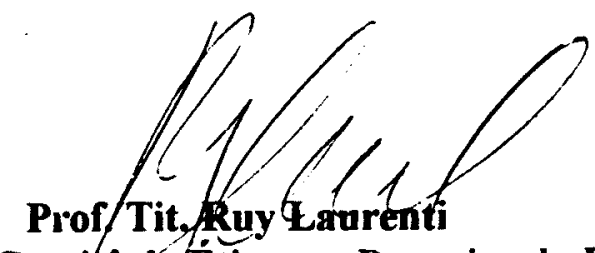

Coordenador do Comitê déética em Pesquisa da FSP-COEP 
ANEXO 4: Termo de consentimento 


\section{CONSENTIMENTO LIVRE E INFORMADO}

$\mathrm{Eu}$

RG residente à

$\mathrm{n}^{\circ}$ , na cidade de , dou o meu consentimento para que seja utilizada, para fins científicos, toda a informação por mim fornecida, em entrevista no meu domicílio, relativa ao óbito de bem como a informação que consta nos documentos pertencentes ao seu prontuário hospitalar. Fui informado que as informações são parte de pesquisa científica, na área de Saúde Pública, sendo que os responsáveis se comprometem a manter total sigilo dessas informações e todos os demais requisitos éticos, de acordo com a Resolução n. ${ }^{\circ} 196$ de 10/10/1996 do Conselho Nacional de Saúde.

de de 